\title{
Transitions Within Opioid Therapy and Their Impact on Morbidity, Healthcare Utilization, and Costs
}

James Douglas Thornton

Follow this and additional works at: https://researchrepository.wvu.edu/etd

\section{Recommended Citation}

Thornton, James Douglas, "Transitions Within Opioid Therapy and Their Impact on Morbidity, Healthcare Utilization, and Costs" (2017). Graduate Theses, Dissertations, and Problem Reports. 6804.

https://researchrepository.wvu.edu/etd/6804

This Dissertation is protected by copyright and/or related rights. It has been brought to you by the The Research Repository @ WVU with permission from the rights-holder(s). You are free to use this Dissertation in any way that is permitted by the copyright and related rights legislation that applies to your use. For other uses you must obtain permission from the rights-holder(s) directly, unless additional rights are indicated by a Creative Commons license in the record and/ or on the work itself. This Dissertation has been accepted for inclusion in WVU Graduate Theses, Dissertations, and Problem Reports collection by an authorized administrator of The Research Repository @ WVU.

For more information, please contact researchrepository@mail.wvu.edu. 


\title{
Transitions within opioid therapy and their impact on morbidity, healthcare utilization, and costs
}

\author{
James Douglas Thornton \\ Dissertation submitted to the School of Pharmacy \\ at West Virginia University \\ in partial fulfillment of the requirements \\ for the degree of \\ Doctor of Philosophy \\ in \\ Health Services and Outcomes Research \\ Department of Pharmaceutical Systems and Policy \\ Nilanjana Dwibedi, PhD, Chair \\ Usha Sambamoorthi, PhD \\ Virginia Scott, PhD \\ Charles Ponte, PharmD \\ Douglas Ziedonis, MD \\ Morgantown, West Virginia \\ 2017
}

Copyright 2017 James Douglas Thornton

Keywords: chronic opioid therapy, healthcare expenditures, healthcare utilization, naloxone, opioid, pharmacist education 


\section{ABSTRACT \\ Transitions within opioid therapy and their impact on morbidity, healthcare utilization, and costs \\ James Douglas Thornton}

In the United States (US), chronic non-cancer pain (CNCP) is prevalent among adults with costs exceeding half a billion dollars annually ${ }^{1}$ and can be especially burdensome for working age adults due to lost productivity and negative impacts on quality of life. ${ }^{2-6}$ An estimated $43 \%$ of adults experience pain, and the majority of them are working age (22-64 years). ${ }^{6}$ Despite lack of robust evidence on the efficacy and effectiveness of opioids relieving $\mathrm{CNCP},{ }^{7,8}$ and currently-available effective non-opioid treatments, ${ }^{9}$ many patients still receive opioid therapy. Opioids are associated with significant negative health consequences up to and including addiction to opioids which further increases their risk for overdose and death. ${ }^{10}$ Effective clinical, policy, and community responses to solve the opioid epidemic focus on a continuum beginning with appropriate initiation of opioids and ending with harm reduction efforts. $^{11-17}$ The first step is the appropriate initiation of opioids because as many as $46 \%$ of adults who were initiated on opioids transition into chronic opioid users. ${ }^{18}$ Chronic opioid therapy (COT) can exacerbate current conditions and lead to development of new chronic physical and mental health conditions, and other opioid-related adverse effects including overdose. ${ }^{7,19-22}$ These negative consequences related to opioids lead to high economic burden through increased emergency room, inpatient, and other healthcare utilization and healthcare expenditures. ${ }^{19-24}$ Analysis of COT and its economic burden is especially important among working-age adults who receive opioids more frequently when they experience pain. ${ }^{25}$ 
This study was conducted to (1) assess factors which predict the transition to COT, (2) estimate the changes in healthcare utilization and expenditure associated with the transition to COT, and (3) to identify educational strategies that can be used to fill knowledge gaps about opioids, naloxone, and opioid use disorder treatment medications for a group of healthcare professionals who are well suited to help alleviate the opioid epidemic.

First, we identified leading predictors associated with incident COT among adults without cancer in the US using a 10\% random sample of working-age adults (age 28-63 years) insured in commercial plans, who were initiated on opioids between January 2007 through May 2015. The four leading predictors of COT were opioid duration-of-action [AOR $=12.28 ; 95 \% \mathrm{CI}=$ 8.06-18.72], parent opioid tramadol vs. codeine, $[\mathrm{AOR}=7.26 ; 95 \% \mathrm{CI}=5.20-10.13]$, the presence of conditions highly likely to cause chronic pain $[\mathrm{AOR}=5.47 ; 95 \% \mathrm{CI}=3.89-7.68]$ and drug use disorders $[\mathrm{AOR}=4.02 ; 95 \% \mathrm{CI}=2.53-6.40]$. Next, using the same data source, we assessed the association between transitioning from incident opioid use to chronic opioid therapy (COT), on the trajectories of health utilization and expenditures. Patients who transitioned to COT were more likely to use inpatient services $[\mathrm{AOR}=1.11,95 \% \mathrm{CI}(1.01,1.21)]$ compared to those who did not transition. While expenditures peaked during the transition period (t4) for all users, differences in unadjusted average, 120-day expenditures between COT and no COT users were highest in $\mathrm{t} 4$ for total $(\$ 4,607)$ and inpatient expenditures $(\$ 2,453)$. COT users had significantly higher total $(\beta=0.183, \mathrm{p}<0.01)$ and inpatient expenditures $(\beta=0.448, \mathrm{p}<0.001)$. For these first two aims, we found that initial opioid regimen characteristics are powerful predictors of COT, and the period after incident opioid prescription, but before COT, is an important time for intervention for payers. 
Patients who have already transitioned to COT, or even opioid misuse or abuse need increased levels of care. The third aim sought to identify educational strategies related to opioids, buprenorphine products, and naloxone, for pharmacists, and to determine geographic locations to reduce the risk of opioid overdose in West Virginia (WV). A mixed-methods design included a prospective cross-sectional survey administered in two phases to increase coverage of the whole state, then results were weighted based on a census of all pharmacists in WV. Most pharmacists perceived high risk of opioid misuse in their area and high perceived efficacy about naloxone as a treatment for opioid overdose, but many did not feel comfortable selling naloxone. Opioid attitudes significantly differed between pharmacists in different EPPM-assigned categories. Filling practices differed; $73 \%$ stocked buprenorphine/naloxone and only $58 \%$ stocked buprenorphine. Pharmacists with higher perceived efficacy of buprenorphine products were more likely to be willing to fill non-local prescriptions. County-level disparities between actual and perceived risk for opioid misuse were observed. In the qualitative evaluation, pharmacists listed many barriers to caring for patients prescribed opioids or buprenorphine products. By tailoring educational strategies and objectives to pharmacists in specific geographic locations, more effective $\mathrm{CPE}$ can be delivered to community pharmacists in $\mathrm{WV}$ to improve access to naloxone and buprenorphine products as well as improve their understanding of addiction and psychosocial treatments. 


\section{Acknowledgement}

I would like to thank Dr. Nilanjana Dwibedi, my mentor and dissertation chair for her continued support throughout my graduate studies. She has pushed me to be a better student, researcher, and future faculty member than I would have been without her guidance. My interim advisor was Dr. Kimberly Kelly who put me on the right path from day one, and for that I thank her immensely. Also, my committee members, Dr. Usha Sambamoorthi, Dr. Virginia Scott, Dr. Charles Ponte, and Dr. Douglas Ziedonis, deserve considerable praise for their valued input and patience during the dissertation process. I would also extend thanks to other researchers who contributed to the research performed: Dr. Xi Tan, Mary Zhao, and Dr. Nethra Sambamoorthi. I thank my student colleagues at WVU, Angie Frame for her administrative support, and Dr. Suresh Madhavan for leading such an outstanding group of researchers and professionals. Finally, I would like to thank my parents, sisters, and wife for their emotional guidance and for believing in me over the years. 


\section{Table of Contents}

List of Tables viii

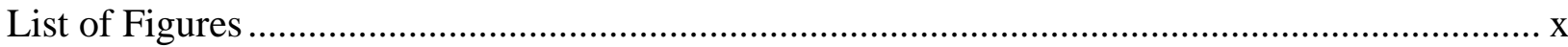

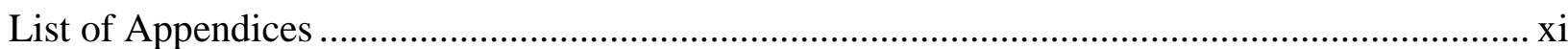

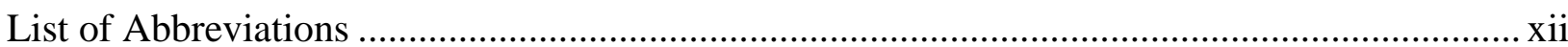

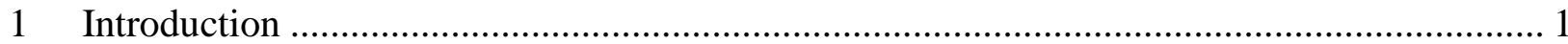

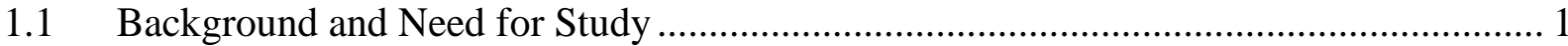

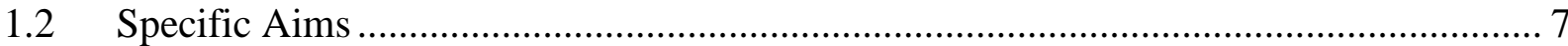

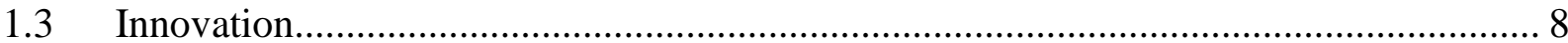

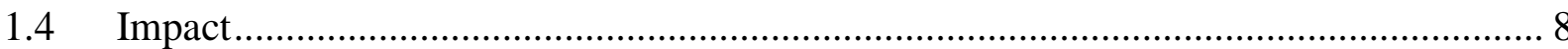

2 Predictors of transitioning to incident chronic opioid therapy among working-aged adults. 11

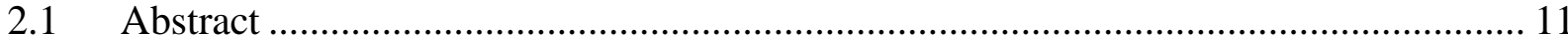

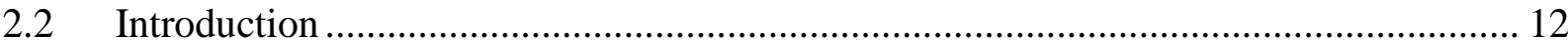

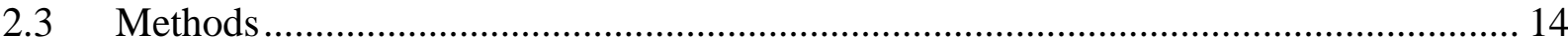

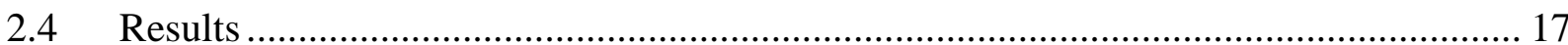

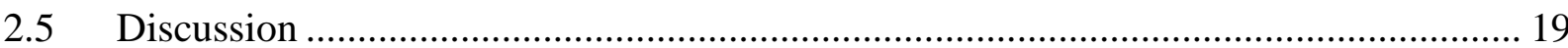

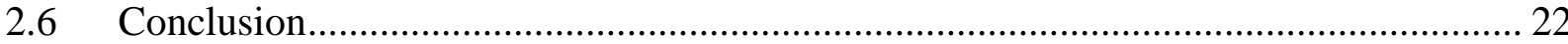

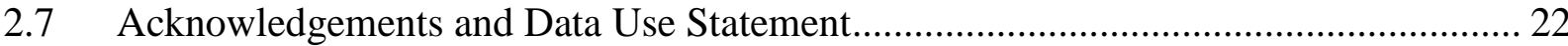

3 Increased healthcare utilization and expenditures associated with transition to chronic opioid

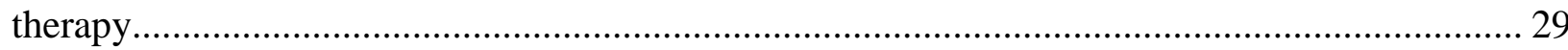

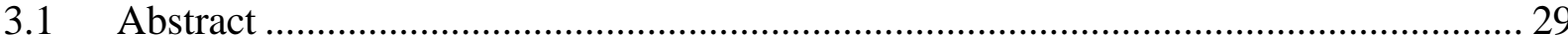

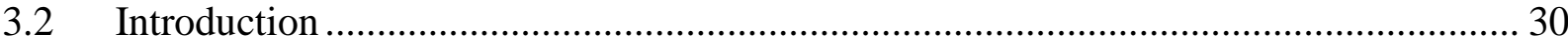

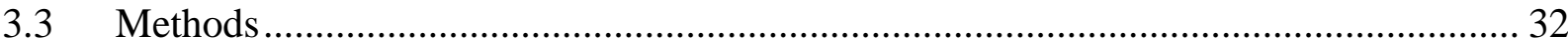

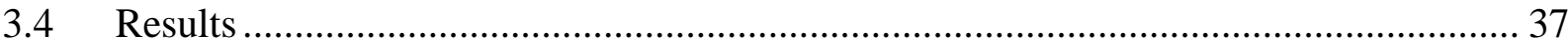

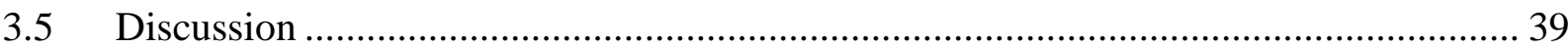

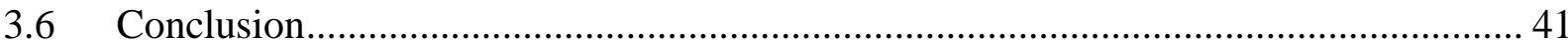

3.7 Acknowledgements and Data Use Statement............................................................. 41

4 Identifying targeted continuing educational strategies to help community pharmacists implement naloxone/buprenorphine-related medications in community pharmacies: A state-wide survey among pharmacists ................................................................................................. 48

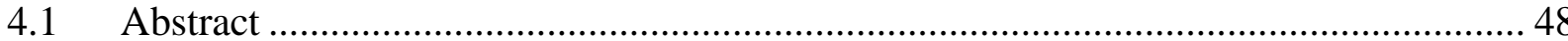

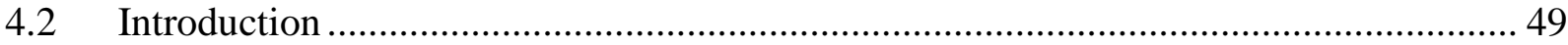

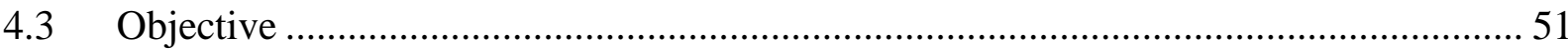




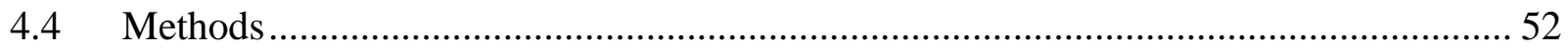

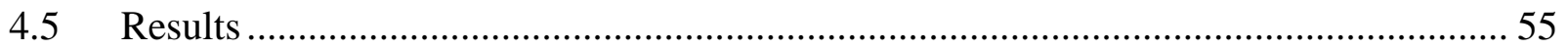

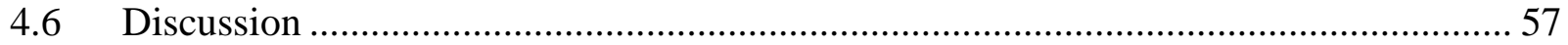

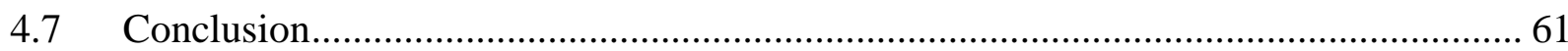

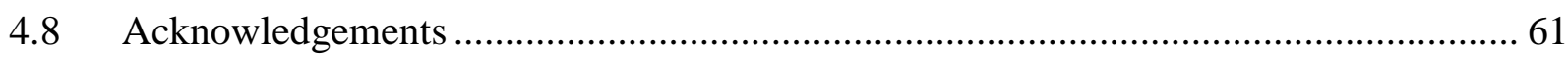

5 Discussion of findings and research implications .................................................. 70

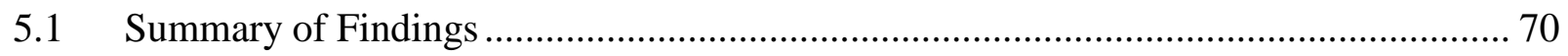

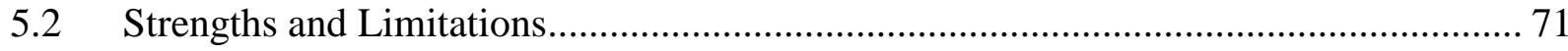

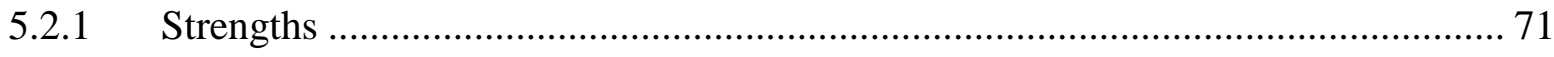

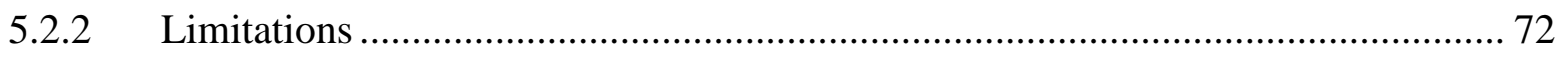

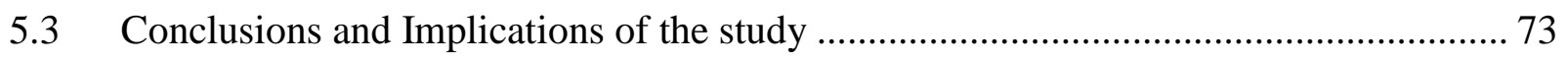

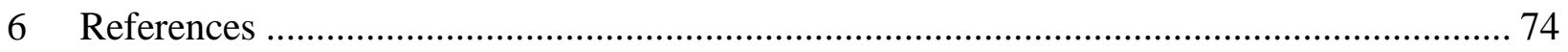

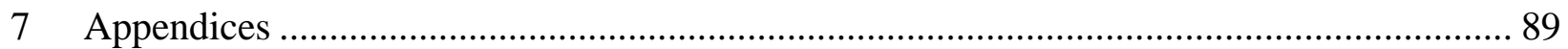

7.1 Supplemental Information- Chapter 2: Predictors of transitioning to incident chronic

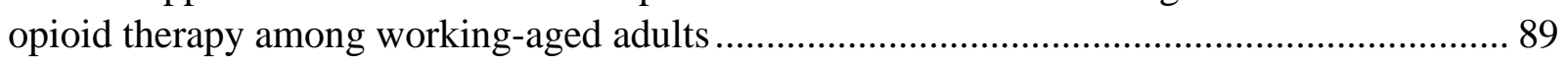

7.2 Supplemental Information- Chapter 3: Increased healthcare utilization and expenditures associated with transition to chronic opioid therapy ........................................................ 93 


\section{List of Tables}

Table 2.1. Sample description for patients with incident opioid use by transition to chronic opioid therapy (COT) after initial opioid prescription, using QuintilesIMS Real-World Data Adjudicated Claims - US, 2006-2015....................................... 24

Table 2.2. Select leading predictors from a logistic regression with adjusted odds ratio (AOR) and $95 \%$ confidence interval (95\% CI) for patients with incident opioid use by transition to chronic opioid therapy (COT) after first opioid prescription, using QuintilesIMS Real-World Data Adjudicated Claims - US, 2006-2015................................... 26

Table 3.1. Rates of emergency department (ED) and inpatient use by transition to chronic opioid therapy (COT) after initial opioid prescription. QuintilesIMS Real-World Data Adjudicated Claims Database- US, 2006-2015.............................................. 43

Table 3.2 Adjusted odds ratio (AOR) and $95 \%$ confidence intervals $(95 \% \mathrm{CI})$ of selected Variables From population-average Generalized Estimating Equations Working-Age Adults with incident Opioid Prescription, QuintilesIMS Real-World Data Adjudicated Claims Database - US, 2006-2015.

Table 3.3 Average expenditures (2015 US dollars) over time by Type of Service and Chronic Opioid Therapy (COT) use Working-age Adults (aged 28 - 63) without Cancer and initiated on Opioid Therapy QuintilesIMS Real-World Data Adjudicated Claims Database- US, 20062015.

Table 3.4. Weighted and adjusted expenditures over time for patients with incident opioid use by transition to chronic opioid therapy (COT) after first opioid prescription, QuintilesIMS RealWorld Data Adjudicated Claims Database - US, 2006-2015...................... 46

Table 4.1. Characteristics of the sample of survey respondents compared to the population of pharmacists licensed and working in West Virginia as of July 2016.

Table 4.2. Description of the sample of community pharmacists licensed and working in WV that responded to the survey, weighted by age based on the state-wise census of

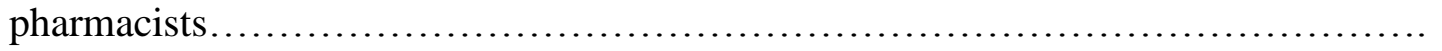

Table 4.3. Extended Parallel Process Model (EPPM) categories for a sample of community pharmacists licensed and working in $\mathrm{WV}$, weighted by age based on the state-wise census of pharmacists.

Table 4.4. Perceived efficacy and misuse/abuse of buprenorphine prescription products by community factors and pharmacist practices in WV.

Table 4.5. Barriers to the availability of opioid, naloxone, and buprenorphine product distribution through community pharmacies, among pharmacists licensed and working in WV 
Supplemental Table 7.1.1. Logistic regression with adjusted odds ratio (AOR) and 95\% confidence interval $(95 \% \mathrm{CI})$ for patients with incident opioid use by transition to chronic opioid therapy after first opioid prescription, using QuintilesIMS Real-World Data Adjudicated Claims - US, 2006-2015. 89

Supplemental Table 7.2.1 Patient characteristics before and after applying inverse probability of treatment weighting (IPTW) for patients with incident opioid use by transition to chronic opioid therapy (COT) after first opioid prescription, QuintilesIMS Real-World Data Adjudicated Claims Database - US, 2006-2015. 


\section{List of Figures}

Figure 1.1 Adapted continuum of care for opioid misuse

Figure 2.1. Application of inclusion and exclusion criteria to the sample of patients with incident opioid prescriptions from QuintilesIMS Real-World Data Adjudicated Claims - US, which were

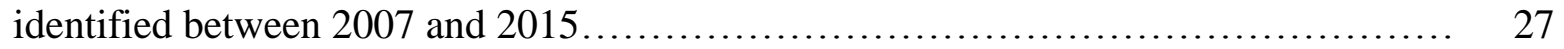

Figure 2.2: Receiver operator characteristic (ROC) curves for Model 1 (orange, AUC $=0.776$ ) and Fully Adjusted Model 2 (purple, AUC = 0.782) using the test subsample......... 28

Figure 3.1. Difference in average total expenditures (no prescription drug costs) between chronic opioid therapy (COT) and no COT transition using a counterfactual prediction technique.

Supplemental Figure 7.1.1: Receiver operator characteristic (ROC) curves for Model 1 (orange, AUC $=0.767$ ) and Fully Adjusted Model 2 (purple, AUC $=0.778$ ) using the training/validation subsamples.

91

Supplemental Figure 7.1.2. Receiver operator characteristic (ROC) curves for Model 1 using the training/validation subsample (black, AUC $=0.767$ ) and Model 1 using the test subsample (green, $\mathrm{AUC}=0.776$ )

Supplemental Figure 7.2.1. Difference in unweighted average expenditures between chronic opioid therapy (COT) and no COT transition for total (no prescription drug), emergency department (ED), inpatient (IP), and physician costs 


\section{List of Appendices}

7.1 Supplemental Information- Chapter 2: Predictors of transitioning to incident chronic opioid therapy among working-aged adults............................... 89

7.2 Supplemental Information- Chapter 3: Increased healthcare utilization and expenditures associated with transition to chronic opioid therapy $\ldots \ldots \ldots \ldots \ldots \ldots \ldots . .93$ 


\section{List of Abbreviations}

$\begin{array}{ll}\text { AHRQ } & \text { Agency for Healthcare Research and Quality } \\ \text { AOR } & \text { Adjusted Odds Ratio } \\ \text { AUC } & \text { Area Under the Curve } \\ \text { CAOS } & \text { Clinicians' Attitudes and beliefs about Opioids Survey } \\ \text { CDC } & \text { Centers for Disease Control and Prevention } \\ \text { CI } & \text { Confidence Interval } \\ \text { CMS } & \text { Centers for Medicare and Medicaid Services } \\ \text { CNCP } & \text { Chronic Non-Cancer Pain } \\ \text { COT } & \text { Chronic Opioid Therapy } \\ \text { CPE } & \text { Continuing Pharmacy Education } \\ \text { CPI } & \text { Consumer Price Index } \\ \text { DEA } & \text { Drug Enforcement Agency } \\ \text { DHHS } & \text { Department of Health \& Human Services } \\ \text { ED } & \text { Emergency Department } \\ \text { EPPM } & \text { Extended Parallel Process Model } \\ \text { FDA } & \text { Food and Drug Administration } \\ \text { GEE } & \text { Generalized Estimating Equation } \\ \text { GLMM } & \text { Generalized Linear Mixed Model } \\ \text { GPI } & \text { Generic Product Identifier } \\ \text { HMO } & \text { Health Maintenance Organization } \\ \text { HR } & \text { Hazard Ratio } \\ \text { ICD-9-CM } & \text { International Classification of Diseases, Ninth Revision, Clinical Modification } \\ \text { IPTW } & \text { Inverse Probability of Treatment Weighting } \\ \text { mgME } & \text { Milligram of Morphine Equivalent } \\ \text { NDC } & \text { National Drug Code } \\ \text { NLM } & \text { National Library of Medicine } \\ \text { PA } & \text { Population-averaged } \\ \text { PCA } & \text { Principal component analysis } \\ \text { PPO } & \text { Preferred Provider Organization } \\ \text { ROC } & \text { Receiver Operating Characteristic } \\ \text { Rx } & \text { Prescription } \\ \text { SD } & \text { Standard Deviation } \\ \text { US } & \text { United States } \\ \text { Wt } & \text { Weighted } \\ \text { WV } & \text { West Virginia } \\ \text { WVBOP } & \text { West Virginia Board of Pharmacy } \\ \text { WVU } & \text { West Virginia University } \\ & \end{array}$




\section{CHAPTER 1}

\section{Introduction}

\subsection{Background and Need for Study}

Pain is classified as acute or chronic with chronic pain defined as pain beyond the time of normal tissue healing, or three months. ${ }^{26,27}$ An estimated $43 \%$ of adults experience pain of any kind in the past 12 months, and the majority of them are working age with an adjusted mean age of 44 years. ${ }^{6}$ Chronic pain can be especially burdensome for the working age population due to lost productivity and negative impacts on quality of life. ${ }^{2-6}$ The most common source of chronic pain for those without cancer, referred to as chronic noncancer pain $(\mathrm{CNCP})$, is musculoskeletal in origin (joint or back pain), but other sources (e.g. migraine or neuropathic) are also prevelant. $^{6,28}$

$\mathrm{CNCP}$ can be managed using many different therapy regimens including pharmacologic options (non-opioid pharmacotherapy and opioid therapy) and non-pharmacologic options which have been shown effective (e.g. electrical stimulation, physical therapy, psychological interventions, or exercise). ${ }^{7,9,29} \mathrm{CNCP}$ is treated with opioids despite lack of robust evidence on the efficacy and effectiveness of COT. Opioids have been recommended to only be used after considering a non-opioid analgesic regimen. ${ }^{7}$ However, in 2012, prescriptions for opioid analgesics in the United States peaked at 259 million $^{30}$ and nearly one in five patients who presented to their healthcare provider with a painful condition in 2010 were prescribed an

opioid. ${ }^{31}$ Although opioids can treat pain effectively in the short term, the long term effectiveness is not established, ${ }^{7,8}$ yet $35 \%$ of adults received opioids for $\mathrm{CNCP} .{ }^{10}$

Many adults with CNCP who were initiated on opioids transition into COT with adverse health consequences; however, research on transitions into long-term opioid use among working 
age adults is lacking. Although the benefits of long-term opioid therapy (over 1 year) have not been sufficiently established in terms of pain, physical functioning, or health-related quality of life, ${ }^{7}$ the percentage of adults who transition to COT varies widely- from as low as $5 \%$ to as high as $46 \% .^{10,18}$ While there is substantial published literature on COT among elderly (age $\geq 65$ years), ${ }^{32-34}$ factors affecting how working-age adults with $\mathrm{CNCP}$ transition into COT are less well understood. ${ }^{7,35}$

Chronic opioid therapy can have serious health consequences. For example, compared to other non-opioid regimens, opioid regimens have been shown to have higher risk for an opioid abuse or dependence diagnosis, increased cardiovascular events, endocrinologic harms (e.g. androgen deficiency), factures, and acute trauma including vehicle crashes. ${ }^{7,29}$ Other opioidrelated side effects (e.g. xerostomia, nausea, constipation, pruritus, dizziness, vomiting, drowsiness) can negatively affect patient's quality of life. ${ }^{7,36-40}$ Many opioid users progress to be diagnosed with an opioid use disorder which further increases their risk for overdose and death. ${ }^{7,10}$ In a claims-based analysis of those with $\mathrm{CNCP}$, it was reported that long-term opioid users were more likely to be diagnosed with opioid use disorder compared to those not prescribed opioids. ${ }^{10}$ Furthermore, COT can exacerbate current conditions and lead to development of new chronic physical and mental health conditions. ${ }^{7,19-22}$ As identified in multiple large patient populations, patients with COT (mean ages ranged from $44.6(\mathrm{SD}=15.1)$ to 55.4 (13.0) years) were more likely to develop depression compared to those without opioids $(\mathrm{HR}=1.35,95 \% \mathrm{CI}=1.26-1.44$ in the Veterans cohort to $2.05(1.75-2.40)$ in an cohort of enrollees in an HMO network). ${ }^{41}$

Preventing inappropriate initiation and utilization of opioid medications is the shared responsibility of patients, prescribers, policy-makers, and healthcare payers. ${ }^{7,42}$ The first step 
towards preventing opioid misuse and/or addiction is appropriate initiation of opioids because persistence in patients with COT is so high. ${ }^{18}$ In a prospective study, $46 \%$ of adults who were initiated on opioids transistioned into chronic opioid users. ${ }^{18}$ One way to aid early identification of individuals at high risk for transitioning to COT is through predictive modeling which can be used to augment clinicians' knowledge. ${ }^{43,44}$ Predictive modeling allows for the inclusion of vast amounts of data coming from previously treated patients and can also be applied to real-time data customized to specific regions, providers, or insurers. ${ }^{43,44}$ Early identification of patients with certain modifiable risk factors (e.g. opioid dose, opioid duration of action, polypharmacy, and number of concomitant pain medications) can help inform early risk mitigation efforts which have shown some efficacy at preventing opioid-related adverse events including overdose and death. ${ }^{7,45,46}$ Current CDC opioid prescribing guidelines recommend follow-up earlier than three months (before the transition to COT) to increase the likelihood of preventing opioid-related adverse events. ${ }^{7}$ This recommendation was made in light of findings that transitioning to COT dramatically increases the risk for opioid use disorders, but there is not enough evidence to recommend monitoring intervals or how monitoring should be performed. ${ }^{7,10}$

Transition into COT can lead to significant economic consequences, however, robust evidence on the effect of transitions to COT on economic consequences is not available. Every year, an estimated $\$ 78$ billion is spent on adverse consequences of opioids including potential misuse, abuse, and adverse effects. ${ }^{24}$ Adverse health effects due to prescription opioids often result in increased healthcare utilization and expenditures of working Americans. ${ }^{2-5}$ For example, prescription opioids accounted for over 14,000 overdose deaths, in $2014 .{ }^{47}$ This can lead to high economic burden through increased emergency room, inpatient, and other healthcare utilization and healthcare expenditures. ${ }^{19-24}$ Drug overdoses due to opioids accounted for nearly 7,000 ED 
visits daily ${ }^{22}$ and the number of emergency department visits due to opioids have doubled from 2004 to $2011 .{ }^{19}$ Over the past two decades, the number of hospital discharges associated with opioid overdoses increased by over two and a half times. ${ }^{21}$ At the patient-level, patients who were prescribed opioids had higher emergency department, inpatient, and outpatient visits, as well as increased analgesic use, out-of-pocket spending, and third-party spending compared to patients not prescribed opioid medications. ${ }^{19,23,48,49}$

However, studies that systematically determined the effect of the transition from acute to COT has on healthcare utilization and expenditures are lacking. ${ }^{10,20}$ One study using data from a large managed care organization reported that healthcare utilization and expenditures were higher among long-term opioid users compare to other opioid users. ${ }^{20}$ This study has many serious limitations such as use of non-standard definition of long-term opioid therapy and opioid regimen characteristics. The definitions for chronic users (>182 days) were different than the Agency for Healthcare Research and Quality (AHRQ) and CDC definition of >90 days (3 months) $)^{7,8}$, as well as opioid regimen characteristics being categorized as strong or weak. ${ }^{20}$ Categorizing opioid regimens based on being "strong" or "weak" does not incorporate potency, and if opioids are prescribed in equipotent doses, they are more or less, equally effective. ${ }^{7,26}$ The proposed study will address the serious limitations of the prior literature and analyze the impact of transitions from initiation of opioids to COT on the economic burden in a nationallyrepresentative sample of working age adults using definitions concordant with definitions used by CDC, AHRQ, and current literature. ${ }^{7,850,51}$

While reducing the likelihood of prescribing poorly monitored or inappropriate COT is a necessary long-term goal, in the short-term we still need community-based harm reduction strategies to prevent unintentional injuries and deaths. ${ }^{46,52-54}$ Unintentional opioid overdose 
deaths can be limited by co-prescribing naloxone to patients with high risk COT. ${ }^{715}$ In addition to prescribers, current policy and intervention efforts have focused on preventing overdose and death (i.e. harm reduction). ${ }^{11-17}$ Naloxone has been approved in many forms (e.g. intranasal, intravenous) and can completely reverse the immediate risks of opioid overdose and prevent deaths due to opioid overdose. ${ }^{55,56}$ State policies are changing to increase accessibility to patients as well as their friends, family members, and caregivers. In states where naloxone is already available in community pharmacies, pharmacists are helping to prevent opioid-related overdose deaths by dispensing naloxone. ${ }^{57}$ Even with these policy changes, providing naloxone within the community is a voluntary act, and needs buy-in from community pharmacists to be effectively implemented.

Pharmacists working in community pharmacies are the most widely available healthcare professionals $^{58}$ and the gatekeepers to prescription opioids as well as the medications used to treat opioid use disorder. As dispensers, they typically function in their gatekeeper position while possessing little clinical or diagnostic information on the intended indication for opioid use. ${ }^{59}$ Despite having little information, pharmacists remain legally accountable to only dispense controlled substances for legitimate medical purposes and to reduce diversion. ${ }^{60}$ Even if the information on potentially inappropriate prescribing is available to the pharmacists (e.g. from a perception drug monitoring program) the interventions a pharmacist can make are limited. ${ }^{54}$ This obligation has other implications as pharmacists may feel the need to stock less and scrutinize more, especially when they feel uncertain about the legitimacy of a controlled substance prescription. ${ }^{61}$ To help alleviate these feelings, provider education must be made available to help pharmacists do their jobs more effectively. ${ }^{62}$ Under ideal circumstances, their provision of naloxone is performed as one component of a larger public health mission that includes health 
promotion, injury prevention, and harm reduction. ${ }^{52}$ Community pharmacies throughout the country have taken on naloxone distribution as part of the public health mission to prevent deaths. ${ }^{52}$ Pharmacists are providing naloxone to the community in unique ways and their legal responsibilities are in a state of change. ${ }^{16,17,52,63,64}$

West Virginia (WV) is an appropriate state to evaluate the capacity of community pharmacies to provide naloxone due to its reliance on community pharmacies to provide access to healthcare and its current high levels of opioid abuse and deaths. ${ }^{47,65}$ In 2015 , WV led the US with 35.5 deaths per 100,000 inhabitants - twice the national average. ${ }^{47}$ Lynne Fruth, owner of 20 community pharmacies in WV supported providing naloxone by stating, "If you live to fight another day, you have another chance at recovery." ${ }^{\prime 66}$ States which have been most burdened by the opioid epidemic have used community pharmacists to increase access to naloxone. ${ }^{17,67,68}$ For example, Kentucky (24.7 drug overdose deaths per 100,000 inhabitants) passed legislation for pharmacists to provide naloxone in the community in 2015 and the state agencies provide education materials tailored to pharmacists in their state.$^{64}$ Despite the anecdotal successes, ${ }^{46,53}$ the true societal impact of naloxone in a community will be determined in the coming months and years.

To optimize the process of providing naloxone to the community in WV requires the educational needs of pharmacists to be evaluated as well as their individual perceptions of perceived opioid efficacy, perceived naloxone efficacy, and willingness to stock naloxone. From this specific harm reduction strategy to improving initiation of COT, elucidating the transitions in opioid use is critical to understanding the opioid epidemic more fully. The findings from this study will provide valuable information to clinicians, insurers, policy makers, and researchers about these transitions and indicate better options for clinical practice and public health policy. 


\subsection{Specific Aims}

The specific aims are guided by the adapted Continuum of Care for Opioid Misuse developed by the Opioid Taskforce for the Alcohol and Drug Abuse Institute at the University of Washington. ${ }^{42}$ The aims of this study are to evaluate the transitions of care a patient may experience in their treatment with COT which are all conceptually linked using this framework (Figure 1.1).

AIM 1: Identify leading predictors of transitioning from acute to COT among working age adults without cancer with advanced predictive modeling techniques using a nationally representative sample of working-age adults.

Hypothesis 1: Modifiable factors related to opioid regimen such as dose and duration of action, polypharmacy, and concomitant pain medications, will be the leading predictors of COT in working age adults.

AIM 2: Analyze the effect of transitions from incident acute opioid therapy to incident COT on the trajectories of healthcare utilization and expenditures using a nationally representative sample of working-age adults.

Hypothesis 2: The growth in utilization and expenditures over time will be higher among adults who transitioned to COT as compared to adults who did not transition into COT, even after adjusting for initial opioid regimen characteristics, comorbidities, and demographic information.

AIM 3: Evaluate the potential for harm reduction capacity, in terms of naloxone distribution from community pharmacies, of a high abuse state with assessment of perceptions, behaviors, and educational needs of pharmacists licensed and working in West Virginia. 


\subsection{Innovation}

Identification of leading, modifiable predictors using routinely collected data such as insurance claims and electronic heath records to identify patients at high risk for with incident COT will allow clinicians, policy makers, insurers and other stakeholders develop strategies to intervene early for patients. WV is the only state situated entirely within Appalachia, and home to people who rank among the oldest, poorest, and least-educated in the US, who face limited health care access due to geographic isolation, and have among the highest prevalence of most health-related risk factors in the nation. With the recent passage of a WV law allowing pharmacists the opportunity to act as naloxone providers, effective educational strategies are needed quickly. ${ }^{69}$ This study can make a significant difference towards solving the opioidepidemic in the state. Education has been identified as a key component in reducing opioid abuse in the United States. ${ }^{7,62,70}$ The Extended Parallel Process Model (EPPM) will be used to assess educational needs and provide a framework for categorizing types of pharmacists based on their perceptions relating to opioid use, misuse, and abuse. EPPM is used for the first time to develop public communications for pharmacists. WV is well-known for its limited healthcare infrastructure and pharmacists are well-positioned to respond to the opioid crisis. Evaluating the perceptions and actions of the community pharmacists being tasked with providing naloxone in their pharmacies has been identified as an important next step by clinicians and promulgated by the American Pharmacists Association. ${ }^{63}$

\subsection{Impact}

By predicting incident COT, clinicians and insurers can personalize treatment options including non-opioid regimens for adults at high risk for COT. By tracking the economic burden of opioid use from initiation to COT, payers can identify crucial time-windows for designing and 
implementing value-based designs with financial incentives and disincentives to prevent expensive COT and its complications. Further, by evaluating community pharmacists' readiness to support harm-reduction efforts will help regulators, policy makers, and patients in implementation of policy around co-prescription of naloxone in community-pharmacies. 
Figure 1.1 Adapted continuum of care for opioid misuse ${ }^{42}$

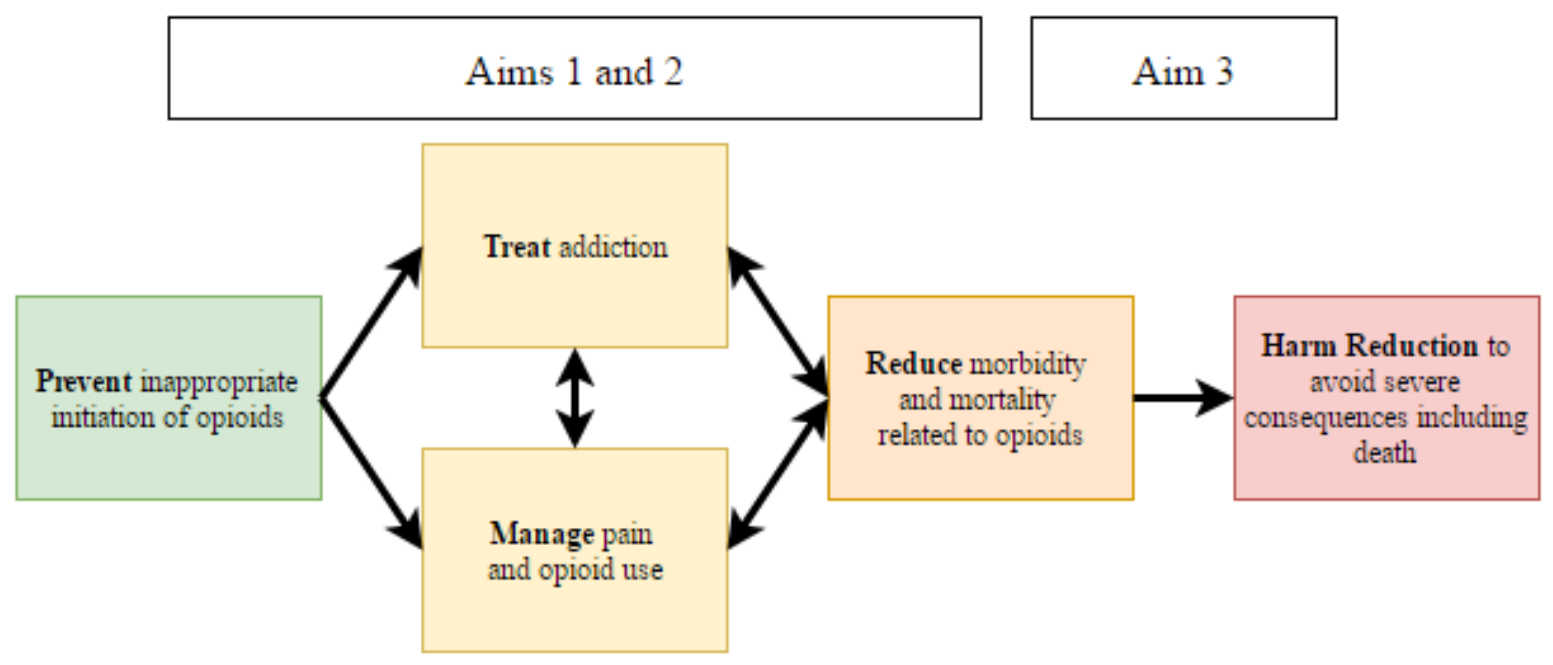




\section{CHAPTER 2}

\section{Predictors of transitioning to incident chronic opioid therapy among working-aged adults}

\subsection{Abstract}

Background: Opioids are being prescribed and used for chronic non-cancer pain at prolific rates in the United States over the last two decades. Patients who transition to incident chronic opioid therapy (COT) are at higher risk for significant, negative health consequences including cardiovascular risk, endocrine disorders, opioid use disorder, and death. Objective: The objective of this study was to identify leading predictors associated with incident COT among adults without cancer in the US. Design: Retrospective observational cohort with claims from a nationally-representative sample of adults enrolled in commercial insurance plans. Standard parametric (logistic regressions) and non-parametric methods based on decision tree were used for prediction. For easier comparison with published literature, we also present adjusted odds ratios (AOR) and 95\% confidence intervals (CI). Participants: A 10\% random sample of working-age adults (age 28-63 years) insured in commercial plans, without cancer and who were initiated on opioids between January 2007 through May 2015. Main Measures: Transition to incident COT (at least 90 days of opioids claimed within 120 days) after initiation of opioids. Predictive models included a comprehensive list of factors available in claims data: opioid regimen characteristics, pain conditions, physical and mental health conditions, concomitant medications (benzodiazepine, stimulants, non-opioid analgesics, and polypharmacy), patient characteristics, and insurance type. Key Results: In our sample, transition to incident COT was $1.3 \%$ and pain-specific diagnoses were rare $(31.7 \%)$. The four leading predictors of COT were opioid duration-of-action $[\mathrm{AOR}=12.28 ; 95 \% \mathrm{CI}=8.06-18.72]$, parent opioid [tramadol vs. 
codeine, $[\mathrm{AOR}=7.26 ; 95 \% \mathrm{CI}=5.20-10.13]$, the presence of conditions highly likely to cause chronic pain $[\mathrm{AOR}=5.47 ; 95 \% \mathrm{CI}=3.89-7.68]$ and drug use disorders $[\mathrm{AOR}=4.02 ; 95 \% \mathrm{CI}=$ 2.53-6.40]. Conclusions: Initial opioid regimen characteristics are powerful predictors of COT. Predictive algorithms developed from readily available claims data can be used to develop realtime predictions on future risk of transition to COT.

\subsection{Introduction}

Chronic non-cancer pain (CNCP) is prevalent among US adults, has costs exceeding half a billion dollars annually, and can be especially burdensome for working-age adults due to lost productivity and negative impacts on quality of life. ${ }^{1-6}$ Many patients suffering from CNCP still receive opioid therapy, despite lack of robust evidence on the efficacy and effectiveness of opioids relieving $\mathrm{CNCP},{ }^{7,8}$ and currently-available effective non-opioid treatments. ${ }^{9}$ In 2012 , prescriptions for opioids peaked at 259 million prescriptions. ${ }^{7,30}$

Patients who receive short-term opioid therapy may be at high risk of becoming users of chronic opioid therapy (COT), defined as use of opioid over 90 days. ${ }^{7,18}$ COT places patients at risk of exacerbating current conditions, developing new chronic physical and mental health conditions, and opioid-related adverse effects such as overdose, abuse, and death. ${ }^{7,19-22} \mathrm{An}$ estimated 1 in 550 patients with CNCP die from an opioid overdose and the rate of death increases to 1 in 32 patients, who were prescribed very high daily doses. ${ }^{71}$ These findings suggest that opioid regimen characteristics play a crucial role in escalating the risk of COT and its associated adverse consequences.

However, factors affecting how working-age adults with CNCP transition into COT are not well understood. ${ }^{7,35}$ It is important to examine COT among working-age adults because they may suffer from unique, negative consequences such as missed worked days, loss of 
employment, and decreased productivity ${ }^{19-24}$ in addition to the complications related to opioids such as high economic burden through increased emergency room, inpatient, and other healthcare utilization. ${ }^{19-24}$ Given these potentially serious consequences, it is important to determine the predictors of transitioning from acute to COT among working age adults. ${ }^{25}$ Identifying working-aged adults who are at high risk for transitioning to COT and determining the factors which place them at risk for the transition can augment clinicians' knowledge to aid with prescribing decisions, initial opioid regimen selection, or monitoring, ${ }^{43,44}$ as well as to help inform early risk mitigation efforts, which have shown some efficacy at preventing overdose and death. ${ }^{7,45,46}$

Researchers have assessed the transition from acute to COT among Veterans, among patients using a single healthcare system, or among low-income individuals using Medicaid claims. ${ }^{18,72,73}$ Other studies have used predictive models to identify patients who were diagnosed with incident substance use disorders or opioid abuse. ${ }^{74,75}$ To date, no study has analyzed the transition to incident COT in working-aged adults using nation-wide data. Therefore, the objective of this study was to identify predictors of transition to incident COT among workingage adults using data from a nationally representative sample of commercially-insured adults in the US. With this information, clinicians and insurers can personalize treatment options including non-opioid regimens for adults at high risk for transition to COT; changes to treatment guidelines based on these predictors can be assessed by researchers, policy makers, and government payers. We used robust predictive modeling techniques to identify leading predictors of incident COT using readily available information in claims databases; such modeling can be applied to real-time data customized to specific regions, providers, or insurers. ${ }^{27,28}$ 


\subsection{Methods}

$\underline{\text { Data }}$

The data were derived from adjudicated claims (inpatient, outpatient, emergency room, and prescription) database of commercial enrollees (approximately 150 million enrollees) which covered ten years from 2006 to 2015 . The researchers received data on $10 \%$ random sample of commercial enrollees released under licensing from the QuintilesIMS information services (QuintilesIMS RWD Adjudicated Claims - US). The full data from which the $10 \%$ was sampled covers $90 \%$ of hospitals, $80 \%$ of doctors, and $85 \%$ of large companies in the US. This data only includes health plans who submit data for all of their members and the data are considered nationally representative for the US commercial-insured population. ${ }^{76,77}$

\section{$\underline{\text { Study Design }}$}

A retrospective cohort design, with baseline and follow-up periods was used. A patient's first prescription for an opioid during the period between January 2007 and May 2015 was defined as the index date; this index date was used to create baseline (12 months before index date) and follow-up (120 days after index date) periods. To ensure that we captured individuals who were opioid-free in the baseline, we used the first prescription date between January 2007 and May 2015. The National Drug Codes (NDCs) for opioids were extracted from the National Library of Medicine's (NLM) RxNav (https://mor.nlm.nih.gov/RxNav/) and RxMix (https://mor.nlm.nih.gov/RxMix/). ${ }^{78}$ These conversions allowed for categorizing opioids more granularly (e.g. by parent opioid and duration of action).

\section{$\underline{\text { Study Sample }}$}

The study sample $(\mathrm{N}=491,422)$ consisted of adults, aged 28-63 years at index date, without cancer, and who were continuously enrolled in a primary, commercial insurance plan 
during the entire observation period (baseline and follow-up periods). Continuous enrollment in both pharmacy benefits and medical benefits was required. We excluded individuals who had more than one opioid prescription on the index date because we were unable to evaluate initial opioid regimen characteristics for these individuals $(\mathrm{N}=10,594)$. We excluded few individuals $(\mathrm{N}=23$ ) because of missing of data on region (Figure 2.1).

\section{$\underline{\text { Measures }}$}

\section{Dependent variable}

Transition to incident chronic opioid therapy (COT): An enrollee was classified as having incident COT if he/she had at least 90-day supply of opioids during the follow-up period (i.e. 120 days after index date).

\section{Independent variables}

Opioid regimen characteristics included duration of action (long-acting and immediate release), standardized dose, and parent opioid. These were assessed using the first opioid prescription. Parent opioid was grouped into five categories: 1) codeine; 2) hydrocodone; 3 ) oxycodone; 4) tramadol; and 5) other opioids. As the data use agreement with QuintilesIMS specified that opioids manufactured by a single manufacturer could not be isolated, we combined all the single manufacturer drugs and other opioids into one category. Methadone can be used to treat opioid use disorder or pain, so it was not included as an eligible opioid for the sample. Standardized dose was calculated in milligrams of morphine equivalents (mgME) using the opioid morphine equivalent conversion factors approved by the Centers for Medicare and Medicaid Services (CMS). ${ }^{79}$

Enrollment characteristics of patients were: insurance plan type (Health Maintenance Organization, Preferred Provider Organization, or other) and primary insured relationship (self, 
spouse, other, and unknown). Patient demographics included age, sex, and region (East, Midwest, South, and West).

Clinical factors were presence or absence of diagnoses for: painful conditions, mental illnesses, ${ }^{80}$ and a set of chronic conditions adapted from Department of Health and Human Services (DHHS) priority conditions for research, program, and policy. ${ }^{81}$ Painful conditions were also categorized as: 1) conditions highly likely for chronic pain; ${ }^{82}$ 2) likely for chronic pain; ${ }^{82}$ and 3) acute pain. ${ }^{83}$ Arthritis was separated because it was a painful condition as well as a DHHS priority condition, so that it would not be double counted. The International Classification of Diseases, Ninth Revision, Clinical Modification (ICD-9-CM) codes were used to assess each of these conditions. The ICD-9-CM codes did not overlap between lists. Drug use disorders included ICD-9-CM codes for drug dependence (304), drug abuse (305.2-305.9), and druginduced mental disorders (292).

Generic Product Identifier (GPI) codes, a hierarchical classification system that identifies drugs from their primary therapeutic use to package size in 2-digit increments, were used to assess medication-related characteristics. Medication-related characteristics included concomitant use of benzodiazepines (GPI-4 $=57.10)$, stimulants (GPI-4 $=61.10$ or 61.40), or non-opioid analgesics (GPI-2 $=66$ or 64). Pharmacotherapy burden was estimated with polypharmacy defined as five or more medication classes. ${ }^{84}$ Concomitant medications were measured during the last four months of the baseline period.

\section{Statistical Analyses: Predictive Modeling}

Both standard parametric (logistic regressions) and non-parametric methods based on decision tree were used for prediction. Random forest, a decision tree method is often used for predictive accuracy. ${ }^{43}$ In Random forest, collection of decision trees are built and averaged by 
bootstrapping of samples and variables. ${ }^{43}$ The two methods were compared using receiver Operator Characteristic (ROC) curves. Predictive modeling differs from the standard regression approaches in many ways. While standard regressions focus on the average relationship between transition to COT and explanatory variables, predictive modeling can be used to target the patients at highest risk for transitioning to COT like has been done to help develop interventions for patients with diabetes. ${ }^{85}$

Standard regressions are typically conducted in a given sample, while predictive models use bootstrap samples of observations (bagging) and a sample of variables (attribute bagging) and testing the estimated model in a hold-out or test sample. ${ }^{43,86}$ To accomplish this, we randomly split the eligible sample into three subsamples (60\% training, 20\% validation, and $20 \%$ testing). After a final model was identified using the training and validation subsamples, the predictive model was tested on the hold-out sample to assess performance and potential overfitting. To increase the utility of a predictive model in a clinical setting, we used an abbreviated set of factors that could be easily assessed during a patient visit (Model 1). Predictive modeling was performed in $R$ (R Development Core Team, Vienna, Austria). For comparison with published literature, we present adjusted odds ratios (AOR) and 95\% Confidence intervals (CI) by conducting a logistic regression of the final models in the test subsample.

\subsection{Results}

\section{$\underline{\text { Sample description }}$}

Overall, in this sample of working-aged adults, the transition from first opioid prescription to incident COT was $1.3 \%(\mathrm{n}=6,556)$ (Table 2.1). Hydrocodone was the most frequently prescribed first opioid (61.0\%) followed by oxycodone (19.3\%), tramadol (9.9\%), and codeine $(9.1 \%)$. The majority of the eligible sample was female (52.5\%), 45 years of age or older 
(56.7\%), and on PPO plans (73.9\%). The majority of these patients (68.3\%) did not have an indication in their medical claims for acute pain, arthritis, or conditions highly likely or likely for chronic pain.

Selected key sample characteristics by transition to COT are presented in Table 2.1. Opioid regimen characteristics (parent opioid, duration of action, and standardized dose) were all associated with the transition from first opioid prescription to incident COT. A higher percentage of patients with first opioid prescriptions for long-acting formulations (37.0\% vs. $1.3 \%$ immediate release), tramadol ( $4.2 \%$ vs $0.5 \%$ codeine), very high standardized doses (5.1\% vs $1.5 \%$ lower), patients who had conditions most likely to cause chronic pain (17.2\% vs. $1.3 \%$ without), and patients with drug use disorders ( $12.4 \%$ vs. $1.3 \%$ without) transitioned to COT. Predictive modeling

In training/validation subsamples, the following variables were the leading predictors after adjusting for sex, age, presence of painful conditions, and readily available and modifiable opioid regimen factors (opioid duration of action, parent opioid, and standardized dose). Variables of importance (absolute value of the beta-coefficient) in descending order as they related to transition to incident COT included: duration of action, likely chronic pain condition, parent opioid, highly likely pain condition, and drug use disorder diagnoses. In the hold-out sample, the same predictors were found to be important although the order changed somewhat. For example, drug use disorders became the fourth leading predictor in the hold-out sample as opposed to second leading predictor in the training/validation samples. In the fully adjusted model, the leading predictors remained the same in both training/validation and test samples. Again, the order of importance varied somewhat with the drug use disorders variable becoming 
the fifth leading predicator in the hold-out sample as opposed to third leading predictor in the training/validation samples.

The similarity between the two models was also confirmed by the prediction accuracy of Model 1 and fully-adjusted model (Figure 2.2). The Areas under the Curve (AUC) were similar for Model $1(\mathrm{AUC}=0.78)$ and the fully-adjusted model (AUC $=0.78)$ using the hold-out sample. The AUC of decision-tree based models using random forest on the variables from Model 1 and the fully-adjusted model were 0.54 and 0.64 in training/validation subsample, respectively.

As mentioned earlier, for ease of comparisons with published literature, Table 2.2 summarizes the findings in the form of AOR and 95\% CIs from a logistic regression of the test sample. As can be seen from the table, fully-adjusting the model did not make large changes to the AORs. For example duration of action (long acting vs. immediate release, AOR = 12.43, $95 \% \mathrm{CI}=8.13-18.83)$ in model 1 was similar in the fully-adjusted model $(\mathrm{AOR}=12.28,95 \% \mathrm{CI}$ $=8.06-18.72$ ).

\subsection{Discussion}

This is the first study to identify incident COT in a sample of working-aged adults, who were initiated on opioid therapy. This is an important group to focus on because of the impact on productivity and their increased likelihood to receive opioid therapy when they experience pain. ${ }^{25}$ In absolute terms, nearly half a million working-age adults in this sample were initiated on opioid therapy over the observation period. For example, in 2014 there were 1,799,106 million prescriptions for opioid drugs in our $10 \%$ sample. As a rate, we found that 13 out of 1000 patients with initial prescription of opioids transitioned to COT. 
Another important finding was differences between states in the US. The rates of patients who transitioned to incident COT was higher in Ohio, West Virginia, Kentucky, Mississippi, and Nevada than other states. These states are often in the media reporting opioid overdoses and problems; however, more study could be done to look for specific state issues, including monitoring of prescribers, education of public and prescribers, and availability of nonpharmacotherapy treatments for CNCP.

Our study findings demonstrated that a smaller set of more easily assessed factors at initiation (duration of action, standardized dose, parent opioid, age, sex) can be used to gauge the risk of transition to COT. Our predictive models identified four leading predictors that increased the risk of transition to COT by at least four times. These were: duration of action, type of parent opioids, drug use disorders, and painful conditions.

In our sample of working age adults, the highest likelihood of transition to COT was among adults who were prescribed extended release opioids as opposed to immediate release. These findings have implications for clinical practice. First, prescribers can use these factors to determine the potential for an individual patient to transition to incident COT at the time of their first prescription for opioids. With the knowledge of this potential risk, regimens could then be altered or monitoring increased. Pharmacists can also use these factors and provide counseling about goals of pain management or the risks of COT, to a subset of patients who are at high risk of transitioning to COT. Future intervention efforts can effectively target these factors to change prescribing practices of opioids. ${ }^{7}$ For example, immediate release, low-dose codeine can be firstline option. However, other opioids may be needed, since codeine is a weak opioid and there are pharmacogenomic differences (e.g. poor metabolizers will have a reduced response) that need to be considered for codeine use ${ }^{87}$ In addition, future studies using qualitative and quantitative 
analyses could assess prescriber logic in how they chose to prescribe extended release versus immediate release. What clinical characteristics or patient preference issues were considered in making these choices? There may be underlying issues that are uncovered.

In our sample, only a third of working-age adults, with first prescription of opioids had any diagnosis of painful conditions. While it is plausible that ICD-9-CM codes may under-report painful conditions, without the full documentation of indications for opioid use, it is difficult to assess appropriateness of initial opioid prescription. This has implications for prescription monitoring programs, state-based insurers, health care systems, local hospitals, and outpatient practices, as well as emphasizing the need for documentation requirements or recommendations.

Strengths of this study include the availability of a nationally-representative sample of the US commercially-insured population, following individuals across multiple providers and settings, use of statistical and machine learning predictive methods, and availability of dates so that we could identify first, index opioid prescription. Also, this study assessed incident COT, which other studies have not distinguished from prevalent use of chronic or long-term opioid therapy. By using the NLM programs RxMix and RxNav to identify clinical drug components, the duration of action and parent opioid for each prescription could be identified, which allowed for more granular assessment of the opioid regimen using claims data. Finally, the data spanned many unique insurers and plan types, which allowed for the tracking of patients through time and to determine an opioid-free period of 12 months.

The study also has some potential limitations. First, prescription claims do not have information on variables such as pain, socio-economic status, social capital, medication beliefs, and response to pain treatment, which may affect transition to COT. Also, claims data allow for the identification of prescription medication, but not actual use of these medications. There are 
limitations of the predictive modeling results as well. The models were assessed in a unique subsample (testing data) of the overall sample. However, the validity of the model and its predicted probabilities will be more generalizable if applied to a different sample of patients, potentially from other commercial healthcare plans. The importance of factors could change, and even be improved if other types of information were added to the dataset (e.g. social determinants of health, medication use behaviors, prescriber characteristics).

\subsection{Conclusion}

Our study findings suggest that an individual's transition to COT can be predicted by information readily available in a clinical setting such as the initial opioid regimen characteristics, past history of drug use disorder, and painful conditions. Our study highlighted that predictive models can be used to aid clinician's decision making; develop real-time predictions about future risk of transition to COT; influence policy, prescriber education, and prescription monitoring programs; and can applied to other patient populations. Future research may include other factors, including medication taking behaviors, not measured in our study and improve prediction accuracy.

\subsection{Acknowledgements and Data Use Statement}

$\underline{\text { Funders }}$

The views expressed in this academic research paper are those of the authors and do not reflect the official policy or position of West Virginia University (WVU) or any other affiliated organizations. US was partially supported by the National Institutes of Health, National Institute of General Medical Sciences (grant number U54GM104942). JDT was supported by the National Institutes of Health, National Institute of General Medical Sciences (grant number 5T32GM081741-08). 


\section{Data used statement}

The statements, findings, conclusions, views, and opinions contained and expressed in this article are based in part on data obtained under license from the following QuintilesIMS information services: QuintilesIMS Real-World Data Adjudicated Claims - US, 10\% sample January 2006- December 2015, QuintilesIMS Health Incorporated. All Rights Reserved. The statements, findings, conclusions, views, and opinions contained and expressed herein are not necessarily those of QuintilesIMS Health Incorporated or any of its affiliated or subsidiary entities. 
Table 2.1. Sample description for patients with incident opioid use by transition to chronic opioid therapy (COT) after initial opioid prescription, using QuintilesIMS Real-World Data Adjudicated Claims - US, 2006-2015

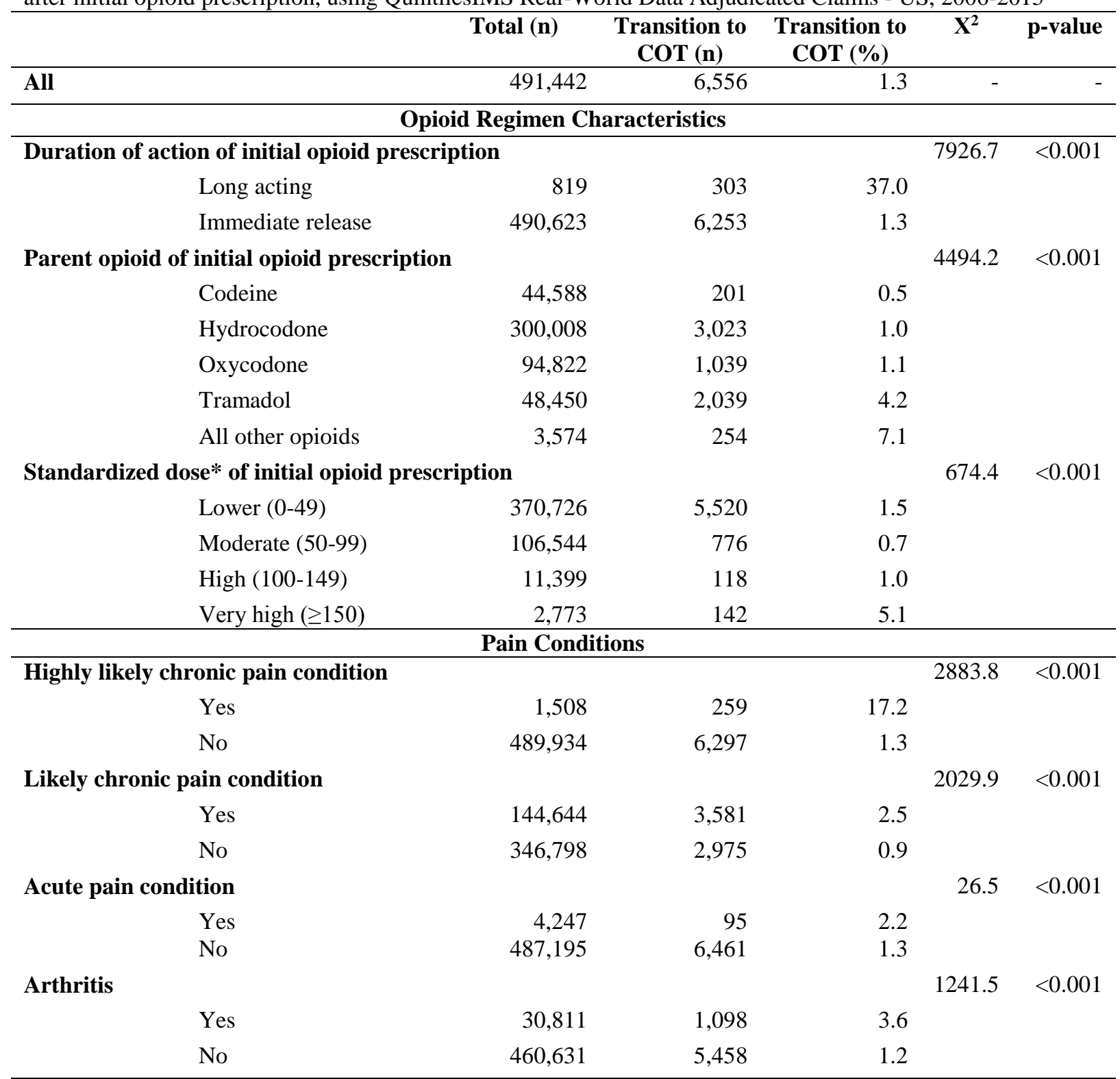

Physical and Mental Health Conditions

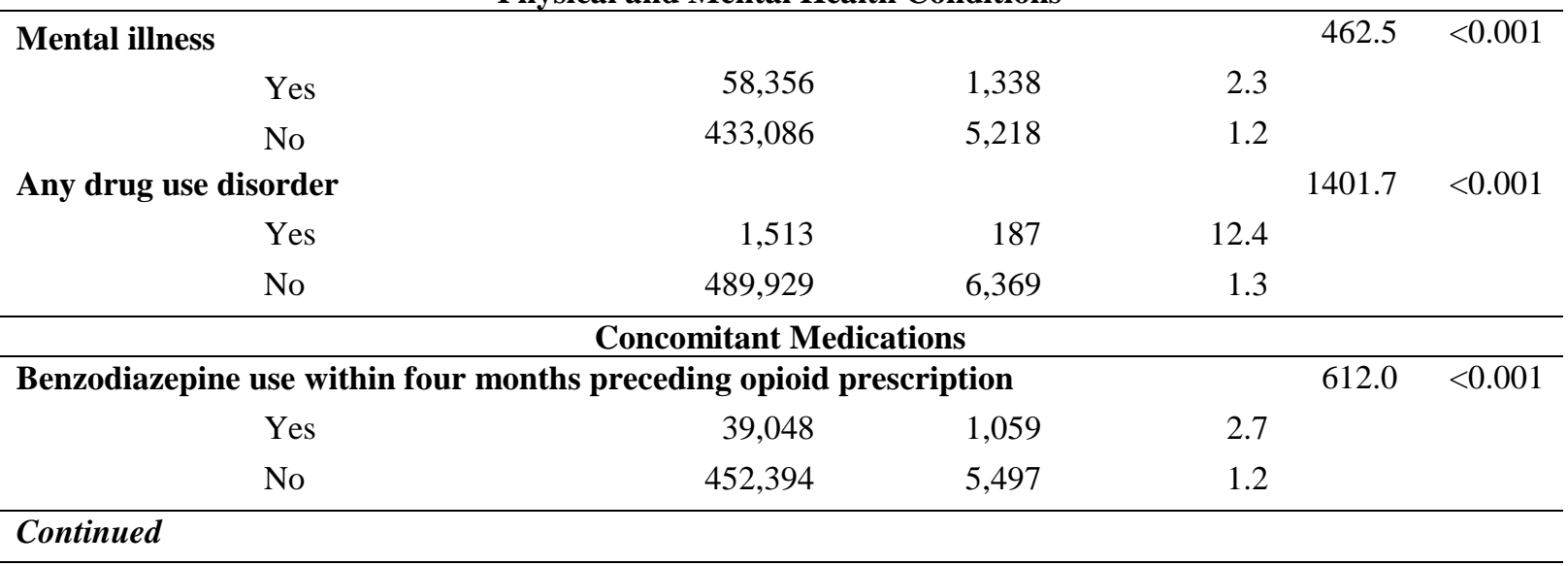


Table 2.1. Sample description for patients with incident opioid use by transition to chronic opioid therapy (COT) after initial opioid prescription, using QuintilesIMS Real-World Data Adjudicated Claims - US, 2006-2015

\begin{tabular}{|c|c|c|c|c|c|c|}
\hline 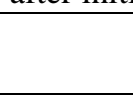 & 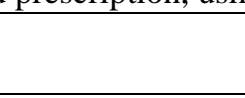 & Total (n) & $\begin{array}{c}\text { Transition to } \\
\text { COT (n) }\end{array}$ & $\begin{array}{c}\text { Transition to } \\
\text { COT }(\%)\end{array}$ & $\mathbf{X}^{2}$ & p-value \\
\hline \multicolumn{5}{|c|}{ Stimulant use within four months preceding opioid prescription } & 105.2 & $<0.001$ \\
\hline & Yes & 7,642 & 204 & 2.7 & & \\
\hline & No & 483,800 & 6,352 & 1.3 & & \\
\hline \multicolumn{5}{|c|}{ Non-opioid analgesic use within four months preceding opioid prescription } & 117.9 & $<0.001$ \\
\hline & Yes & 120,486 & 1,983 & 1.6 & & \\
\hline & No & 370,956 & 4,573 & 1.2 & & \\
\hline \multicolumn{5}{|c|}{ Polypharmacy ( $\geq 5$ drug groups) } & 528.9 & $<0.001$ \\
\hline & Yes & 109,724 & 2,234 & 2.0 & & \\
\hline & No & 381,718 & 4,322 & 1.1 & & \\
\hline \multicolumn{7}{|c|}{ Patient Characteristics } \\
\hline \multirow[t]{3}{*}{ Sex } & & & & & 94.0 & $<0.001$ \\
\hline & Male & 233,393 & 3,503 & 1.5 & & \\
\hline & Female & 258,049 & 3,053 & 1.2 & & \\
\hline \multirow[t]{5}{*}{ Age } & & & & & 594.2 & $<0.001$ \\
\hline & 28-34 years & 81,462 & 602 & 0.7 & & \\
\hline & $35-44$ years & 130,917 & 1,345 & 1.0 & & \\
\hline & $45-54$ years & 156,191 & 2,332 & 1.5 & & \\
\hline & $55-63$ years & 122,872 & 2,277 & 1.9 & & \\
\hline \multirow[t]{5}{*}{ Region } & & & & & 67.2 & $<0.001$ \\
\hline & East & 94,910 & 1,075 & 1.1 & & \\
\hline & Midwest & 156,117 & 2,090 & 1.3 & & \\
\hline & South & 194,746 & 2,862 & 1.5 & & \\
\hline & West & 45,669 & 529 & 1.2 & & \\
\hline \multicolumn{7}{|c|}{ Insurance Characteristic } \\
\hline \multicolumn{5}{|c|}{ Insurance plan type } & 24.0 & $<0.001$ \\
\hline & HMO & 63,181 & 798 & 1.3 & & \\
\hline & PPO & 363,414 & 5,010 & 1.4 & & \\
\hline & Othert & 64,847 & 748 & 1.2 & & \\
\hline
\end{tabular}

Note: This sample includes patients from QuintilesIMS RWD Adjudicated Claims - US, which were identified between 2007-2015 and had enrollment between 2006-2015. These patients were between 28-63 years old, without cancer, had complete demographic information available, and had only one opioid prescription on the index date. Due to data use requirements, some categories were collapsed. These include insurance plan type and other opioids.

*: Doses of opioids were converted to a standardized dose (milligrams of morphine equivalent) using the Centers for Medicare and Medicaid Services conversion table.

$\dagger$ : Other insurance types included fee-for-service, health savings account, and indemnity. 
Table 2.2. Select leading predictors from a logistic regression with adjusted odds ratio (AOR) and $95 \%$ confidence interval $(95 \% \mathrm{CI})$ for patients with incident opioid use by transition to chronic opioid therapy (COT) after first opioid prescription, using QuintilesIMS Real-World Data Adjudicated Claims - US, 2006-2015

\begin{tabular}{llcccccc}
\hline & \multicolumn{3}{c}{$\begin{array}{c}\text { Model 1 in } \\
\text { Test subsample }\end{array}$} & \multicolumn{3}{c}{ Fully adjusted Model 2 } \\
& iOR Test Subsample \\
& 95\% CI & Sig & AOR & 95\% CI & Sig \\
\hline Long-acting vs. Immediate release & 12.43 & {$[8.13,18.83]$} & $* * *$ & 12.28 & {$[8.06,18.72]$} & $* * *$ \\
Tramadol vs. Codeine & 7.59 & {$[5.53,10.74]$} & $* * *$ & 7.26 & {$[5.20,10.13]$} & $* * *$ \\
Highly likely chronic pain vs. None & 5.91 & {$[4.18,8.20]$} & $* * *$ & 5.47 & {$[3.89,7.68]$} & $* * *$ \\
All other opioids vs. Codeine & 5.71 & {$[3.38,9.59]$} & $* * *$ & 5.64 & {$[3.34,9.53]$} & $* * *$ \\
Drug use disorder diagnosis vs. None & 4.96 & {$[3.13,7.58]$} & $* * *$ & 4.02 & {$[2.53,6.40]$} & $* * *$ \\
Oxycodone vs. Codeine & 2.70 & {$[1.92,3.90]$} & $* * *$ & 2.67 & {$[1.87,3.81]$} & $* * *$ \\
Likely chronic pain vs. None & 2.08 & {$[1.84,2.34]$} & $* * *$ & 2.02 & {$[1.79,2.28]$} & $* * *$ \\
Hydrocodone vs. Codeine & 2.04 & {$[1.49,2.87]$} & $* * *$ & 1.97 & {$[1.42,2.73]$} & $* * *$ \\
Benzodiazepine prescription vs. None & 1.99 & {$[1.69,2.33]$} & $* * *$ & 1.82 & {$[1.54,2.16]$} & $* * *$ \\
Arthritis vs. None & 1.92 & {$[1.63,2.25]$} & $* * *$ & 1.86 & {$[1.58,2.20]$} & $* * *$ \\
Male vs. Female & 1.43 & {$[1.27,1.60]$} & $* * *$ & 1.46 & {$[1.30,1.65]$} & $* * *$ \\
Very high vs. Low dose $\dagger$ & 1.27 & {$[0.73,2.08]$} & & 1.24 & {$[0.74,2.08]$} & \\
Age (continuous) & 1.02 & {$[1.02,1.03]$} & $* * *$ & 1.02 & {$[1.01,1.03]$} & $* * *$ \\
High vs. Low dose $\dagger$ & 0.71 & {$[0.47,1.05]$} & & 0.68 & {$[0.45,1.02]$} & \\
Moderate vs. Low dose $\dagger$ & 0.45 & {$[0.37,0.55]$} & $* * *$ & 0.45 & {$[0.37,0.54]$} & $* * *$ \\
\hline
\end{tabular}

Note: This sample includes patients from QuintilesIMS RWD Adjudicated Claims - US, which were identified between 2007 and 2015 and had enrollment between 2006 and 2015. These patients were between 28-63 years old, without cancer, had complete demographic information available, and had only one opioid prescription on the index date. Due to data use requirements, some categories were collapsed. These include insurance plan type and other opioids. Other variables included in the fully adjusted model can be seen in the supplemental materials.

$\dagger$ : Doses of opioids were converted to a standardized dose (milligrams of morphine equivalent) using the Centers for Medicare and Medicaid Services conversion table.

Significance: $0<\mathrm{p}<0.001=* * *, 0.001 \leq \mathrm{p} 0.01=* *, 0.01 \leq \mathrm{p}<0.05=*$ 
Figure 2.1. Application of inclusion and exclusion criteria to the sample of patients with incident opioid prescriptions from QuintilesIMS Real-World Data Adjudicated Claims - US, which were identified between 2007 and 2015.

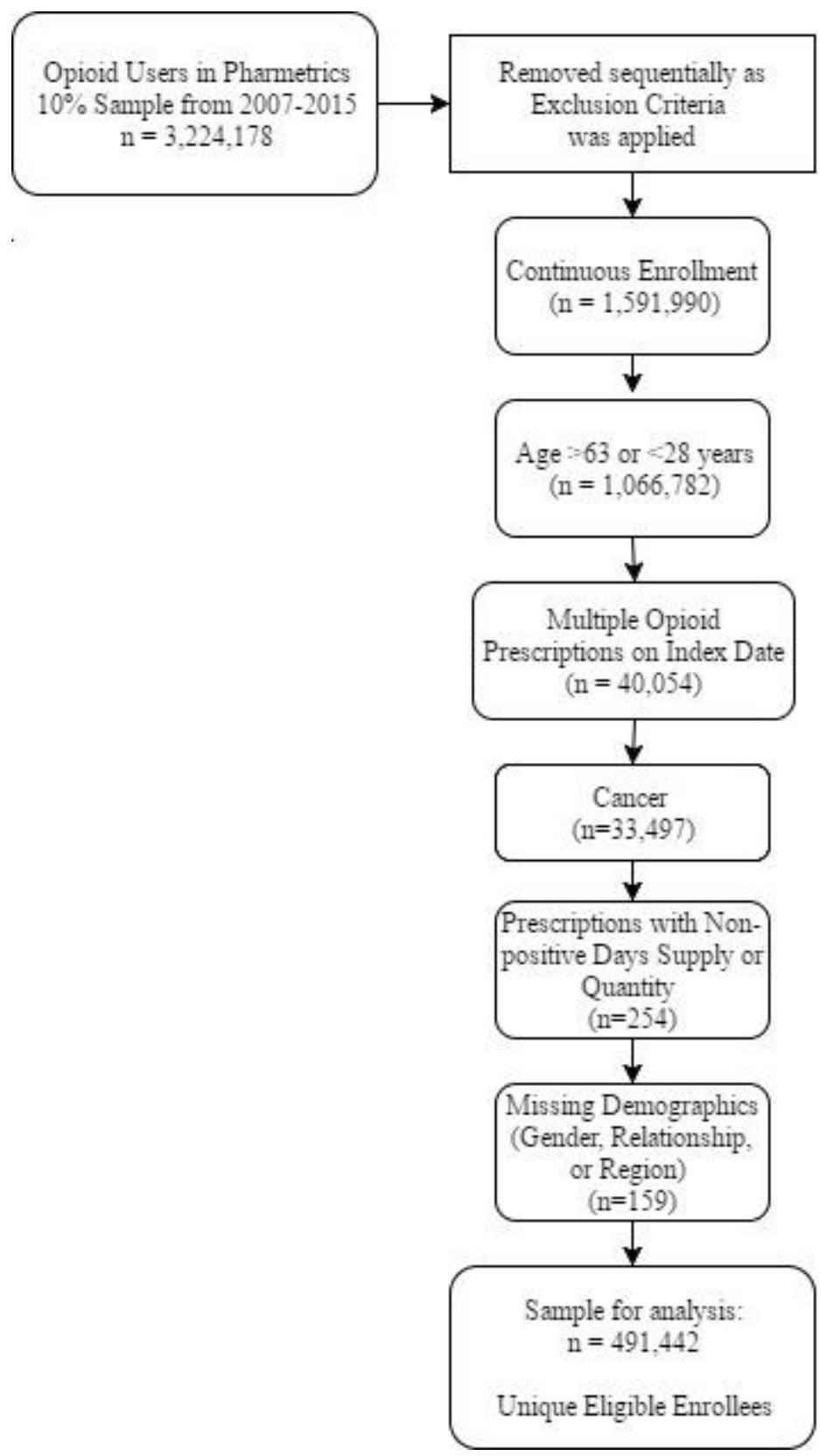


Figure 2.2: Receiver operator characteristic (ROC) curves for Model 1 (orange, AUC = 0.776) and Fully Adjusted Model 2 (purple, AUC $=0.782$ ) using the test subsample

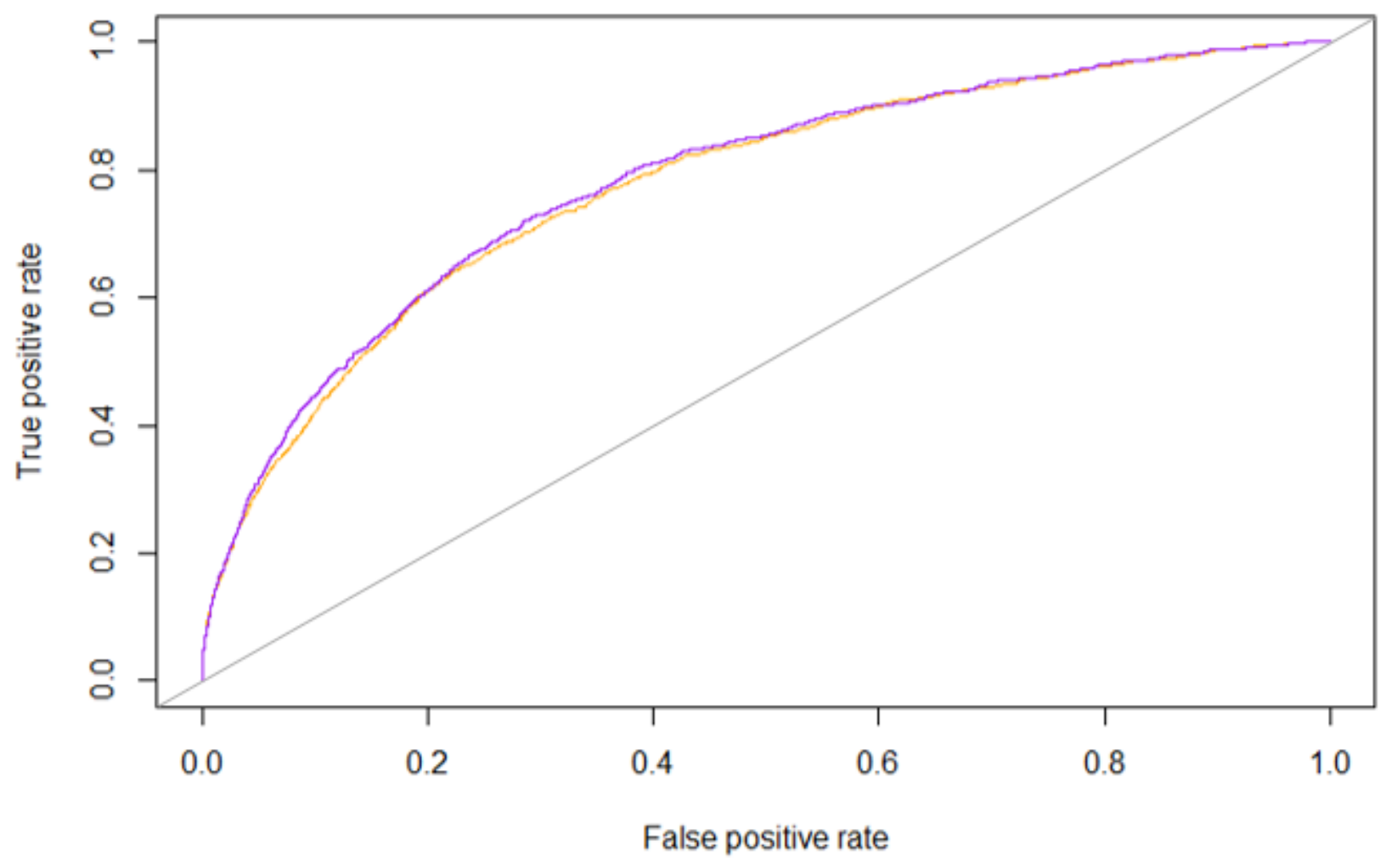




\section{CHAPTER 3}

\section{Increased healthcare utilization and expenditures associated with transition to chronic opioid therapy}

\subsection{Abstract}

Objective: To assess the association between transitioning from incident opioid use to chronic opioid therapy (COT), on the trajectories of health utilization and expenditures Data sources: Commercial claims database (10\% sample of QuintilesIMS Real-World Data Adjudicated Claims - US) from 2006-2015 Study design: Longitudinal, retrospective cohort design, using seven, 120-day time periods covering pre-index $\left(\mathrm{t}_{1}-\mathrm{t}_{3}\right)$, index $\left(\mathrm{t}_{4}\right)$, and post-index $\left(\mathrm{t}_{5}-\mathrm{t}_{7}\right)$ with data from adults, aged 28-63 years, without cancer, and who were continuously-enrolled in a primary, commercial insurance plan $(n=20,201)$. Multivariable analyses were performed on utilization [population-average (PA) logistic regression], expenditures (PA generalized estimating equations), and expenditure estimates (counterfactual prediction). Data collection/extraction methods: Fully-adjudicated pharmacy, hospital, and medical claims sourced from commercial payers Principal findings: Patients who transitioned to COT were more likely to use inpatient services $[\mathrm{AOR}=1.11,95 \% \mathrm{CI}(1.01,1.21)]$ compared to those who did not transition. While expenditures peaked during the transition period (t4) for all users, differences in unadjusted average, 120-day expenditures between COT and no COT users were highest in t4 for total $(\$ 4,607)$ and inpatient expenditures $(\$ 2,453)$. COT users had significantly higher total $(\beta=0.183, p<0.01)$ and inpatient expenditures $(\beta=0.448, p<0.001)$. Conclusions: The period after incident opioid prescription, but before COT, is an important time for intervention for payers. 


\subsection{Introduction}

Nearly half of Americans have experienced pain in the past year, and approximately 100 million suffer from chronic pain ${ }^{1,3}$. The vast majority of these patients suffer from pain not related to cancer, also known as chronic non-cancer pain (CNCP), and are working age ${ }^{1,2,4-6}$. CNCP can be managed using many different therapy regimens including pharmacologic options (non-opioid pharmacotherapy and opioid therapy) and non-pharmacologic options, which have been shown effective (e.g. electrical stimulation, physical therapy, psychological interventions, or exercise) ${ }^{7,9,29}$. Opioids have been recommended to be used only after considering a nonopioid analgesic regimen. Nearly one in five patients who presented to their healthcare provider with a painful condition in 2010 were prescribed an opioid even though the effectiveness of opioids in relieving non-cancer pain has not been proven ${ }^{31}$.

In addition to the lack of evidence for opioids to treat $\mathrm{CNCP}$, they also lead to adverse health consequences including cardiovascular risk, endocrine disorders, opioid use disorder, and death ${ }^{7}$. Multiple studies have also documented increased healthcare utilization and expenditures to patients and payers due to adverse health effects of opioids ${ }^{3-5,23}$. Patients who were prescribed opioids had higher emergency department, inpatient, and outpatient visits, as well as increased analgesic use, out-of-pocket spending, and third-party spending compared to patients not prescribed opioid medications ${ }^{19,23,48,49}$. For example, prescription opioids accounted for nearly 16,000 age-adjusted overdose deaths, in $2015^{88}$. This can lead to high economic burden through increased emergency room, inpatient, and other healthcare utilization and healthcare expenditures ${ }^{19-24}$. Using older data from 2011, it has been reported that 1,000 people were treated in emergency rooms daily for misuse of prescription opioids ${ }^{22}$. The number of annual emergency department visits due to opioids doubled from 2004 to $2011^{19}$. From 1993 to 2012, 
the rate of hospital inpatient stays related to opioid overuse, per 100,000 population, increased from 116.7 to 295.6 , a cumulative increase of $153 \% .^{21}$

Patients who receive initial opioid therapy, even for only a few days, are at risk of transitioning to chronic opioid therapy (COT), defined as 90 days of use ${ }^{7,18}$. For example our preliminary analysis has shown that initial opioid prescription characteristics (parent opioid, duration of action, and standardized dose) are the leading predictors of transitioning to COT ${ }^{89}$. Another, prospective, study found that expectations about opioid use in the future predicted COT ${ }^{18}$. Both patients and payers can bare the economic consequences of COT, which results from exacerbation of current medical conditions, development of new physical and mental health conditions, and opioid-related adverse effects including drug use disorder, and opioid overdose 7,19-22. Every year, an estimated $\$ 78$ billion is spent on these adverse consequences of opioids ${ }^{24}$. Although researchers have estimated the economic burden of developing an opioid use disorder in patients on opioid therapy ${ }^{24,49,90}$; studies that systematically examined the effect of the transition to COT has on healthcare utilization and expenditures are sparse ${ }^{10,20}$. Such studies are important because they assess a transition state generally earlier in patient's continuum of care $^{42}$, and this earlier period has been identified by the Centers for Disease Control and Prevention (CDC) as a time to take action ${ }^{7}$. To date, only one study analyzed the association between long-term opioid therapy and other opioid therapy on healthcare utilization and expenditures $^{20}$. Using data from commercial health plans, the study reported that healthcare expenditures were higher among long-term opioid users compared to other opioid users ${ }^{20}$. This study had some limitations such as use of non-standard definition of long-term opioid therapy, and unequal follow-up time periods between short- and long-term opioid users. The definition for chronic opioid users (>182 days) was different from the commonly-used Agency for 
Healthcare Research and Quality (AHRQ) and CDC definition of $\geq 90$ days ( 3 months) ${ }^{7,8}$. Furthermore, the study was not restricted to working-age adults who may have different transition rates and factors affecting those rates. Our study addresses the limitations of the prior literature and analyzes the impact of transitions from initiation of opioids to COT on economic outcomes in a nationally-representative sample of working age adults using definitions concordant with definitions used by CDC, AHRQ, and current literature $7,8,50,51$.

Focusing on working age adults in the age group 18-64 years is important because this group may have higher risk of transition to COT transition ${ }^{91}$ and their healthcare utilization patterns may be unique compared to the elderly ${ }^{92}$. Therefore, the objective of our study was to assess the association between transitioning from incident opioid use to incident chronic opioid therapy (COT), on the trajectories of health utilization and expenditures using a nationallyrepresentative sample of commercially-insured working-aged adults in the United States (US).

\subsection{Methods}

\section{Data Source}

The data were derived from a 10\% random sample of commercial enrollees released under licensing from the QuintilesIMS (QuintilesIMS RWD Adjudicated Claims - US).

\section{Study design}

A retrospective cohort design with longitudinal data for seven, 120-day, time periods covering pre-index $\left(\mathrm{t}_{1}, \mathrm{t}_{2}\right.$, and $\left.\mathrm{t}_{3}\right)$, index $\left(\mathrm{t}_{4}\right)$, and post-index $\left(\mathrm{t}_{5}, \mathrm{t}_{6}\right.$, and $\left.\mathrm{t}_{7}\right)$ was used. The patient cohort consisted of working aged adults, without cancer and who were initiated on opioids between January 2007 and May 2014. The first observed prescription for an opioid represented the index date. The pre-index periods were identified before the index date, the index period was 
identified as 120 days after the index opioid prescription, and the post-index periods were identified after the end of the index period.

Study sample

The sample was restricted to adults, aged 28-63 years at index date, without cancer, and who were continuously enrolled in a primary, commercial insurance plan during the entire observation period. The patient age of 63 was chosen so that full index and post-index periods would still result in a patient less than 65 years (the age in which they are eligible for Medicare). Cancer was identified using the International Classification of Diseases, Ninth Revision, Clinical Modification (ICD-9-CM) codes. Patients with at least one claim with any cancer code (except for non-melanoma skin cancer) in any of the 12 diagnosis code fields available in the claims data were considered as having cancer ${ }^{81}$. Continuous enrollment in both pharmacy benefits and medical benefits was required. We excluded individuals who had more than one opioid prescription on the index date because we were unable to evaluate initial opioid regimen characteristics for these individuals. After applying the exclusion criteria, we observed 3,776 adults in the COT group. A 5\% random sample, approximately 5 controls per case, of patients without COT was selected to represent the No COT group $(\mathrm{N}=16,425)$ (See Appendix 1).

\section{Measures}

Dependent variables: Healthcare utilization and expenditures

All healthcare utilization and expenditures were repeatedly measured for each time period. Utilization consisted of emergency department (ED) and inpatient. ED use was identified using previously published algorithm based on place of service, procedure codes, and revenue center codes ${ }^{93}$. Inpatient use was identified based on the claim having a non-missing value for confinement number (a unique number with the claims, indicating hospitalization). 
Inpatient claims with the same confinement number were aggregated to get the admission and discharge dates. We measured utilization by any use of ED or inpatient, defined as having at least one claim for these services during the 120-day time period.

Expenditures were distinguished by type of service [ED, inpatient, physician, and other (e.g. surgical services, diagnostics, and laboratory tests)]. Total expenditures (without prescription drugs) were the sum of ED, inpatient, physician, and other. Expenditures were calculated using the actual amount paid by the insurance plan; they were converted to 2015 US dollars using the US Bureau of Labor Statistics Consumer Price Index (CPI) for Medical Care Services ${ }^{94}$.

$\underline{\text { Key independent variable }}$

Transition to incident chronic opioid therapy (COT): Opioids were identified using the National Drug Codes (NDCs). NDCs for opioids were extracted from the National Library of Medicine's (NLM) RxNav (https://mor.nlm.nih.gov/RxNav/) and RxMix (https://mor.nlm.nih.gov/RxMix/) ${ }^{78}$. A patient was classified as having incident COT in he/she had at least 90-day supply of opioids during the 120-day index period.

Other independent variables

Time invariant characteristics (patient's sex, region of residence, and clinical factors) were measured during the 12 months before index date. Age was calculated as of the index date for initial opioid prescription. Clinical factors were presence or absence of diagnoses for: painful conditions ${ }^{82}$, mental illnesses ${ }^{80}$, drug use disorders, and number of other chronic conditions adapted from Department of Health and Human Services (DHHS) priority conditions for research, program, and policy ${ }^{81}$ Painful conditions were categorized as conditions highly likely for chronic pain or likely for chronic pain ${ }^{82}$. Drug use disorders included ICD-9-CM codes for 
drug dependence (304), drug abuse (305.2-305.9), and drug-induced mental disorders (292). The ICD-9-CM codes were used to assess each of these conditions and did not overlap between lists. The clinical complexity of a patient was also measured during each time period by the number of unique medication classes. We also assessed concomitant medication use, specifically benzodiazepines and prescription non-opioid analgesics, at each time period. Generic Product Identifier (GPI) codes were used to identify number of unique medication classes, as well as benzodiazepines (GPI-4 = 57.10) and prescription non-opioid analgesics (GPI-2 = 66 or 64$)$. Additional independent variables included continuous time (range 0-6 corresponding to $\mathrm{t}_{1}-\mathrm{t}_{7}$ ) and an indicator variable for the index period $\left(\mathrm{t}_{4}\right)$ to capture the differential rates of healthcare utilization and expenditures during this period.

\section{Statistical Analyses}

As we repeatedly measured healthcare utilization, expenditures, unique medication classes, and concomitant medication use every 120-days, each individual had seven observations. These seven observations were not independent and applying standard regression techniques can lead to misleading results. Therefore, the unadjusted and adjusted relationships between COT and economic outcomes were analyzed with a repeated measures design. Healthcare expenditures are unique (e.g. non-normal distribution, high number of enrollees with zerovalues, and non-negative measurement of the outcomes of interest). Therefore, we used the generalized linear mixed models (GLMM), which can accommodate both linear and non-linear outcome variables. Mixed-effects regressions can model both within and between subject variations. However, one needs to distinguish between population-averaged (PA) and subjectspecific (SS) models for binary outcomes ${ }^{95}$ as well as continuous outcomes within GLMM. We used PA models with generalized estimating equations (GEE) to analyze the relationship 
between COT and ED use, inpatient use, and expenditures. For this study, the population average (PA) approach was used because the objective was to estimate the average treatment effects between the COT and non-COT group. In multivariable GEE models, we adjusted for time as a continuous variable (range $0-6$ ), number of other chronic conditions, sex, age, region, history of drug use disorder, painful conditions, benzodiazepine use, non-opioid analgesic use, and number of unique medication classes.

Three models were developed to analyze the relationship between COT indicator and the dependent variables. The first model (Model 1) is only adjusted for continuous time, and the index period $\left(\mathrm{t}_{4}\right)$. Model 2 additionally adjusted for the number of chronic conditions, while Model 3 is the fully adjusted model and includes additional adjustments for sex, age, region, history of drug use disorder, painful conditions, benzodiazepine use, non-opioid analgesic use, and number of unique medication classes.

We calculated the differences in average expenditures between COT and no COT groups with a counterfactual prediction technique. This was done because exponentiating expenditures for the COT and no COT groups to derive absolute differences in dollar amount assumes a reference case scenario. Rather than simply comparing the expenditures between the groups, by holding other variables constant, we used the counterfactual prediction technique. Under this technique, expenditures for counterfactual scenarios (e.g. assuming all patients with and without COT while keeping their other characteristics as given) were calculated and differences in average expenditures were estimated ${ }^{96-99}$. Confidence intervals for these estimates were obtained using 1000 bootstrap replications using the percentile method. Datasets for these analyses were created using SAS (version 9.4) and analyses were performed using STATA (version 14). Inverse Probability of Treatment Weighting 
Patients receiving COT or non-COT regimens may systematically differ in observed characteristics (e.g. painful conditions). Therefore, to control for observed selection bias between patients transitioning to COT and those not transitioning to COT, we used inverse probability of treatment weighting (IPTW) ${ }^{100}$. Patient sex, age categories, region, and pain conditions were used in a logistic regression on COT use to derive IPTW and were used as patient weights in designated analyses.

\subsection{Results}

Description of the study sample by COT

The sample characteristics (sex, age, region, and pain conditions) were significantly different between COT and non-COT groups (all p<0.001). After adjustment for IPTW, there were no longer any significant differences. The sample comparison before and after IPTW is displayed in Supplemental Table 7.2.1.

\section{Healthcare utilization}

ED utilization differed significantly across time periods $(\mathrm{p}<0.001)$ between patients that transitioned to COT compared to those who did not, in the unadjusted analyses (Table 3.1). For patients with COT, ED use increased from $6.0 \%\left(\mathrm{t}_{1}\right)$ to $15.5 \%\left(\mathrm{t}_{4}\right)$; similarly, for patients without COT, ED use increased from $4.3 \%\left(\mathrm{t}_{1}\right)$ to $15.3 \%\left(\mathrm{t}_{4}\right)$. ED use remained higher in the COT group as compared to the no COT group in the follow up time periods $\left(\mathrm{t}_{5}, \mathrm{t}_{6}\right.$, and $\left.\mathrm{t}_{7}\right)$. As displayed in Table 3.2, using adjusted Models 1 and 2, patients who transitioned to COT were more likely to have ED utilization $[\mathrm{AORs}=1.33,95 \% \mathrm{CI}(1.25,1.42)$ and $1.26(1.17,1.34)$, respectively] compared to those who did not transition to COT. However, in Model 3, the patients who transitioned to COT were less likely to have ED use $[\mathrm{AOR}=0.92,95 \% \mathrm{CI}(0.86,0.99)]$. 
Similarly, inpatient use increased from $1.5 \%\left(\mathrm{t}_{1}\right)$ to $10.9 \%\left(\mathrm{t}_{4}\right)$ in patients with COT; for patients without COT, inpatient use increased from $1.1 \%\left(\mathrm{t}_{1}\right)$ to $5.4 \%\left(\mathrm{t}_{4}\right)$ (Table 3.1). Inpatient use remained higher in the COT group as compared to the no COT group in the follow-up time periods $\left(\mathrm{t}_{5}, \mathrm{t}_{6}\right.$, and $\left.\mathrm{t}_{7}\right)$. Patients who transitioned to COT were more likely to have inpatient use in all three models $[\mathrm{AOR}=1.7895 \% \mathrm{CI}(1.63,1.94), 1.45(1.33,1.58)$, and $1.11(1.01,1.21)$, for Models 1, 2, and 3, respectively] (Table 3.2). Finally, both ED and inpatient use were more likely to occur during the index period $\left(\mathrm{t}_{4}\right)$ compared to all other periods $(\mathrm{p}<0.001)$ (Table 3.2).

\section{Healthcare expenditures}

Average expenditures over time and by COT use are summarized in Table 3.3 and differences in unadjusted mean expenditures over time, among COT and non-COT users by type of service, are graphed in Supplemental Figure 7.2.1. Patients who transitioned to COT had higher total expenditures at every time point, and the difference in mean expenditures between these groups varied significantly as time progressed. In $\mathrm{t}_{1}$, the patients that transitioned to COT only had $\$ 511$ higher total expenditures, but that increased to $\$ 4,607$ in $t_{4}$. The differences in average expenditures peaked during the index period $\left(\mathrm{t}_{4}\right)$ and remained higher than baseline through the entire follow-up period, driven mostly by inpatient expenditures.

Patients who transitioned to COT had significantly higher total $(\mathrm{p}=0.002)$ and inpatient $(\mathrm{p}<0.001)$ expenditures in the fully adjusted analyses (Table 3.4). Also, the index period (time period 4) was associated with higher expenditures for every type, compared to baseline. In the

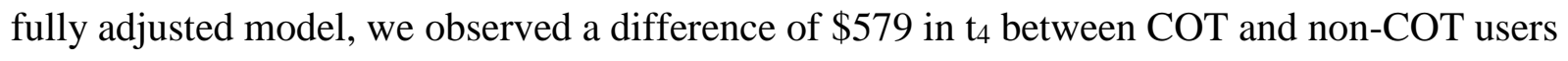
using the counterfactual prediction technique (Figure 3.1). 


\subsection{Discussion}

Generally, healthcare utilization and expenditures were higher during the index period $\left(\mathrm{t}_{4}\right)$ compared to all other time periods for all opioid users (regardless of transition to COT). The only exception to this was for non-COT users, inpatient expenditures were higher in $\mathrm{t}_{3}$. For those with and without transition to COT, expenditures increased by $594 \%$ and $698 \%$ in the period prior to the initial prescription of opioids $\left(t_{1}\right.$ to $\left.t_{3}\right)$ suggesting that the periods surrounding the initial opioid prescription are associated with high utilization and expenditures. However, COT users had higher rate of increase in expenditures as compared to no COT users.

Most trajectories of healthcare utilization and expenditures (from $t_{1}$ through $t_{7}$ ) were different between COT and non-COT users. For example, among COT users, healthcare utilization and expenditures were the highest at the index period $\left(\mathrm{t}_{4}\right)$, but for those who did not transition to COT, the peak utilization and expenditures were observed in $t_{3}$, prior to initial opioid receipt. Furthermore, for patients who transitioned to COT, the utilization and expenditures remained higher than baseline. For patients who did not transition to COT, utilization and expenditures returned to closer to initial pre-opioid levels measured at $\mathrm{t}_{1}$ after adjusting for other characteristics.

In the fully-adjusted models, transition to COT was associated with higher inpatient utilization and inpatient expenditures as well as total expenditures (without prescription drugs). The has implications for payers because inpatient use has been reported to be the primary driver of total expenditures ${ }^{20}$. In our study, the proportion of inpatient expenditures to total expenditures varied from $50 \%\left(\mathrm{t}_{1}\right)$ to $80 \%\left(\mathrm{t}_{3}\right)$ in COT users.

Any intervention focused on curbing transition to COT has the potential to prevent inpatient use and can lead to cost savings for the payer(s). Interventions include extensive 
physician and patient education about pain management and opioids, the further interoperability of state-level prescription drug monitoring programs, and increase options for disposal of unused opioid medications ${ }^{101}$. Future research could use this study as part of the way to assess the cost effectiveness of the mentioned interventions. In addition to expenditures, reduction in inpatient utilization has benefits for the patient including improved quality of life and lower out of pocket costs.

Without adjustments for patient complexity (e.g. number of unique medication classes, highly likely chronic pain conditions, and likely chronic pain conditions), patients who transitioned to COT were more likely to use ED as compared to patients who did not. However, in the fully-adjusted model, ED use was less likely between patients who transitioned to COT compared to those who did not. While we do not know the reasons for this counter-intuitive finding, we speculate that ED use may be due to patient complexity requiring pain management, which may have led to an initial prescription of opioid in the index period $\left(\mathrm{t}_{4}\right)$. Initial prescription for opioids may have provided short-term relief decreasing their need for emergency care.

Although not directly comparable, our study findings were similar to the study published by Kern, et.al. assessing the transition from initial opioid prescription to long-term opioid use ${ }^{20}$. For example, Kern, et.al. reported that for long-term users of opioids, healthcare utilization rates (e.g. ED, inpatient, and outpatient visits) and costs decreased after the first 6 months of followup, but remained above the baseline levels ${ }^{20}$. Kern et.al. also reported that the number of ED visits per patient-year of follow-up were lower for patients receiving long-term opioid therapy compared to short-term use (0.44 vs. 0.93$)$.

Strengths and limitations 
Strengths of this study include the use of a nationally-representative sample of the US commercially-insured population, following individuals across multiple providers and settings. This longitudinal design with repeated measures of utilization and expenditures for patients with and without transition to COT allowed for an assessment of baseline utilization and expenditures. This allowed us to control for baseline profiles in terms of utilization, expenditures, and patient complexity. The data spanned many unique insurers and plan types, which allowed for the tracking of patients through time and to determine an opioid-free period of 12 months $\left(\mathrm{t}_{1-3}\right)$. Furthermore, we applied robust statistical methods to control for observed selection bias.

This study also has some potential limitations. We only observed prescription claims and not actual use of medications. The database did not have information on variables such as pain, socio-economic status, social capital (i.e. social relationships that have benefits to production), medication beliefs, and response to pain treatment, which may have affected the transition and associated healthcare utilization and expenditures. Although observed selection bias was controlled for, we did not control for selection bias due to unobserved characteristics. Thus, all selection bias may not have been eliminated.

\subsection{Conclusion}

Transitioning to COT can place a significant economic burden on payers and patients in terms of healthcare utilization and expenditures. Despite having similar baseline values, patients making the transition to COT had persistently high levels of utilization and expenditures even after 12 months following the transition to COT. The period of time after incident opioid prescription, but before COT, is an important time for intervention for payers and clinicians.

\subsection{Acknowledgements and Data Use Statement}

$\underline{\text { Funders }}$ 
The views expressed in this academic research paper are those of the authors and do not reflect the official policy or position of West Virginia University (WVU) or any other affiliated organizations. US was partially supported by the National Institutes of Health, National Institute of General Medical Sciences (grant number U54GM104942). JDT was supported by the National Institutes of Health, National Institute of General Medical Sciences (grant number 5T32GM081741-08).

$\underline{\text { Data used statement }}$

The statements, findings, conclusions, views, and opinions contained and expressed in this article are based in part on data obtained under license from the following QuintilesIMS information services: QuintilesIMS Real-World Data Adjudicated Claims - US, 10\% sample January 2006- December 2015, QuintilesIMS Health Incorporated. All Rights Reserved. The statements, findings, conclusions, views, and opinions contained and expressed herein are not necessarily those of QuintilesIMS Health Incorporated or any of its affiliated or subsidiary entities. 


\begin{tabular}{|c|c|c|c|c|}
\hline \multicolumn{5}{|c|}{$\begin{array}{l}\text { Table 3.1. Rates of emergency department (ED) and inpatient use by transition to chroni } \\
\text { therapy (COT) after initial opioid prescription } \\
\text { QuintilesIMS Real-World Data Adjudicated Claims Database- US, 2006-2015 }\end{array}$} \\
\hline & \multicolumn{2}{|c|}{ Emergency Department Use* } & \multicolumn{2}{|c|}{ Inpatient Use * } \\
\hline Time & $\operatorname{COT}(\mathrm{Wt} . \%)$ & No COT (Wt. \%) & $\operatorname{COT}(\mathrm{Wt} . \%)$ & No COT (Wt. \%) \\
\hline 1 & 6.0 & 4.3 & 1.5 & 1.1 \\
\hline 2 & 5.5 & 4.1 & 1.7 & 0.9 \\
\hline 3 & 11.2 & 12.4 & 5.9 & 9.2 \\
\hline 4 & 15.5 & 15.3 & 10.9 & 5.4 \\
\hline 5 & 11.4 & 5.3 & 5.9 & 1.9 \\
\hline 6 & 10.1 & 5.7 & 4.5 & 2.2 \\
\hline 7 & 9.3 & 5.2 & 4.0 & 1.6 \\
\hline \multicolumn{5}{|c|}{$\begin{array}{l}\text { Note: This sample includes patients from QuintilesIMS RWD Adjudicated Claims - US, which were } \\
\text { identified between 2007-2014 and had enrollment between 2006-2015. These patients were between } \\
28-63 \text { years old, without cancer, had complete demographic information available, and had only one } \\
\text { opioid prescription on the index date. Individual weights based on IPTW have been used for this } \\
\text { analysis. } \\
\text { *: Significant differences in ED use and IP use by COT category over time using chi-square tests } \\
\text { Abbreviations: COT- chronic opioid therapy; Wt- weighted }\end{array}$} \\
\hline
\end{tabular}




\begin{tabular}{|c|c|c|c|c|c|c|}
\hline \multicolumn{7}{|c|}{$\begin{array}{c}\text { Table 3.2 Adjusted odds ratio (AOR) and } 95 \% \text { confidence intervals }(95 \% \text { CI) of selected } \\
\text { From population-average Generalized Estimating Equations } \\
\text { Working-Age Adults with incident Opioid Prescription } \\
\text { QuintilesIMS Real-World Data Adjudicated Claims Database - US, 2006-2015 }\end{array}$} \\
\hline & \multicolumn{3}{|c|}{ Emergency Department Use } & \multicolumn{3}{|c|}{ Inpatient Use } \\
\hline \multicolumn{7}{|c|}{ Model 1: Adjusted for COT, Time and Index Period(t4) } \\
\hline Variables & AOR & $95 \% \mathrm{CI}$ & Sig & AOR & $95 \% \mathrm{CI}$ & Sig \\
\hline COT & 1.32 & {$[1.25,1.42]$} & $* * *$ & 1.78 & {$[1.63,1.94]$} & $* * *$ \\
\hline Time & 1.04 & {$[1.03,1.06]$} & $* * *$ & 1.04 & {$[1.03,1.06]$} & $* * *$ \\
\hline Index Period (Time 4) & 2.26 & {$[2.12,2.40]$} & $* * *$ & 1.62 & {$[1.43,1.83]$} & $* * *$ \\
\hline \multicolumn{7}{|c|}{ Model 2: Adjusted for COT, Time Index Period(t4), and Number of other Chronic Conditions } \\
\hline COT & 1.25 & {$[1.17,1.34]$} & $* * *$ & 1.45 & {$[1.33,1.58]$} & $* * *$ \\
\hline Time & 1.04 & {$[1.03,1.06]$} & $* * *$ & 1.05 & {$[1.03,1.07]$} & $* * *$ \\
\hline Index Period (Time 4) & 2.27 & {$[2.13,2.41]$} & $* * *$ & 1.81 & {$[1.62,2.02]$} & $* * *$ \\
\hline \multicolumn{7}{|c|}{$\begin{array}{l}\text { Model 3: Adjusted for COT, Time Index Period (t4), and Number of other Chronic Conditions, Sex, } \\
\text { Age, Region, History of Drug Use Disorder, Painful Conditions, Benzodiazepine Use, Non-opioid } \\
\text { Analgesic Use, and Number of Unique Medication Classes. }\end{array}$} \\
\hline COT & 0.92 & {$[0.86,0.99]$} & $*$ & 1.11 & {$[1.01,1.21]$} & $*$ \\
\hline Time & 0.99 & {$[0.98,1.00]$} & & 0.978 & {$[0.96,0.99]$} & $*$ \\
\hline Index Period (Time 4) & 1.64 & {$[1.54,1.75]$} & $* * *$ & 1.13 & {$[1.00,1.29]$} & \\
\hline \multicolumn{7}{|c|}{$\begin{array}{l}\text { Note: This sample includes patients from QuintilesIMS RWD Adjudicated Claims - US, which were identified } \\
\text { between } 2007-2014 \text { and had enrollment between } 2006-2015 \text {. These patients were between } 28-63 \text { years old, } \\
\text { without cancer, had complete demographic information available, and had only one opioid prescription on the } \\
\text { index date. Individual weights based on inverse probability of treatment weighting (IPTW) have been used for } \\
\text { this analysis. } \\
\text { Abbreviations: COT- chronic opioid therapy; Wt- weighted; AOR- adjusted odds ratio; } \\
\text { Sig: } 0<\mathrm{p}<0.001=* * *, 0.001 \leq \mathrm{p} 0.01=* *, 0.01 \leq \mathrm{p}<0.05=*\end{array}$} \\
\hline
\end{tabular}




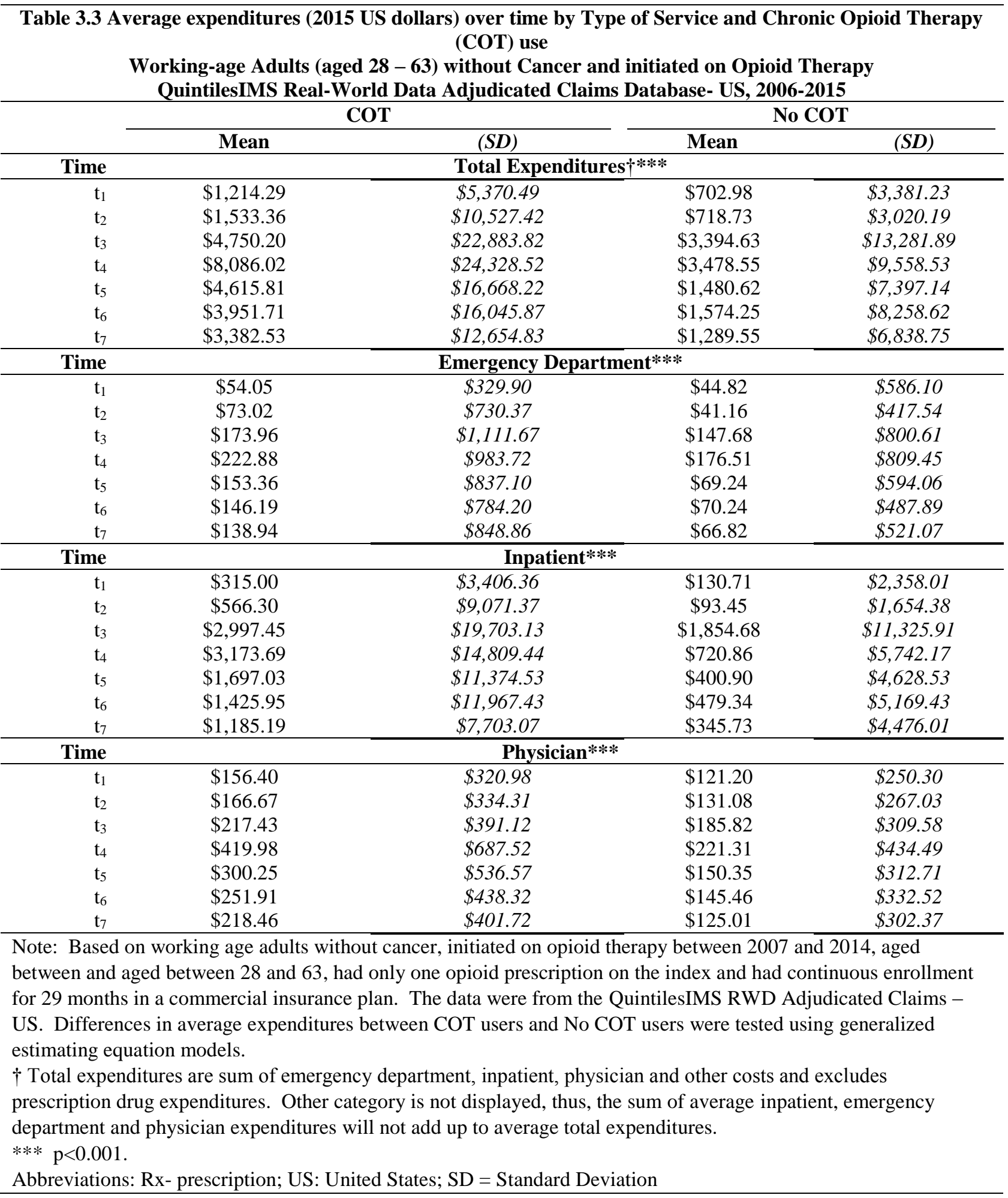




\begin{tabular}{|c|c|c|c|c|c|c|c|c|c|}
\hline \multicolumn{10}{|c|}{$\begin{array}{c}\text { Table 3.4 Weighted and adjusted expenditures over time for patients with incident opioid use by } \\
\text { transition to chronic opioid therapy (COT) after first opioid prescription, } \\
\text { QuintilesIMS Real-World Data Adjudicated Claims Database - US, 2006-2015 }\end{array}$} \\
\hline \multicolumn{2}{|c|}{ Cost Type } & \multicolumn{2}{|c|}{$\begin{array}{l}\text { I-World Data Adj } \\
\text { COT }\end{array}$} & \multicolumn{3}{|c|}{ Index Period (Time 4) } & \multicolumn{3}{|c|}{ Intercept } \\
\hline Total (No RX) & $\beta$ & SE & p-value & $\boldsymbol{\beta}$ & $\mathbf{S E}$ & p-value & $\beta$ & SE & p-value \\
\hline Model 1 & 0.11 & 0.04 & $<0.001$ & 0.81 & 0.04 & $<0.001$ & 6.97 & 0.03 & $<0.001$ \\
\hline Model 2 & 0.41 & 0.05 & $<0.001$ & 0.92 & 0.04 & $<0.001$ & 6.52 & 0.04 & $<0.001$ \\
\hline Model 3 & 0.18 & 0.06 & 0.002 & 0.68 & 0.04 & $<0.001$ & 6.44 & 0.10 & $<0.001$ \\
\hline \multicolumn{10}{|l|}{$\begin{array}{l}\text { Emergency } \\
\text { Department }\end{array}$} \\
\hline Model 1 & 0.38 & 0.06 & $<0.001$ & 0.72 & 0.05 & $<0.001$ & 4.05 & 0.05 & $<0.001$ \\
\hline Model 2 & 0.31 & 0.06 & $<0.001$ & 0.79 & 0.05 & $<0.001$ & 3.74 & 0.05 & $<0.001$ \\
\hline Model 3 & 0.01 & 0.08 & 0.884 & 0.42 & 0.05 & $<0.001$ & 4.12 & 0.10 & $<0.001$ \\
\hline \multicolumn{10}{|l|}{ Inpatient } \\
\hline Model 1 & 0.78 & 0.07 & $<0.001$ & 0.49 & 0.07 & $<0.001$ & 6.09 & 0.06 & $<0.001$ \\
\hline Model 2 & 0.69 & 0.09 & $<0.001$ & 0.67 & 0.08 & $<0.001$ & 5.26 & 0.06 & $<0.001$ \\
\hline Model 3 & 0.45 & 0.11 & $<0.001$ & 0.31 & 0.10 & 0.002 & 5.70 & 0.17 & $<0.001$ \\
\hline \multicolumn{10}{|l|}{ Physician } \\
\hline Model 1 & 0.27 & 0.02 & $<0.001$ & 0.49 & 0.02 & $<0.001$ & 4.82 & 0.02 & $<0.001$ \\
\hline Model 2 & 0.18 & 0.03 & $<0.001$ & 0.51 & 0.02 & $<0.001$ & 4.54 & 0.02 & $<0.001$ \\
\hline Model 3 & -0.01 & 0.02 & 0.582 & 0.29 & 0.02 & $<0.001$ & 4.32 & 0.04 & $<0.001$ \\
\hline \multicolumn{10}{|c|}{$\begin{array}{l}\text { Note: This sample includes patients from QuintilesIMS RWD Adjudicated Claims - US, which were identified } \\
\text { between } 2007 \text { and } 2014 \text { and had enrollment between } 2006 \text { and } 2015 \text {. These patients were between } 28-63 \text { years } \\
\text { old, without cancer, had complete demographic information available, and had only one opioid prescription on } \\
\text { the index date. Individual weights based on inverse probability of treatment weighting (IPTW) have been used } \\
\text { for this analysis. Model } 1 \text { is only adjusted for time and chronic opioid therapy; Model } 2 \text { is also adjusted for } \\
\text { number of other chronic conditions; Model } 3 \text { is also adjusted for number of other chronic conditions, sex, age, } \\
\text { region, history of drug abuse, painful conditions, benzodiazepine use, non-opioid analgesic use, and number of } \\
\text { unique medication classes. } \\
\text { Abbreviations: COT- chronic opioid therapy; Wt- weighted; AOR- adjusted odds ratio; Rx- prescription; SE- } \\
\text { semi-robust standard error } \\
\text { Sig: } 0<p<0.001=* * *, 0.001 \leq p 0.01=* *, 0.01 \leq p<0.05=*\end{array}$} \\
\hline
\end{tabular}


Figure 3.1. Difference in average total expenditures (no prescription drug costs) between chronic opioid therapy (COT) and no COT transition using a counterfactual prediction technique

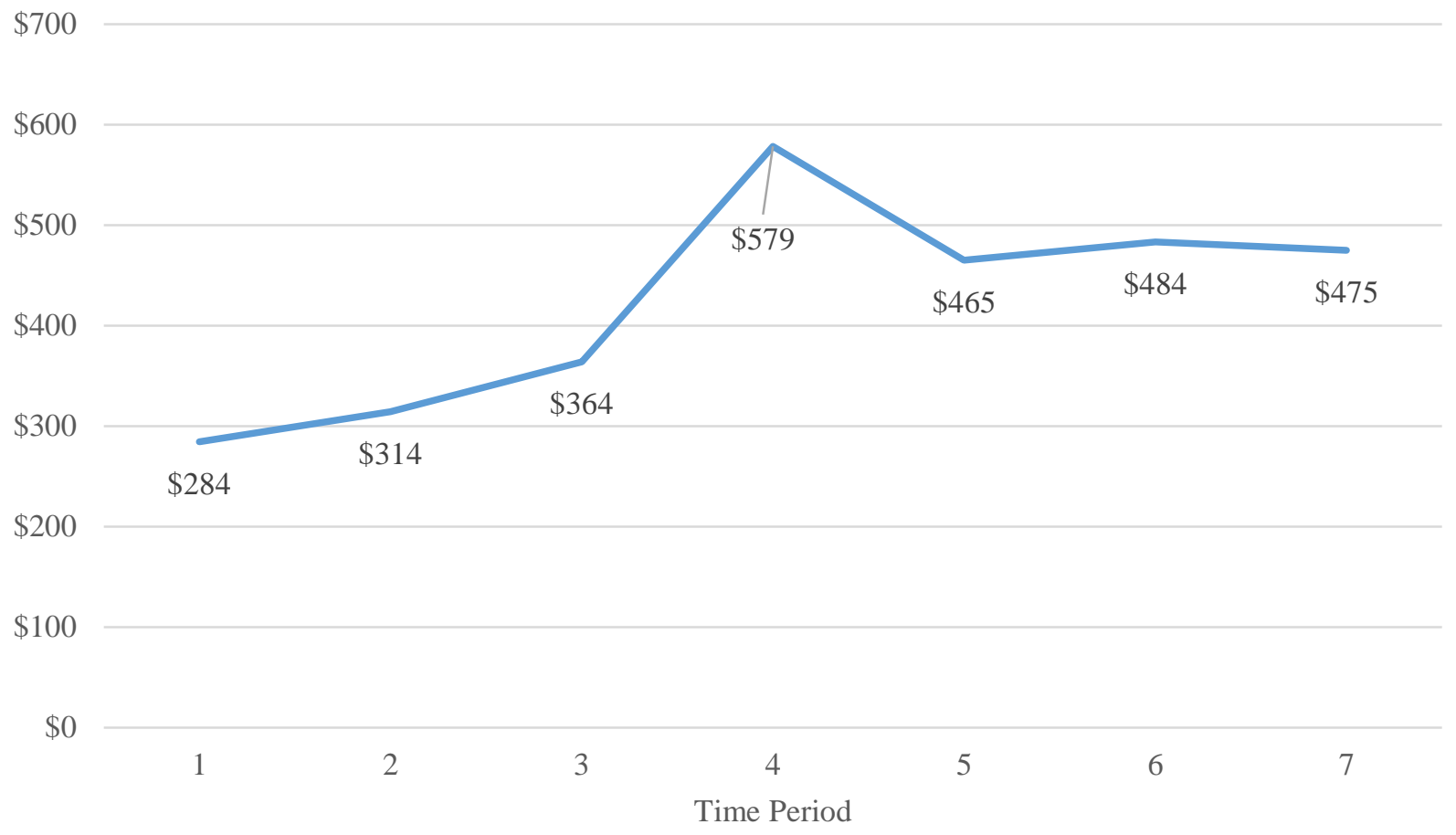




\section{CHAPTER 4}

\section{Identifying targeted continuing educational strategies to help community pharmacists implement naloxone/buprenorphine-related medications in community pharmacies: A}

state-wide survey among pharmacists

\subsection{Abstract}

Objective: To identify educational strategies related to opioids, buprenorphine products, and naloxone, for pharmacists, and to determine geographic locations to reduce the risk of opioid overdose in West Virginia (WV). Methods: A mixed-methods design included a prospective cross-sectional survey administered in two phases [in-person $(n=157)$ and online $(n=144)$ ] to increase coverage of the whole state, then results were weighted based on a census of all pharmacists in WV. Educational strategies for community pharmacists $(n=179)$ were identified with the Extended Parallel Process Model (EPPM), while educational objectives were based on attitudes, dispensing/stocking practices, and knowledge gaps about opioids, naloxone, and buprenorphine products. Qualitative responses $(n=97)$ were also evaluated and themes were developed. Results: Most pharmacists perceived high risk of opioid misuse in their area and high perceived efficacy about naloxone as a treatment for opioid overdose, but many did not feel comfortable selling naloxone. Opioid attitudes significantly differed between pharmacists in different EPPM-assigned categories. Filling practices differed; $73 \%$ stocked buprenorphine/naloxone and only 58\% stocked buprenorphine. Pharmacists with higher perceived efficacy of buprenorphine products were more likely to be willing to fill non-local prescriptions. County-level disparities between actual and perceived risk for opioid misuse were observed. In the qualitative evaluation, pharmacists listed many barriers to caring for patients prescribed opioids or buprenorphine products. Conclusion: By tailoring educational strategies 
and objectives to pharmacists in specific geographic locations, more effective CPE can be delivered to community pharmacists in $\mathrm{WV}$ to improve access to naloxone and buprenorphine products as well as improve their understanding of addiction and psychosocial treatments.

\subsection{Introduction}

Opioids, both prescription and illicit, contribute to the vast majority of drug overdose deaths, and are the leading cause of unintentional death among adults in the United States (US). ${ }^{102}$ In 2015, West Virginia (WV) led the country with 35.5 deaths per 100,000 inhabitants more than twice the national average. ${ }^{47}$ Adverse effects due to prescription opioids often result in increased emergency room visits, inpatient visits, and other healthcare utilization. ${ }^{2-5}$ Access to both naloxone and comprehensive opioid use disorder treatment programs is very limited in the US, especially in West Virginia (WV). ${ }^{103}$

Opioid use disorder, one of the diagnoses with highest risk for opioid overdose, can be managed with combination of psychosocial and pharmacological treatments, including methadone, naltrexone, and buprenorphine-containing regimens. ${ }^{104,105}$ Also, unintentional opioid overdose deaths can be avoided with the use of naloxone. ${ }^{7,15,55,56}$ Naloxone has been approved in many forms (e.g. intranasal, intravenous) and can completely block or reverse the effects of opioid medications, including extreme drowsiness, slowed breathing, or loss of consciousness, and prevent death due to opioid overdose. ${ }^{55,56}$ Expanding access in the community to buprenorphine products and naloxone is part of a nation strategy for avoiding mortality due to opioid overdoses. ${ }^{54,104,106}$

Naloxone delivery in a community needs a multipronged approach including two important system strategies as described in previous research. ${ }^{107}$ First, access to naloxone must be made available through state legislation and Boards of Pharmacy, promoted by departments of 
public health, and covered by insurers. ${ }^{107}$ In states where naloxone is already available in community pharmacies, there is evidence of reduction in overdose related deaths. ${ }^{57}$ Second, pharmacists and pharmacy technicians need the training and motivation to support the implementation of increased naloxone availability in urban and rural settings. ${ }^{107}$

Pharmacists working in community pharmacies are the most widely available healthcare professionals $^{58}$ and the gatekeepers to prescription opioids as well as the medications used to treat opioid use disorder. However, pharmacists are currently under-utilized as stakeholders to affect change in the patients succumbing to adverse consequences of opioid abuse including drug overdoses and deaths. ${ }^{54}$ As providing naloxone within the community is a voluntary act, expanding capacity to provide such a service will require the buy-in from local pharmacists thus making an assessment of pharmacists' perceptions and providing for their educational needs a critical component of the second strategy to increase naloxone delivery in the community.

Buprenorphine products (buprenorphine/naloxone and buprenorphine single-ingredient products) are prescribed widely as part of a comprehensive treatment plan for use in patients with opioid use disorders. ${ }^{108}$ Access to these products has been limited by the quantity limits placed on the number of dosage units a wholesaler has to distribute to individual pharmacies, ${ }^{109}$ and by pharmacists having mixed attitudes as to whether or not to stock or dispense these medications. ${ }^{104,110,111}$ The willingness to stock and dispense medications to treat opioid use disorder as well as educational strategies used to increase this willingness, can be assessed similarly to naloxone.

Given the extent of the opioid crisis in WV, the state can be seen as a focal point needing evaluation regarding the capacity of community pharmacies to provide naloxone and other opioid-related medications due to its reliance on community pharmacies to provide access to 
healthcare and its current high levels of opioid abuse and deaths. ${ }^{112}$ In our previous study of WV community pharmacists, opioid stocking was universal, stocking of buprenorphine products was less common, readiness to dispense naloxone was low, and general educational strategies were identified. ${ }^{110}$ To optimize the process of providing naloxone to the communities of $\mathrm{WV}$ requires an evaluation of the educational needs of pharmacists as well as their individual perceptions on opioid-related medication efficacy, naloxone efficacy, and willingness to stock naloxone and buprenorphine products.

The Extended Parallel Process Model (EPPM), has been used to create public communication and education in order to increase awareness and create change to address important health issues by appealing to the individual's desire to control either danger or fear. ${ }^{113,114}$ It has also been used to assign broad, educational strategies to pharmacists based on perceptions of efficacy and risk. ${ }^{110}$ The key EPPM constructs include perceived severity, perceived susceptibility, response efficacy, and self-efficacy. ${ }^{110,113-115}$ By assessing these four constructs in this study, pharmacists can be placed into one of four categories defined by the EPPM based on their perception of both the risk (High/Low) and efficacy (High/Low). Targeted education can be created for each of these four categories to effectively tailor and deliver the intervention to pharmacists throughout WV to have the greatest impact.

\subsection{Objective}

The objective of this study was to identify broad educational strategies and educational objectives related to opioids, buprenorphine products, and naloxone, for pharmacists, and to identify geographic locations to provide targeted continuing pharmacists education (CPE) events, using a state-wide, representative survey of pharmacists licensed and working in WV. 


\subsection{Methods}

\section{Design/Data collection}

A prospective cross-sectional design with survey methodology was used to assess the educational needs of community pharmacists in WV. A 49-item data collection instrument which was previously created and validated in WV pharmacists ${ }^{110}$ was administered in two phases. In the first phase, the surveys $(n=157)$ were collected at live CPE events with preliminary results, including validation of scales, as published previously. ${ }^{110}$ For the second phase, additional responses ( $n=144$ complete responses) were collected online to increase coverage of pharmacists throughout the state. Pharmacists who were at any CPE event where surveys were collected were not eligible for the online survey. Both phases of data collection occurred between April 2016 and April 2017.

To ensure representativeness, a census of all pharmacists licensed and working in WV was collected. With the agreement of the West Virginia Board of Pharmacy (WVBOP), three researchers (JDT, XZ, and ND) collected demographic information [email, gender, date or birth, current status (active/inactive), and county of employer] of all pharmacists licensed and working in WV. This information was up-to-date as of the most recent license renewal in July 2016. This is the first time the effort has been made to determine which pharmacists work in $\mathrm{WV}$, as opposed to those licensed in WV but working elsewhere. Email addresses were used to send the electronic version of the survey to pharmacists who did not attend a live CPE event earlier in the year using Qualtrics's anonymous data collection option. The study, survey, and census data collection were approved by the West Virginia University Institutional Review Board.

\section{$\underline{\text { Measures }}$}


Components of the survey have been described, in detail, in our previous publication. ${ }^{110}$ Other measures for this study not previously described are included below: EPPM Category (High Risk/High Efficacy; High Risk/Low Efficacy; Low Risk/High Efficacy; Low Risk/Low Efficacy): The main constructs used in the EPPM (1- severity, 2- susceptibility, 3response efficacy, and 4- self-efficacy) were assessed with (1) opioid adverse event scale, (2) perceived misuse of opioids, (3) efficacy of naloxone to reverse an opioid overdose, and (4) ability to dispense naloxone at a community pharmacy, respectively. For the continuouslymeasured constructs used to assess Risk (severity and susceptibility), the median score was used to categorize pharmacists (High or Low). For categorically-measured constructs (response efficacy and self-efficacy) a response of 4 or greater on a 5-point Likert-type scale which indicated "Agree" or "Strongly Agree" was used to categorize pharmacists based into High Efficacy or Low Efficacy groups. If a pharmacist had high in either severity/susceptibility or response efficacy/self-efficacy, they were considered as having a High Risk or High efficacy, respectively.

Buprenorphine perceived efficacy scale consisted of three items adapted from the Clinicians' Attitudes and beliefs about Opioids Survey's (CAOS) perceived effectiveness subscale, for use with pharmacists. ${ }^{116}$

Drug-overdose death rate (by county): To assess broader, county-level risk, the age-adjusted drug-overdose mortality rates for each county in $\mathrm{WV}^{102}$ were categorized as high (>30 per 100,000 population) or low $(\leq 30)$.

Data analyses

Census data from the WVBOP were manually entered into an Excel (Microsoft, 2016) spreadsheet by two of the researchers (JDT and XZ). For the electronic survey responses, 
Qualtrics data output was imported into SPSS (v22, IBM, 2016) for cleaning and converted for use in SAS (v9.4, Cary, NC) for analysis. Principal component analysis (PCA) and Cronbach's alpha was assessed for the buprenorphine efficacy scale. Principal component analysis (PCA) is a data reduction technique that selects a subset of variables based on correlation or covariance (validity). Cronbach's alpha is a measure of internal consistency of the scale (reliability).

Descriptive (e.g., frequencies, means, and standard deviations) and inferential statistics were used to describe the data from this cross-sectional research survey. Chi-square analysis were used to examine the differences in the community pharmacist subgroups based on the EPPM constructs, geography, and stocking/dispensing practices. If expected cell sizes were less than five for at least $20 \%$ of cells, exact statistics were assessed (e.g. Fisher's Exact Test). All statistical analyses assumed a significance level of alpha $=0.05$. The study data were analyzed using SAS (v9.4; Cary, NC).

\section{Sample weighting}

Ideally, the sample of pharmacists represents the population from which they were selected. However, in our study, we observed significant differences in the age distribution of respondents and the WVBOP sampling frame data. There were 2,058 pharmacists licensed and working in WV, as of the most recent license renewal in July 2016.; 9.6\% of the state pharmacists were in the age group 24-29 while $15.6 \%$ of the study sample was in that age group. Therefore, we created sampling weights based on and age of pharmacists licensed and working in WV. These weights were calculated as inverse probability using the age distribution of the WVBOP sampling frame. However, results were presented both before and after applying individual weights. Qualitative Assessment 
The open-ended items from the survey's written responses were evaluated using qualitative methods. Each response was entered into ATLAS.ti (version 1.0.51), a program used for qualitative assessment and coding. Two researchers (JDT and XZ) reviewed the responses independently to identify codes for qualitative assessment. The codes were discussed and agreed upon through consensus with a third researcher (ND) serving as an arbitrator and reviewer. Codes were then assigned to the responses independently and agreed upon. The codes were grouped into themes which were developed using the Grounded Theory approach. ${ }^{117}$

\subsection{Results}

Overall, 301 pharmacists responded to the survey either in person or on-line, and Table 4.1 compares the sample of survey respondents to the population of WV pharmacists. There were 172 community pharmacists who completed the survey.). Age-weighted and unweighted characteristics of responding pharmacists can be seen in Table 4.2, and the unweighted sample was mostly female (50.3\%), first licensed after $1990(66.9 \%)$, worked in a fulltime (76.0\%) staff position $(55.3 \%)$, in counties with drug-overdose death rates of $\leq 30$ per 100,000 population.

The descriptive information on the values of the constructs used in the EPPM (severity, susceptibility, response efficacy, and self-efficacy), opioid attitudes, naloxone attitudes, stocking practices, filling practices, and whether the respondent left information to be included in the qualitative assessment (56.2\%) was provided in Table 4.2. Of note, pharmacists in WV believed that opioids are being over-prescribed in their county $(82.7 \%)$, agreed that they are helping to curb opioid diversion by declining to fill some prescriptions for opioids (73.2\%), but $41.5 \%$ agreed they were harming patients who have legitimate pain issues. There was a large gap in stocking practices between opioids and buprenorphine products with all community pharmacists stocking opioids, but only $73.0 \%$ stocked buprenorphine/naloxone and only $58.0 \%$ 
buprenorphine. Along these same lines, more pharmacists would refuse to fill a prescription for an out of local area or out-of-state buprenorphine prescription (77.8\% and $73.5 \%$, respectively), compared to an opioid prescription (58.4\% and 53.9\%, respectively). Most pharmacists agreed that they are not adequately trained to use naloxone over the counter $(67.6 \%)$.

The EPPM constructs, from which educational strategies are defined, were used to place pharmacists into four categories [High Risk/High Efficacy (HR/HE); High Risk/Low Efficacy (HR/LE); Low Risk/High Efficacy (LR/HE); or Low Risk/Low Efficacy (LR/LE)]. After weighting the sample for age, the majority of community pharmacists were categorized as having HR/HE (56.0\%). The HR/HE group was more likely to be staff pharmacists or managers compared to owners $(\mathrm{p}<0.05)$. Opioid attitudes significantly differed between pharmacists in different EPPM-assigned categories as well. The HR/HE group was less likely to think chronic opioids were necessary for their chronic non-cancer pain patients ( $\mathrm{p}<0.001)$, but were more likely to neither agree nor disagree that opioids were being prescribed in their county $(\mathrm{p}<0.01)$. Also, pharmacists in the HR/HE group were less likely to agree that letting patients purchase naloxone over the counter will increase opioid overdosing $(\mathrm{p}<0.05)$. Other comparisons can be seen in Table 4.3.

To identify educational objectives based on buprenorphine products, perceived efficacy and misuse of buprenorphine products were compared to county characteristics and stocking/dispensing practices of these products. The newly-validated three-item buprenorphine efficacy scale for pharmacists had all three items load on one component ( $>0.8)$, was reliable with a Cronbach's $\alpha=0.79$, and had a mean of $7.88(\mathrm{SD}=2.72)$. Overall, WV pharmacists on average estimated that $30.7 \%$ of prescriptions for buprenorphine products were misused or abused. Lower perceived buprenorphine efficacy was associated with a lack of willingness to fill 
a non-local $(\mathrm{p}<0.001)$ or out-of-state $(\mathrm{p}<0.01)$ prescription for those products. Perceived buprenorphine misuse was associated with declining a prescription for not being for a legitimate medical purpose $(\mathrm{p}<0.05)$. Other comparisons for buprenorphine constructs can be seen in Table 4.4 .

Qualitative responses were assessed for the 97 community pharmacists in WV who provided comments on the open-ended items. A common theme was that opioids are being overprescribed in general, and in their local areas. Another frequent theme was that there is a responsibility on the prescriber since pharmacists are not able to make opioid regimen changes. Table 4.5 has quotations from pharmacists used to categorize qualitative responses into themes relating to barriers to making available opioids, naloxone, or buprenorphine products. There were many reasons for refusing prescriptions that included need for education (e.g. "All healthcare providers need more education in handling patients with pain...") and stigma towards patients (e.g. "...it's very hard to determine who has a legitimate need due to the stigma of opioid use"). In addition to reasons for refusing to fill prescriptions, pharmacists expected buprenorphine regimens to be de-escalated regularly (e.g. "it is very rare that I see the [buprenorphine products] dose decreased").

\subsection{Discussion}

The Extended Parallel Process Model can be used to help tailor educational strategies for pharmacists to improve access to naloxone and buprenorphine products as well as their understanding of addiction and psychosocial treatments. Although the majority of the respondents surveyed expressed concerns about opioid overuse in their counties, most of them were not adequately trained to dispense naloxone over the counter. There were significant differences in opioid, naloxone, and buprenorphine product attitudes among community 
pharmacists, which can be targeted in different CPE events. Educational objectives can be determined based on the gaps in knowledge.

Two components are needed to deliver effective CPE: educational materials developed based on need and target areas where an impact can be made. The EPPM has been used to identify board educational strategies for pharmacists, that takes into account their ability to be influenced by certain components of the EPPM (namely, affect and cognition). ${ }^{110,115}$ According to this conceptual framework, most of the respondents had High Risk and High Efficacy levels (HR/HE) and they will be responsive to a call to action and information on the infrastructure available to deliver naloxone through their community pharmacies. ${ }^{115}$ Whereas pharmacists with Low Efficacy or Low Risk, strategies will need to focus on their ability to act and their role to play, or the actual risk in their community of adverse consequences of opioids, respectively. ${ }^{110,115}$ Identifying counties to provide CPE can be based on the disparity between actual (based on drug death rate) and perceived risk. For example, based on our state-wide survey results, pharmacists in Raleigh County (7\% of all pharmacists licensed and working in WV) were more likely to have a low perceived risk, but the actual drug-overdose death rate in the county was over 30 deaths per 100,000 population. ${ }^{102}$ This is one location where risk-based education can be emphasized, to have a greater impact. Alternatively, another county, Mingo County, has high actual risk and the pharmacists who responded indicated a high perceived risk, thus risk-based education ${ }^{118}$ might not be as impactful.

For patients with chronic painful conditions or patients with opioid use disorders to have access to their medications, pharmacists working in community pharmacies must be willing to stock and fill those medications. Lower perceived efficacy or suspected misuse of these medications made it less likely that the pharmacist would either stock or fill prescriptions for 
these products. To this point, quantitative results were reinforced by the qualitative responses provided by the pharmacists. Community pharmacists emphasized the need for increased education on pain management and effective communication between all stakeholders (patients, pharmacists, prescribers, and the government regulators).

The availability of buprenorphine is a problem throughout the US, especially in WV. Only certain prescribers can write prescriptions for these medications, and patients seeking treatment for opioid use disorder far outpaces the number of spots available for treatment in high-quality centers. ${ }^{119}$ Buprenorphine products are also limited by wholesalers who report high use pharmacies and prescribers to the FDA and DEA. ${ }^{109}$ Due to the scarcity of these products, some patients must travel great distances to fill their legal prescription. Pharmacists can be compounding this problem because they are worried about out-of-state and out of local area prescriptions. Again, the qualitative responses reinforced the quantitative results, that pharmacists are worried about misuse and abuse of buprenorphine products. Many pharmacists noted that they expected buprenorphine regimens to have tight oversight with regular dose deescalation. The treatment paradigm for opioid use disorder is changing so that patients are treated as though they have a chronic illness. ${ }^{120}$ Some of these patients will have better outcomes in terms of recovery with fewer relapses if buprenorphine regimens are maintained long-term. Education for pharmacists that focuses on these use-cases can possibly decrease the perceived misuse and increase perceived efficacy of these products.

Providing education on pain management, use of naloxone in the community, opioid use disorder, and how to improve communication with both prescribers and patients will be beneficial to pharmacists and patients seeking care. Education on addiction may help reduce stigma and increase a sense of the broad range of psychosocial and pharmacological treatment 
options. Future research can focus on providing pharmacists with tailored education to reduce stigma and encourage participation to dispense buprenorphine and naloxone to help people suffering from opioid use disorder and potential drug overdose. These future studies can be guided by the Kirkpatrick model used to evaluate training programs. ${ }^{121}$ Using this model, four factors would be assessed throughout a follow-up period starting with reaction to the tailored intervention, then an evaluation of learning after the training program. Longer-term evaluations of tailored educational interventions would assess changes in behavior and impact to the community.

This is the first study to identify targeted continuing educational intervention for community pharmacists based on the EPPM conceptual framework. These education components can be used to affect change in terms of availability of naloxone and buprenorphine products. There were many strengths to this study including the use of a population census of pharmacists licensed and working in WV to generalize the survey results for the entire state of WV. This study collected the first functional census of WV pharmacists to ensure state-wide representativeness of the findings. Also, this population-based survey of pharmacists focused on currently under-utilized providers who can play a critical role in preventing opioid-related overdose and death. This study had a few potential limitations. Surveys were collected over the period of one year, so pharmacists could have received education on naloxone through their employers or the state. However, current naloxone education in WV is not tailored to pharmacists and focuses on emergency administration. The surveys were collected via two modes of data collection, but the sample was assessed for representativeness and weighted based on age to mitigate this limitation. Survey research has certain potential limitations associated with the data collection process. The validity of the results may be affected by the usual 
limitations of self-report questionnaires and thus may not fully reflect the respondents' beliefs, attitudes, or actual practices.

\subsection{Conclusion}

West Virginia community pharmacists's stocking and dispensing of naloxone and buprenorphine products are affected by their beliefs about efficacy, misuse, and abuse of these products. Most pharmacists felt unprepared to dispense naloxone over the counter. Using targeted educational strategies, locations, and objectives, more effective CPE can be delivered to community pharmacists in the state to improve access to critical, potentially life-saving, medications.

\subsection{Acknowledgements}

The views expressed in this academic research paper are those of the authors and do not reflect the official policy or position of West Virginia University (WVU) or any other affiliated organizations. Dr. Sambamoorthi was partially supported by the National Institutes of Health, National Institute of General Medical Sciences (grant number U54GM104942). Dr. Thornton was supported by the National Institutes of Health, National Institute of General Medical Sciences (grant number 5T32GM081741-08). In addition, the WV Pharmacist Census was collected using funds from the Claude Worthington Benedum Foundation funded Health Outcomes Policy and Evaluation Center (HOPE). 
Table 4.1. Characteristics of the sample of survey respondents compared to the population of pharmacists licensed and working in West Virginia as of July 2016.

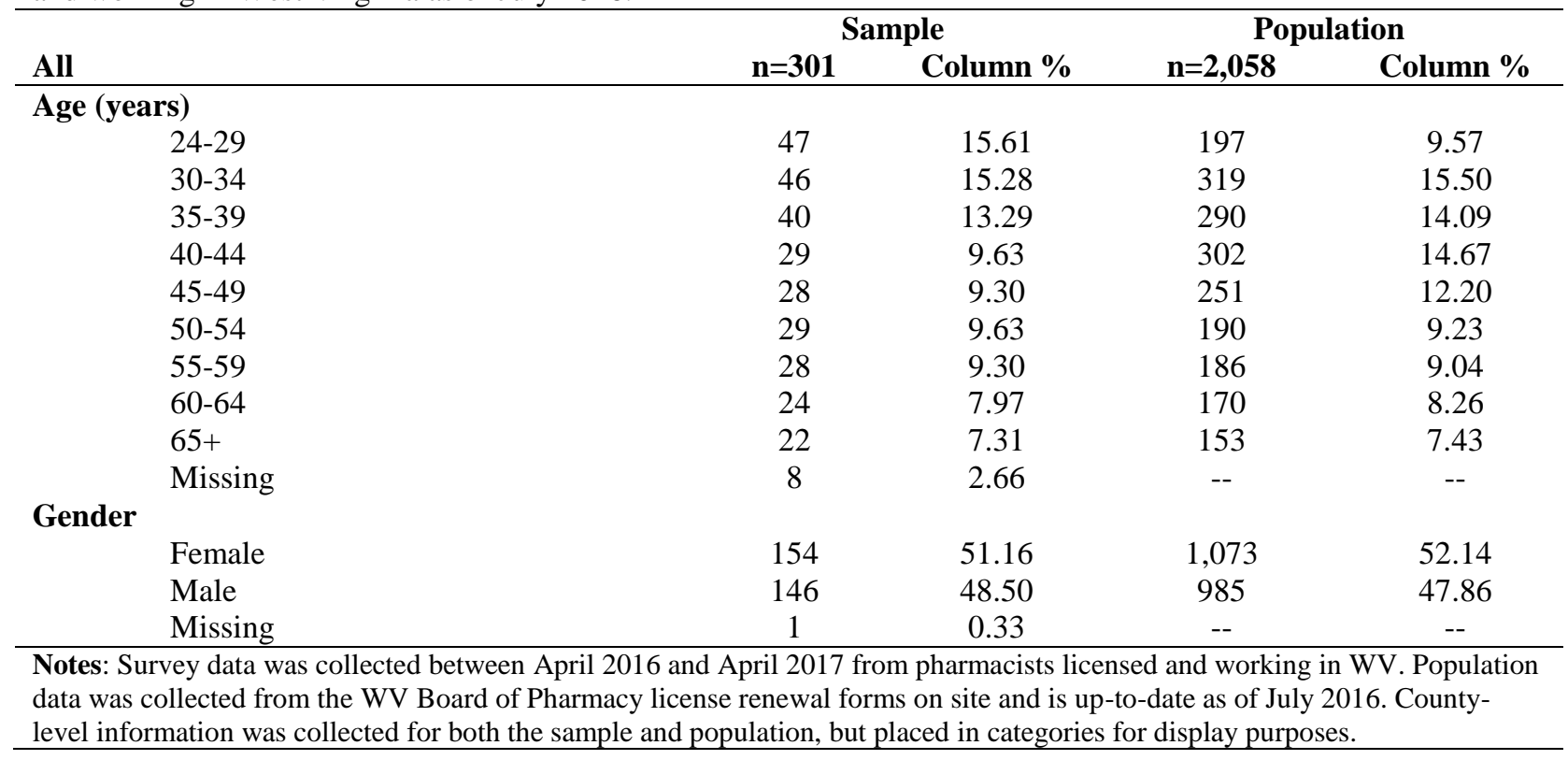


Table 4.2. Description of the sample of community pharmacists licensed and working in WV that responded to the survey, weighted by age based on the state-wise census of pharmacists.

All

$\mathbf{n}=\mathbf{1 7 2}$ Wt. \%

\section{Gender (n=171)}

Female

Male

$86 \quad 51.6$

Year first licensed

1980 and before

$85 \quad 48.3$

1981-1990

1991-2000

2001 and after

Position (n=170)

Owner or Part owner

Management (including Pharmacist in Charge)

26

14.8

$31 \quad 17.0$

$44 \quad 32.4$

Staff

$71 \quad 35.8$

Work schedule $(\mathbf{n = 1 7 1})$

Fulltime

Part-time

Region (US Congressional District) $(\mathbf{n}=170)$

First (Northern)

$130 \quad 76.3$

Second (Central and Eastern)

Third (Southern)

$\begin{array}{ll}69 & 39.5\end{array}$

Drug-related deaths in county of workplace $(n=170)$

High $(>30)$

62

Low $(\leq 30)$

EPPM Constructs $(\mathbf{n}=172)$

Severity: Opioid adverse event scale score

Susceptibility: Perceived misuse of opioids at community pharmacy

108

\begin{tabular}{|c|c|c|}
\hline (2) & Mean $=29.5$ & $\mathrm{SD}=24.5$ \\
\hline \multicolumn{3}{|c|}{ Response efficacy: Efficacy of naloxone } \\
\hline High & 130 & \\
\hline Low & 42 & \\
\hline \multicolumn{3}{|c|}{ Self-efficacy: Dispense naloxone at community pharmacy } \\
\hline High & 39 & \\
\hline Low & 133 & \\
\hline \multicolumn{3}{|c|}{ Opioid Attitudes } \\
\hline \multicolumn{3}{|c|}{ Opioid perceived efficacy scale $(n=168)$} \\
\hline & Mean $=14.9$ & $\mathrm{SD}=3.5$ \\
\hline \multicolumn{3}{|c|}{$\begin{array}{l}\text { Taking opioids for long periods of time is necessary for many of my chronic } \\
\text { non-cancer pain patients. }(n=171)\end{array}$} \\
\hline Disagree & 90 & 52.0 \\
\hline Neither & 33 & 18.9 \\
\hline Agree & 48 & 29.1 \\
\hline \multicolumn{3}{|c|}{$\begin{array}{l}\text { Long-term use of opioids is overprescribed for patients with chronic non-cancer } \\
\text { pain. }\end{array}$} \\
\hline Disagree & 8 & 5.0 \\
\hline Neither & 11 & 6.7 \\
\hline Agree & 153 & 88.3 \\
\hline
\end{tabular}


Table 4.2. Description of the sample of community pharmacists licensed and working in WV that responded to the survey, weighted by age based on the state-wise census of pharmacists.

All

Some clinicians in my county prescribe opioids to their patients with chronic

$\mathbf{n}=172$

Wt. \% non-cancer pain for long periods of time too frequently.

Disagree

Neither

$4 \quad 2.8$

Agree

Opioids are being overprescribed by practitioners in my county.

Disagree

154

87.7

Neither

9

5.6

Agree

Pharmacists are curbing opioid diversion and/or abuse by declining to fill some prescriptions for opioids.

Disagree

Neither

Agree

Pharmacists are harming some patients who have legitimate pain issues by

declining to fill some prescriptions for opioids. $(n=171)$

Disagree

Neither

Letting patients purchase naloxone over the counter will increase opioid overdosing. $(\mathbf{n}=171)$

Disagree

Neither

Agree

I do not believe that I am adequately trained in the use of naloxone over the counter.

Agree

\section{Stock opioids $(\mathbf{n}=171)$}

Yes, stocked

Not stocked

Stock buprenorphine/naloxone $(\mathbf{n}=171)$

Yes, stocked

Not stocked

Stock buprenorphine $(\mathbf{n}=\mathbf{1 7 0})$

Yes, stocked

Fill a non-local (outside a 20-mile radius of your pharmacy) prescription for opioid

Would not fill

Fill an out-of-state prescription for an opioid 
Table 4.2. Description of the sample of community pharmacists licensed and working in WV that responded to the survey, weighted by age based on the state-wise census of pharmacists.

All n $=172 \quad$ Wt. $\%$

Fill a non-local (outside a 20-mile radius of your pharmacy) prescription for buprenorphine/naloxone $(\mathbf{n}=\mathbf{1 6 6})$

Would not fill

Would fill

Fill an out-of-state prescription for a buprenorphine/naloxone $(n=164)$

Would not fill

Would fill

\section{Responded to at least one qualitative item}

No

Yes

Notes: This sample includes patients a survey of pharmacist licensed and working in West Virginia as of July 2016. Some categories were collapsed. Weighted $\mathrm{N}$ were rounded to nearest whole person. EPPM categories were created using unweighted measures of central tendency, so weighted results are not presented.

Abbreviations: Wt. \% = weighted percentage 
Table 4.3. Extended Parallel Process Model (EPPM) categories for a sample of community pharmacists licensed and working in WV, weighted by age based on the state-wise census of pharmacists

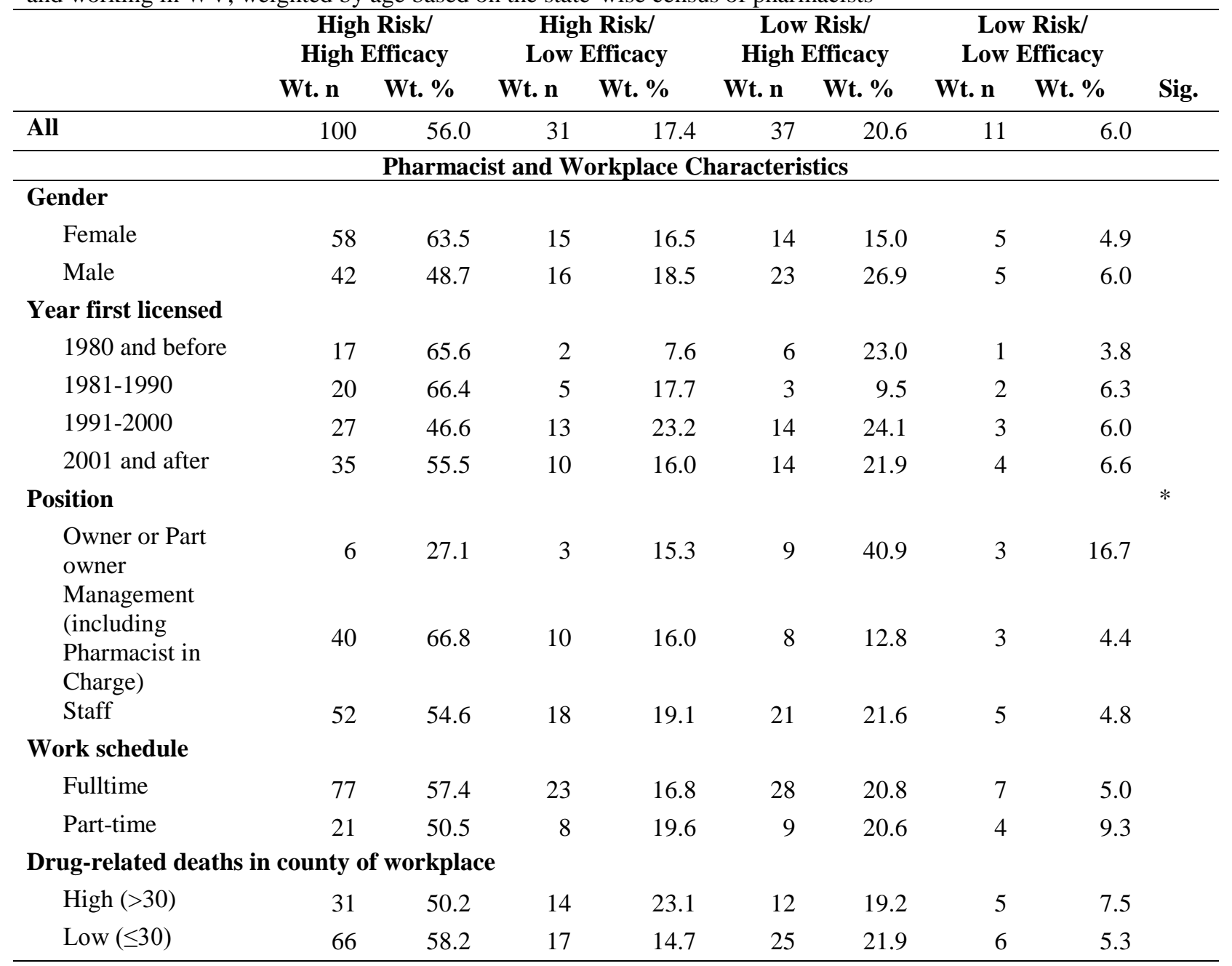

Opioid Attitudes

Taking opioids for long periods of time is necessary for many of my chronic non-cancer pain patients.

$\begin{array}{lrrrrrrrr}\text { Disagree } & 56 & 61.0 & 22 & 24.4 & 10 & 11.1 & 3 & 3.5 \\ \text { Neither } & 20 & 59.2 & 2 & 6.6 & 7 & 21.2 & 4 & 13.0 \\ \text { Agree } & 23 & 44.1 & 6 & 12.2 & 19 & 37.8 & 3 & 5.8\end{array}$

Long-term use of opioids is overprescribed for patients with chronic non-cancer pain.

$\begin{array}{lrrrrrrrr}\text { Disagree } & 3 & 32.5 & 0 & 0.0 & 6 & 67.5 & 0 & 0.0 \\ \text { Neither } & 7 & 54.9 & 0 & 0.0 & 3 & 28.8 & 2 & 16.4 \\ \text { Agree } & 91 & 57.3 & 31 & 19.6 & 28 & 17.6 & 9 & 5.5\end{array}$

Opioids are being overprescribed by practitioners in my county.

\begin{tabular}{lrrrrrrrr} 
Disagree & 3 & 27.0 & 0 & 0.0 & 7 & 73.0 & 0 & 0.0 \\
Neither & 16 & 77.9 & 3 & 12.5 & 2 & 9.6 & 0 & 0.0 \\
Agree & 81 & 54.9 & 28 & 19.2 & 28 & 18.7 & 11 & 7.2 \\
\hline Continued & &
\end{tabular}


Table 4.3. Extended Parallel Process Model (EPPM) categories for a sample of community pharmacists licensed and working in WV, weighted by age based on the state-wise census of pharmacists

\begin{tabular}{|c|c|c|c|c|c|c|c|c|c|}
\hline & \multicolumn{2}{|c|}{$\begin{array}{c}\text { High Risk/ } \\
\text { High Efficacy }\end{array}$} & \multicolumn{2}{|c|}{$\begin{array}{l}\text { High Risk/ } \\
\text { Low Efficacy }\end{array}$} & \multicolumn{2}{|c|}{$\begin{array}{c}\text { Low Risk/ } \\
\text { High Efficacy }\end{array}$} & \multicolumn{2}{|c|}{$\begin{array}{l}\text { Low Risk/ } \\
\text { Low Efficacy }\end{array}$} & \multirow[b]{2}{*}{ Sig. } \\
\hline & Wt. n & Wt. \% & Wt. n & Wt. \% & Wt. n & Wt. \% & Wt. n & Wt. \% & \\
\hline All & 100 & 56.0 & 31 & 17.4 & 37 & 20.6 & 11 & 6.0 & \\
\hline \multicolumn{10}{|c|}{$\begin{array}{l}\text { Pharmacists are curbing opioid diversion and/or abuse by declining to fill some prescriptions } \\
\text { for opioids. }\end{array}$} \\
\hline Disagree & 13 & 63.4 & 1 & 4.8 & 7 & 31.8 & 0 & 0.0 & \\
\hline Neither & 14 & 51.9 & 5 & 17.1 & 4 & 15.6 & 4 & 15.4 & \\
\hline Agree & 73 & 55.7 & 25 & 19.5 & 26 & 19.9 & 7 & 5.0 & \\
\hline \multicolumn{10}{|c|}{$\begin{array}{l}\text { Pharmacists are harming some patients who have legitimate pain issues by declining to fill some } \\
\text { prescriptions for opioids. }\end{array}$} \\
\hline Disagree & 37 & 60.0 & 13 & 21.2 & 9 & 14.6 & 3 & 4.2 & \\
\hline Neither & 21 & 52.0 & 8 & 18.5 & 8 & 19.5 & 4 & 10.0 & \\
\hline Agree & 41 & 56.1 & 10 & 13.9 & 18 & 24.7 & 4 & 5.3 & \\
\hline \multicolumn{10}{|c|}{$\begin{array}{ll} & \text { Naloxone Attitudes } \\
\end{array}$} \\
\hline \multicolumn{9}{|c|}{ Letting patients purchase naloxone over the counter will increase opioid overdosing. } & * \\
\hline Disagree & 32 & 61.6 & 5 & 9.8 & 14 & 27.5 & 0 & 1.2 & \\
\hline Neither & 34 & 64.6 & 8 & 14.6 & 6 & 12.0 & 5 & 8.7 & \\
\hline Agree & 32 & 44.9 & 18 & 25.3 & 16 & 22.3 & 5 & 7.6 & \\
\hline \multicolumn{10}{|c|}{ I do not believe that I am adequately trained in the use of naloxone over the counter. } \\
\hline Agree & 66 & 54.3 & 24 & 20.2 & 22 & 18.4 & 9 & 7.2 & \\
\hline Unsure & 21 & 73.3 & 1 & 3.6 & 5 & 16.1 & 2 & 6.9 & \\
\hline Disagree & 13 & 45.6 & 6 & 19.5 & 10 & 34.9 & 0 & 0.0 & \\
\hline
\end{tabular}

Filling Practices

Fill a non-local (outside a 20-mile radius of your pharmacy) prescription for opioid

$\begin{array}{lllllllll}\text { Will not fill } & 59 & 56.3 & 19 & 18.2 & 21 & 20.2 & 5 & 5.3 \\ \text { Will fill } & 41 & 55.5 & 12 & 16.3 & 16 & 21.2 & 5 & 7.0\end{array}$

Fill an out-of-state prescription for an opioid

$\begin{array}{lllllllll}\text { Will not fill } & 52 & 54.1 & 19 & 19.7 & 17 & 18.2 & 8 & 8.0 \\ \text { Will fill } & 48 & 58.3 & 12 & 14.7 & 19 & 23.4 & 3 & 3.6\end{array}$

Notes: This sample includes patients a survey of pharmacist licensed and working in West Virginia as of July 2016. Some categories were collapsed. Due to small expected cell sizes, exact tests were used to verify any significant results. Respondents in the sample with missing age values were given a weight of one for the weighted analysis. Weighted $\mathrm{N}$ were rounded to nearest whole person.

Significance: $0 \leq \mathrm{p}<0.001=* * *, 0.001 \leq \mathrm{p} 0.01=* *, 0.01 \leq \mathrm{p}<0.05=*, 0.05 \leq \mathrm{p}<0.1=+$

Abbreviations: $\mathrm{Wt}=$ weighted 
Table 4.4. Perceived efficacy and misuse/abuse of buprenorphine prescription products by community factors and pharmacist practices in WV.

\begin{tabular}{|c|c|c|c|c|c|c|c|c|c|c|}
\hline \multirow[b]{2}{*}{ All } & \multicolumn{3}{|c|}{$\begin{array}{l}\text { Buprenorphine Efficacy } \\
\text { Scale Score }\end{array}$} & \multicolumn{7}{|c|}{$\begin{array}{l}\text { Estimated Misuse/Abuse of } \\
\text { Buprenorphine Products }(\%)\end{array}$} \\
\hline & $\begin{array}{r}\text { Mean }= \\
7.88\end{array}$ & $\begin{array}{r}\mathrm{SD}= \\
\mathbf{2 . 7 2}\end{array}$ & $\begin{array}{l}n= \\
169\end{array}$ & p value & Sig & $\begin{array}{r}\text { Mean }= \\
30.74\end{array}$ & $\begin{array}{l}\mathrm{SD}= \\
31.56\end{array}$ & $\begin{array}{l}n= \\
140\end{array}$ & p value & Sig \\
\hline \multicolumn{4}{|c|}{ Drug death in county } & 0.6314 & & & & & \multirow[t]{3}{*}{0.0796} & \multirow[t]{6}{*}{+} \\
\hline High & 7.77 & 2.96 & 61 & & & 36.94 & 32.22 & 53 & & \\
\hline Low & 7.98 & 2.59 & 106 & & & 27.28 & 30.77 & 86 & & \\
\hline \multicolumn{4}{|c|}{ Stocking buprenorphine products } & 0.0794 & + & & & & \multirow[t]{3}{*}{0.1056} & \\
\hline Yes & 8.10 & 2.84 & 123 & & & 32.64 & 31.21 & 121 & & \\
\hline No & 7.27 & 2.28 & 45 & & & 19.72 & 32.61 & 18 & & \\
\hline \multicolumn{4}{|c|}{$\begin{array}{l}\text { Willing to fill non-local buprenorphine } \\
\text { product }\end{array}$} & $<0.001$ & $* *$ & & & & \multirow[t]{3}{*}{0.8613} & \\
\hline Yes & 9.15 & 2.70 & 39 & & & 30.44 & 28.02 & 39 & & \\
\hline No & 7.49 & 2.61 & 124 & & & 31.48 & 33.00 & 99 & & \\
\hline \multicolumn{4}{|c|}{$\begin{array}{l}\text { Willing to fill out of state buprenorphine } \\
\text { product }\end{array}$} & 0.0023 & ** & & & & \multirow[t]{3}{*}{0.6765} & \\
\hline Yes & 9.00 & 2.80 & 41 & & & 29.71 & 29.91 & 42 & & \\
\hline No & 7.51 & 2.62 & 120 & & & 32.17 & 32.41 & 95 & & \\
\hline \multicolumn{10}{|c|}{$\begin{array}{l}\text { Declined prescription for buprenorphine } \\
\text { for not being for a legitimate medical }\end{array}$} & * \\
\hline Yes & 7.15 & 2.78 & 40 & & & 41.58 & 31.80 & 38 & \multirow{2}{*}{0.0207} & \\
\hline No & 8.09 & 2.71 & 113 & & & 27.64 & 30.91 & 98 & & \\
\hline \multicolumn{11}{|c|}{$\begin{array}{l}\text { Notes: This sample includes patients a survey of pharmacist licensed and working in West Virginia as of July 2016. Some categories } \\
\text { were collapsed. } \\
\text { Significance (Sig): } 0 \leq \mathrm{p}<0.001=* * *, 0.001 \leq \mathrm{p} 0.01=* *, 0.01 \leq \mathrm{p}<0.05=*, 0.05 \leq \mathrm{p}<0.1=+ \\
\text { Abbreviations: SD }=\text { Standard Deviation }\end{array}$} \\
\hline
\end{tabular}


Table 4.5. Barriers to the availability of opioid, naloxone, and buprenorphine product distribution through community pharmacies, among pharmacists licensed and working in WV.

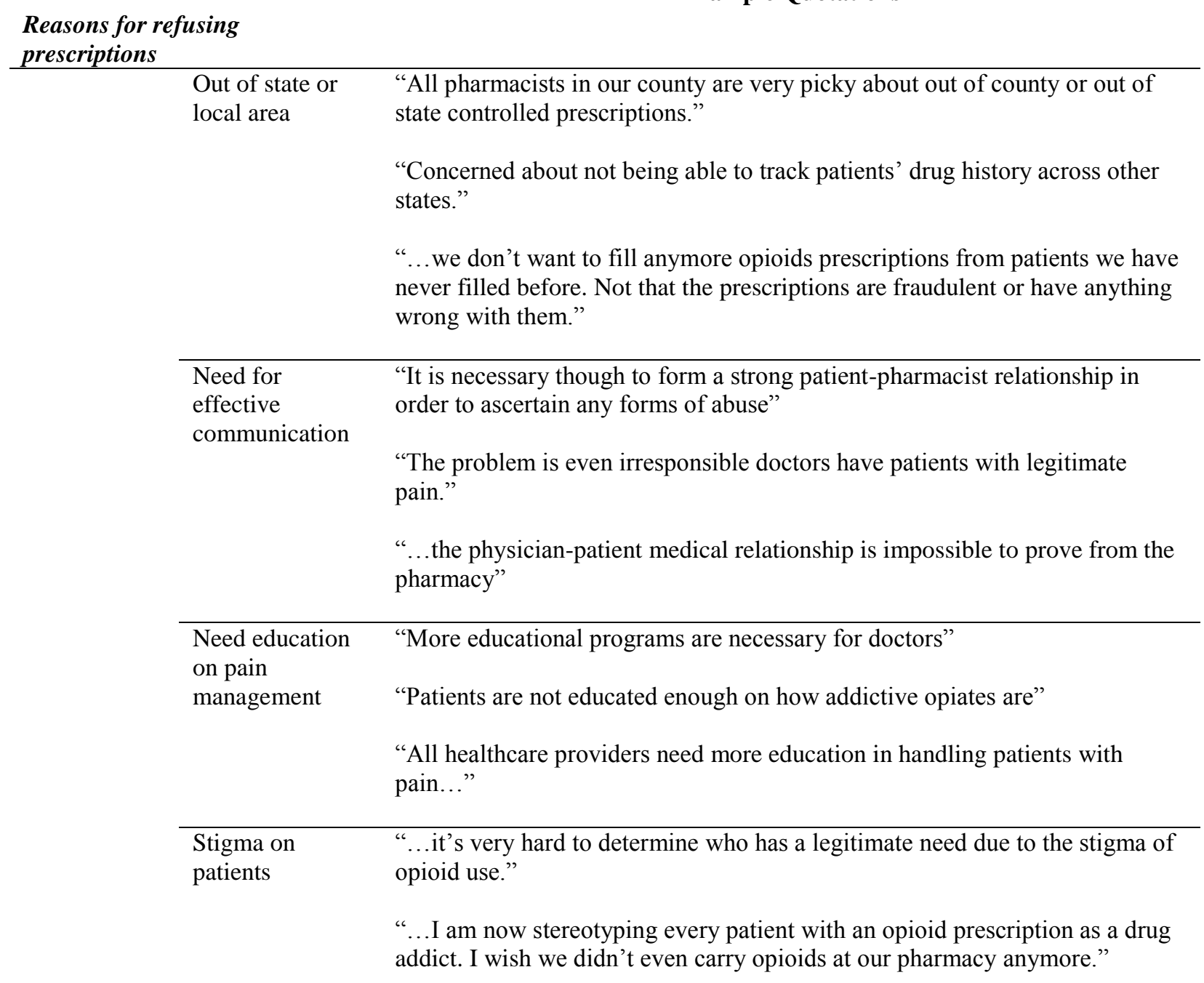

\section{Perceptions of abuse of \\ buprenorphine products}

No reduction in "It is very rare that I see the [buprenorphine products] dose decreased." dose

“...patients are prescribed [buprenorphine products] without much oversight or without changes in dosages for long periods of time."

“... [prescribers] never reduce dose...”

Association with "I feel that [buprenorphine product] is more abused and sold on the street patient demeanor than taken to treat opioid dependence." 


\section{CHAPTER 5}

\section{Discussion of findings and research implications}

\subsection{Summary of Findings}

This dissertation had many unique components. This is the first study to identify incident COT in a nationally-representative sample of working-aged adults, who were initiated on opioid therapy. This is an important group to focus on because of the impact on productivity and their

increased likelihood to receive opioid therapy when they experience pain. ${ }^{25}$ As a rate, we found that 13 out of 1000 patients with initial prescription of opioids transitioned to COT. As demonstrated in this study, a smaller set of more easily assessed factors at initiation (duration of action, standardized dose, parent opioid, age, sex) can be used to gauge the risk of transition to COT. Our predictive models identified four leading predictors that increased the risk of transition to COT by at least four times. These were: duration of action, type of parent opioids, drug use disorders, and painful conditions.

The patients who do transition to COT have an increase in healthcare utilization and expenditures, as we found in the second aim of this study. Most trajectories of healthcare utilization and expenditures throughout the follow-up periods were different between COT and non-COT users. Any intervention focused on curbing transition to COT has the potential to prevent inpatient use and can lead to cost savings for the payer(s).

Despite the consequences of transitioning to COT, the answer is not to withhold care. In the third aim of this study, all community pharmacies surveyed stocked opioid medications, but fewer stocked naloxone or buprenorphine products. The Extended Parallel Process Model can be used to help tailor educational strategies for pharmacists to improve access to naloxone and buprenorphine products as well as their understanding of addiction and psychosocial treatments. 
The stocking and dispensing of naloxone and buprenorphine products by community pharmacists in WV are affected by their beliefs about efficacy, misuse, and abuse of these products. Using targeted educational strategies, locations, and objectives, more effective CPE can be delivered to community pharmacists in the state to improve care.

\subsection{Strengths and Limitations}

\subsubsection{Strengths}

Strengths of this study include the availability of a nationally-representative sample of the US commercially-insured population, following individuals across multiple providers and settings, use of statistical and machine learning predictive methods, and availability of dates so that we could identify first, index opioid prescription. Also, this study assessed incident COT, which other studies have not distinguished from prevalent use of chronic or long-term opioid therapy. By using the NLM programs RxMix and RxNav to identify clinical drug components, the duration of action and parent opioid for each prescription could be identified, which allowed for more granular assessment of the opioid regimen using claims data. Finally, the data spanned many unique insurers and plan types, which allowed for the tracking of patients through time and to determine an opioid-free period of 12 months.

The longitudinal design with repeated measures of utilization and expenditures for patients with and without transition to COT allowed for an assessment of baseline utilization and expenditures in the second aim. This allowed us to control for baseline profiles in terms of utilization, expenditures, and patient complexity. Furthermore, we applied robust statistical methods to control for observed selection bias.

The conceptual framework (EPPM) was used to help tailor educational strategies for pharmacists to improve access to naloxone and buprenorphine products as well as their 
understanding of addiction and psychosocial treatments These education components can be used to affect change in terms of availability of naloxone and buprenorphine products. This study collected the first functional census of WV pharmacists to ensure state-wide representativeness of the findings. Also, this population-based survey of pharmacists focused on currently underutilized providers who can play a critical role in preventing opioid-related overdose and death.

\subsubsection{Limitations}

The study also has some potential limitations. Prescription claims do not have information on variables such as pain, socio-economic status, social capital, medication beliefs, and response to pain treatment, which may affect transition to COT. Also, claims data allow for the identification of prescription medication, but not actual use of these medications. There are limitations of the predictive modeling results as well. The models were assessed in a unique subsample (testing data) of the overall sample. However, the validity of the model and its predicted probabilities will be more generalizable if applied to a different sample of patients, potentially from other commercial healthcare plans. The importance of factors could change, and even be improved if other types of information were added to the dataset (e.g. social determinants of health, medication use behaviors, prescriber characteristics).

Surveys were collected over the period of one year, so pharmacists could have received education on naloxone through their employers or the state. However, current naloxone education in WV is not tailored to pharmacists and focuses on emergency administration. The surveys were collected via two modes of data collection, but the sample was assessed for representativeness and weighted based on age to mitigate this limitation. Survey research has certain potential limitations associated with the data collection process. The validity of the results 
may be affected by the usual limitations of self-report questionnaires and thus may not fully reflect the respondents' beliefs, attitudes, or actual practices.

\subsection{Conclusions and Implications of the study}

Our study findings suggest that an individual's transition to COT can be predicted by information readily available in a clinical setting such as the initial opioid regimen characteristics, past history of drug use disorder, and painful conditions. Predictive models can be used to aid clinician's decision making; develop real-time predictions about future risk of transition to COT; influence policy, prescriber education, and prescription monitoring programs; and can applied to other patient populations. This transition to COT can also place a significant economic burden on payers and patients in terms of healthcare utilization and expenditures. Despite having similar baseline values, patients making the transition to COT had persistently high levels of utilization and expenditures even after 12 months following the transition to COT. The period of time after incident opioid prescription, but before COT, is an important time for intervention for payers and clinicians.

Providing care for patients using, misusing, or even abusing opioid medications can be difficult, especially in rural states throughout the US. WV community pharmacists' stocking and dispensing of naloxone and buprenorphine products are affected by their beliefs about efficacy, misuse, and abuse of these products. Most pharmacists felt unprepared to dispense naloxone over the counter. Using targeted educational strategies, locations, and objectives, more effective CPE can be delivered to community pharmacists in the state to improve access to critical, potentially life-saving, medications. 


\section{References}

1. Institute of Medicine. Relieving Pain in America: A Blueprint for Transforming Prevention, Care, Education, and Research. Washington (DC)2011.

2. Birnbaum HG, White AG, Schiller M, Waldman T, Cleveland JM, Roland CL. Societal costs of prescription opioid abuse, dependence, and misuse in the United States. Pain Med. 2011;12(4):657-667.

3. Substance Abuse and Mental Health Services Administration. Results from the 2006 National Survey on Drug Use and Health: National Findings 2007; https://www.asipp.org/documents/2006NSDUH.pdf.

4. Fudin J. The Economics of Opioids: Abuse, REMS, and Treatment Benefits. American Journal of Managed Care. 2015;21:S188-S194.

5. Benyamin R, Trescot AM, Datta S, et al. Opioid complications and side effects. Pain physician. 2008;11(2 Suppl):S105-120.

6. Tsang A, Von Korff M, Lee S, et al. Common chronic pain conditions in developed and developing countries: gender and age differences and comorbidity with depressionanxiety disorders. J Pain. 2008;9(10):883-891.

7. Dowell D, Haegerich TM, Chou R. CDC Guideline for Prescribing Opioids for Chronic Pain-United States, 2016. JAMA. 2016.

8. Agency for Healthcare Research and Quality. The Effectiveness and Risks of Long-Term Opioid Treatment of Chronic Pain. 2014; http://effectivehealthcare.ahrq.gov/index.cfm/search-for-guides-reviews-andreports/?productid=1988\&pageaction=displayproduct, 2016. 
9. Nadler SF. Nonpharmacologic management of pain. J Am Osteopath Assoc. 2004;104(11 Suppl 8):S6-12.

10. Edlund MJ, Martin BC, Russo JE, DeVries A, Braden JB, Sullivan MD. The role of opioid prescription in incident opioid abuse and dependence among individuals with chronic noncancer pain: the role of opioid prescription. Clin J Pain. 2014;30(7):557-564.

11. Marlatt GA. Harm reduction: come as you are. Addictive behaviors. 1996;21(6):779-788.

12. Hawk KF, Vaca FE, D'Onofrio G. Reducing Fatal Opioid Overdose: Prevention, Treatment and Harm Reduction Strategies. Yale J Biol Med. 2015;88(3):235-245.

13. North Carolina Harm Reduction Coalition. US Law Enforcement Who Carry Naloxone. 2016; http://www.nchrc.org/law-enforcement/us-law-enforcement-who-carry-naloxone/.

14. North Carolina Harm Reduction Coalition. Is this program successful? LAW ENFORCEMENT FAQ ON NALOXONE PROGRAMS 2016; http://www.nchrc.org/lawenforcement/law-enforcement-faq-on-naloxone/.

15. Coffin PO, Behar E, Rowe C, et al. Nonrandomized Intervention Study of Naloxone Coprescription for Primary Care Patients Receiving Long-Term Opioid Therapy for Pain. Ann Intern Med. 2016;165(4):245-252.

16. West Virginia Board of Pharmacy. Protocol for Pharmacist or interns Furnishing Opioid Antagonist Naloxone Hydrochloride. 2016; http://www.wvbop.com/naloxone_protocol.pdf.

17. Bonner L. Naloxone Access: More states look to pharmacists to increase naloxone access. Pharmacy Today. 2016;22(2):57. 
18. Thielke S, Shortreed SM, Saunders K, Turner JA, LeResche L, von Korff M. A Prospective Study of Predictors of Long-term Opioid Use among Patients with Chronic Non-cancer Pain. Clin J Pain. 2016.

19. Substance Abuse and Mental Health Services Administration. Highlights of the 2011 Drug Abuse Warning Network (DAWN) Findings on Drug Related Emergency Department Visits. Drug Abuse Network 2013; http://www.samhsa.gov/data/sites/default/files/DAWN2k11ED/DAWN2k11ED/DAWN2 k11ED.pdf.

20. Kern DM, Zhou S, Chavoshi S, et al. Treatment patterns, healthcare utilization, and costs of chronic opioid treatment for non-cancer pain in the United States. The American journal of managed care. 2015;21(3):e222-234.

21. Owens PL, Barrett ML, Weiss AJ, Washington RE, Kronick R. Hospital Inpatient Utilization Related to Opioid Overuse Among Adults, 1993-2012. 2014; http://www.hcup-us.ahrq.gov/reports/statbriefs/sb177-Hospitalizations-for-OpioidOveruse.pdf.

22. Centers for Disease Control and Prevention. Prescription Drug Overdose in the United States: Fact Sheet. 2015; http://www.cdc.gov/homeandrecreationalsafety/overdose/facts.html.

23. Zhou CF, C.S.; Dowell, D. Payments For Opioids Shifted Substantially To Public And Private Insurers While Consumer Spending Declined, 1999-2012. Health Affairs. 2016;35(5):824-831. 
24. Florence CS, Zhou C, Luo F, Xu L. The Economic Burden of Prescription Opioid Overdose, Abuse, and Dependence in the United States, 2013. Medical Care. 2016;54:901-906.

25. Wang D, Thumula V, Liu, T. Interstate Variations in Use of Narcotics. 2nd ed: Workers Compensation Research Institute; 2014.

26. Ballantyne JC, Shin NS. Efficacy of opioids for chronic pain: a review of the evidence. Clin J Pain. 2008;24(6):469-478.

27. Eriksen J, Sjogren P, Bruera E, Ekholm O, Rasmussen NK. Critical issues on opioids in chronic non-cancer pain: an epidemiological study. Pain. 2006;125(1-2):172-179.

28. Hah J, Mackey S. A Review of Chronic Noncancer Pain: Epidemiology, Assessment, Treatment, and Future Needs. Focus: The Journal of Lifelong Learning in Psychiatry. 2015;13(3):267-282

29. Centers for Disease Control and Prevention. Nonopioid treatments for chronic pain. 2016; https://www.cdc.gov/drugoverdose/pdf/alternative_treatments-a.pdf.

30. Centers for Disease Control and Prevention. Opioid Painkiller Prescribing. CDC Vital Signs 2014; http://www.cdc.gov/vitalsigns/opioid-prescribing/, 2016.

31. Daubresse M, Chang HY, Yu Y, et al. Ambulatory diagnosis and treatment of nonmalignant pain in the United States, 2000-2010. Med Care. 2013;51(10):870-878.

32. Chau DL, Walker V, Pai L, Cho LM. Opiates and elderly: use and side effects. Clinical interventions in aging. 2008;3(2):273-278.

33. Vadivelu N, Hines RL. Management of chronic pain in the elderly: focus on transdermal buprenorphine. Clinical interventions in aging. 2008;3(3):421-430. 
34. Pergolizzi J, Boger RH, Budd K, et al. Opioids and the management of chronic severe pain in the elderly: consensus statement of an International Expert Panel with focus on the six clinically most often used World Health Organization Step III opioids (buprenorphine, fentanyl, hydromorphone, methadone, morphine, oxycodone). Pain practice : the official journal of World Institute of Pain. 2008;8(4):287-313.

35. Chou R, Turner JA, Devine EB, et al. The effectiveness and risks of long-term opioid therapy for chronic pain: a systematic review for a National Institutes of Health Pathways to Prevention Workshop. Ann Intern Med. 2015;162(4):276-286.

36. Zedler B, Xie L, Wang L, et al. Risk factors for serious prescription opioid-related toxicity or overdose among Veterans Health Administration patients. Pain Med. 2014;15(11):1911-1929.

37. Bohnert AS, Valenstein M, Bair MJ, et al. Association between opioid prescribing patterns and opioid overdose-related deaths. JAMA. 2011;305(13):1315-1321.

38. Gwira Baumblatt JA, Wiedeman C, Dunn JR, Schaffner W, Paulozzi LJ, Jones TF. Highrisk use by patients prescribed opioids for pain and its role in overdose deaths. JAMA Intern Med. 2014;174(5):796-801.

39. Liang Y, Turner BJ. Assessing risk for drug overdose in a national cohort: role for both daily and total opioid dose? J Pain. 2015;16(4):318-325.

40. Moore RA, McQuay HJ. Prevalence of opioid adverse events in chronic non-malignant pain: systematic review of randomised trials of oral opioids. Arthritis Res Ther. 2005;7(5):R1046-1051. 
41. Scherrer JF, Salas J, Copeland LA, et al. Prescription Opioid Duration, Dose, and Increased Risk of Depression in 3 Large Patient Populations. Ann Fam Med. 2016;14(1):54-62 .

42. Banta-Green C. Continuum of care for opioid misuse. 2016.

43. PHYTEL. Predictive Modeling and Population Health Management. Whitepaper 2013; https://app.compendium.com/uploads/user/863cc3c6-3316-459a-a747$\underline{3323 b d 3 b 6428 / 4 c 5909 e 8-1708-4751-873 e-}$ 4129cb2ed878/File/86f9d9a5e2f21fb11a5ad8ef2239a76e/1393861691669.pdf.

44. Regierer B, Zazzu V, Sudbrak R, Kuhn A, Lehrach H. Future of medicine: models in predictive diagnostics and personalized medicine. Adv Biochem Eng Biotechnol. 2013;133:15-33.

45. Substance Abuse and Mental Health Services Administration. Finding Interventions to Prevent or Reduce Opioid Abuse and Overdose: Selected Resources. 2014; http://www.samhsa.gov/capt/sites/default/files/resources/interventions-opioidoverdose.pdf, 2016.

46. Walley AY, Xuan Z, Hackman HH, et al. Opioid overdose rates and implementation of overdose education and nasal naloxone distribution in Massachusetts: interrupted time series analysis. BMJ. 2013;346:f174.

47. Rudd RA, Aleshire N, Zibbell JE, Gladden RM. Increases in Drug and Opioid Overdose Deaths - United States, 2000-2014. MMWR Morb Mortal Wkly Rep. 2016;64(5051):1378-1382.

48. Krebs EE, Kroenke K, Wu J, Bair MJ, Kozak MA, Yu Z. Opioid Use as a Predictor of Health Care Use and Pain Outcomes: Analysis of Clinical Trial Data. Pain Med. 2016. 
49. Ronan MV, Herzig SJ. Hospitalizations Related To Opioid Abuse/Dependence And Associated Serious Infections Increased Sharply, 2002-12. Health Aff (Millwood). 2016;35(5):832-837.

50. Chou R, Clark E, Helfand M. Comparative efficacy and safety of long-acting oral opioids for chronic non-cancer pain: a systematic review. J Pain Symptom Manage. 2003;26(5):1026-1048.

51. Pereira J, Lawlor P, Vigano A, Dorgan M, Bruera E. Equianalgesic dose ratios for opioids. a critical review and proposals for long-term dosing. J Pain Symptom Manage. 2001;22(2):672-687.

52. Bailey AM, Wermeling DP. Naloxone for opioid overdose prevention: pharmacists' role in community-based practice settings. Ann Pharmacother. 2014;48(5):601-606.

53. Bennett AS, Bell A, Tomedi L, Hulsey EG, Kral AH. Characteristics of an overdose prevention, response, and naloxone distribution program in Pittsburgh and Allegheny County, Pennsylvania. J Urban Health. 2011;88(6):1020-1030.

54. Green TC, Dauria EF, Bratberg J, Davis CS, Walley AY. Orienting patients to greater opioid safety: models of community pharmacy-based naloxone. Harm Reduct J. $2015 ; 12: 25$.

55. Wermeling DP. Review of naloxone safety for opioid overdose: practical considerations for new technology and expanded public access. Ther Adv Drug Saf. 2015;6(1):20-31.

56. Kerr D, Kelly AM, Dietze P, Jolley D, Barger B. Randomized controlled trial comparing the effectiveness and safety of intranasal and intramuscular naloxone for the treatment of suspected heroin overdose. Addiction. 2009;104(12):2067-2074. 
57. Davis C. Legal interventions to reduce overdose mortality: naloxone access and overdose good samaritan laws. 2016; https://www.networkforphl.org/_asset/qz5pvn/legalinterventions-to-reduce-overdose.pdf.

58. World Health Organization. The Role of the Pharmacist in the Health Care System. Essential Medicines and Health Products Information Portal 1994; http://apps.who.int/medicinedocs/en/d/Jh2995e/1.6.2.html\#Jh2995e.1.6.2.

59. Kometa N. Community pharmacists need access to patients' medical records. The Pharmaceutical Journal. 2007;278:187.

60. Drug Enforcement Agency. Title 21: Part 1306- Prescriptions. Code of Federal Regulations 2005; http://www.deadiversion.usdoj.gov/21cfr/cfr/1306/1306_04.htm.

61. Buckley B. Pharmacists turning away legitimate pain patients as wholesalers limit shipments of controlled substances. 2014; http://www.pharmacist.com/pharmaciststurning-away-legitimate-pain-patients-wholesalers-limit-shipments-controlled-substance$\underline{0}$.

62. Wachino V. Best Practices for Addressing Prescription Opioid Overdoses, Misuse and Addiction. 2016; https://www.medicaid.gov/federal-policy-guidance/downloads/cib-0202-16.pdf.

63. Harrison L. Pharmacists prescribe naloxone to prevent overdose deaths. 2015; https://www.pharmacist.com/pharmacists-prescribe-naloxone-prevent-overdose-deaths.

64. Palmer E, Hart S, Freeman T. Increasing Naloxone Access in Kentucky: Implementation of SB 192 by Pharmacists. 2015; http://c.ymcdn.com/sites/www.kphanet.org/resource/resmgr/2015_AM_Presentations/Nal oxone_training_program_6-.pdf. 
65. The National Advisory Committee on Rural Health and Human Services. The 2006 Report to the Secretary: Rural Health and Human Service Issues. 2006; ftp://ftp.hrsa.gov/ruralhealth/NAC06forweb.pdf.

66. Brown A. Bill would make naloxone available over the counter in WV. Charleston Gazette-Mail2016.

67. New York State Department of Health. New York State's Opioid Overdose Regulations Questions and Answers. 2015; https://www.health.ny.gov/diseases/aids/general/opioid_overdose_prevention/questions answers.htm.

68. New Mexico Board of Pharmacy. Naloxone. 2014; http://www.nabp.net/system/rich/rich_files/rich_files/000/000/261/original/nm032014.pd f.

69. West Virginia Code. §16-46-3. Licensed health care providers may prescribe opioid antagonists to initial responders and certain individuals; required educational materials; limited liability. 2016; http://www.legis.state.wv.us/wvcode/ChapterEntire.cfm?chap=16\&art=46\&section=3.

70. Manchikanti L, Kaye AM, Kaye AD. Current State of Opioid Therapy and Abuse. Current pain and headache reports. 2016;20(5):34.

71. Kaplovitch E, Gomes T, Camacho X, Dhalla IA, Mamdani MM, Juurlink DN. Sex Differences in Dose Escalation and Overdose Death during Chronic Opioid Therapy: A Population-Based Cohort Study. PLoS One. 2015;10(8):e0134550.

72. Hudson TJ, Painter JT, Martin BC, et al. Pharmacoepidemiologic analyses of opioid use among OEF/OIF/OND veterans. Pain. 2017. 
73. Garg R. Risk of opioid-related adverse events among Medicaid and workers' compensation patients receiving long-term opioid therapy. Thesis (Ph.D.)--University of Washington 2015; https://digital.lib.washington.edu/researchworks/handle/1773/33877, 2017.

74. Cochran BN, Flentje A, Heck NC, et al. Factors predicting development of opioid use disorders among individuals who receive an initial opioid prescription: mathematical modeling using a database of commercially-insured individuals. Drug and alcohol dependence. 2014;138:202-208.

75. Dufour R. Understanding Predictors of Opioid Abuse: Predictive Model Development and Validation. Am J Pharm Benefits. 2014;6(5):208-216.

76. Intelligence DG. IMS Real-World Data Adjudicated Claims: USA [IMS PharMetrics Plus]. BRIDGE to Data 2016; http://www.bridgetodata.org/node/824.

77. IMS' PharMetrics Plus Adjudicated Claims Data User Guide and Data Dictionary. 2016.

78. Peters L, Mortensen J, Nguyen T, Bodenreider O. Enabling complex queries to drug information sources through functional composition. Stud Health Technol Inform. 2013;192:692-696.

79. Centers for Disease Control and Prevention. Opioid Morphine Equivalent Conversion Factors. 2014; https://www.cms.gov/medicare/prescription-drugcoverage/prescriptiondrugcovcontra/downloads/opioid-morphine-eq-conversion-factorsmarch-2015.pdf, 2016.

80. Substance Abuse and Mental Health Services Administration. Behavioral Health Trends in the United States: Results from the 2014 National Survey on Drug Use and Health. 


\section{5; https://www.samhsa.gov/data/sites/default/files/NSDUH-FRR1-2014/NSDUH-}

\section{FRR1-2014.pdf, 2017.}

81. Goodman RA, Posner SF, Huang ES, Parekh AK, Koh HK. Defining and measuring chronic conditions: imperatives for research, policy, program, and practice. Prev Chronic Dis. 2013;10:E66.

82. Tian TY, Zlateva I, Anderson DR. Using electronic health records data to identify patients with chronic pain in a primary care setting. J Am Med Inform Assoc. 2013;20(e2):e275-280.

83. Zeisset AM. Coding Guidelines for Pain. Journal of AHIMA. 2007;78(3):78-79.

84. Maher RL, Hanlon J, Hajjar ER. Clinical consequences of polypharmacy in elderly. Expert Opin Drug Saf. 2014;13(1):57-65.

85. Weber C, Neeser K. Using individualized predictive disease modeling to identify patients with the potential to benefit from a disease management program for diabetes mellitus. Dis Manag. 2006;9(4):242-256.

86. Bryll R, Gutierrez-Osuna R, Quek F. Attribute bagging: improving accuracy of classifier ensembles by using random feature subsets. Pattern Recognition. 2003;36(6):1291-1302.

87. Yiannakopoulou E. Pharmacogenomics and Opioid Analgesics: Clinical Implications. Int J Genomics. 2015;2015:368979.

88. Rudd RA, Seth P, David F, Scholl L. Increases in Drug and Opioid-Involved Overdose Deaths - United States, 2010-2015. Morbidity and Mortality Weekly Report (MMWR) 2016; https://www.cdc.gov/mmwr/volumes/65/wr/mm655051e1.htm. 
89. Thornton JD, Dwibedi N, Scott V, Ponte CD, Ziedonis D, Sambamoorthi N, Sambamoorthi U. Predictors of transitioning to incident chronic opioid therapy among working-aged adults. [Working Paper]. 2017.

90. Kirson NY, Scarpati LM, Enloe CJ, Dincer AP, Birnbaum HG, Mayne TJ. The Economic Burden of Opioid Abuse: Updated Findings. Journal of managed care \& specialty pharmacy. 2017;23(4):427-445.

91. Campbell CI, Weisner C, Leresche L, et al. Age and gender trends in long-term opioid analgesic use for noncancer pain. Am J Public Health. 2010;100(12):2541-2547.

92. Meara E, White C, Culter DM. Trends In Medical Spending By Age, 1963-2000. Health Affairs. 2004;23(4):176-183.

93. Agarwal P, Bias TK, Sambamoorthi U. Longitudinal Patterns of Emergency Department Visits: A Multistate Analysis of Medicaid Beneficiaries. Health Serv Res. 2016.

94. Bureau of Labor Statistics. Consumer Price Index for All Urban Consumers: Medical care services. 2017; https://www.bls.gov/cpi/. Accessed April 1, 2017.

95. Szmaragd C, Clarke P, Steele F. Subject specific and population average models for binary longitudinal data: a tutorial. 2013. 2013;4(2):19.

96. Deb P, Manning W, Norton E. Modeling health care costs and counts. Paper presented at: 8th World Congress on Health Economics2006.

97. Glick HA, Doshi JA, Sonnad SS, Polsky D. Economic evaluation in clinical trials. OUP Oxford; 2014.

98. Basu A, Rathouz PJ. Estimating marginal and incremental effects on health outcomes using flexible link and variance function models. Biostatistics (Oxford, England). 2005;6(1):93-109. 
99. Deb A, Sambamoorthi U, Thornton JD, Schreurs B, Innes K. Direct medical expenditures associated with Alzheimer's and related dementias (ADRD) in a nationally representative sample of older adults - an excess cost approach. Aging Ment Health. 2017:1-6.

100. Thoemmes F, Ong AD. A Primer on Inverse Probability of Treatment Weighting and Marginal Structural Models. Emerging Adulthood. 2015;4(1):40-59.

101. Hahn KL. Strategies to prevent opioid misuse, abuse, and diversion that may also reduce the associated costs. Am Health Drug Benefits. 2011;4(2):107-114.

102. National Center for Health Statistics. Drug Poisoning Mortality: United States, 19992015. County Estimates- 2015 2017; https://www.cdc.gov/nchs/data-visualization/drugpoisoning-mortality/. Accessed April 12, 2017.

103. Abraham AJ, Andrews CM, Yingling ME, Shannon J. Geographic Disparities in Availability of Opioid Use Disorder Treatment for Medicaid Enrollees. Health Serv Res. 2017.

104. Boatwright DE. Buprenorphine and addiction: challenges for the pharmacist. $J$ Am Pharm Assoc (Wash). 2002;42(3):432-438.

105. Kleber HD, Weiss RD, Anton RF, Jr., et al. Treatment of patients with substance use disorders, second edition. American Psychiatric Association. Am J Psychiatry. 2007;164(4 Suppl):5-123.

106. Pierce M, Bird SM, Hickman M, et al. Impact of treatment for opioid dependence on fatal drug-related poisoning: a national cohort study in England. Addiction. 2016;111(2):298308. 
107. Morton KJ, Harrand B, Floyd CC, et al. Pharmacy-based statewide naloxone distribution: A novel "top-down, bottom-up" approach. J Am Pharm Assoc (2003). 2017;57(2S):S99S106 e105.

108. Yokell MA, Zaller ND, Green TC, Rich JD. Buprenorphine and buprenorphine/naloxone diversion, misuse, and illicit use: an international review. Curr Drug Abuse Rev. 2011;4(1):28-41.

109. Food and Drug Administration. Risk Management Plan: Suboxone - Subutex (NDA 20732 and 20-733). 1999; https://www.fda.gov/ohrms/dockets/ac/03/briefing/3978B1_08_B-FDA-Tab\%207.pdf, 2017.

110. Thornton JD, Lyvers E, Scott VG, Dwibedi N. Pharmacists' readiness to provide naloxone in community pharmacies in West Virginia. J Am Pharm Assoc (2003). 2017;57(2S):S12-S18 e14.

111. Raisch DW, Fudala PJ, Saxon AJ, et al. Pharmacists' and technicians' perceptions and attitudes toward dispensing buprenorphine/ naloxone to patients with opioid dependence. J Am Pharm Assoc (2003). 2005;45(1):23-32.

112. America's Health Rankings. Drug Deaths: West Virginia. 2016; http://www.americashealthrankings.org/WV/Drugdeaths, 2016.

113. Witte K. Putting the fear back into fear appeals: The extended parallel process model. Communication Monographs. 1992;59(4):329-349.

114. Popova L. The extended parallel process model: illuminating the gaps in research. Health Educ Behav. 2012;39(4):455-473. 
115. Health Communication Capacity Collaborative. The Extended Parallel Process Model:

An HC3 Research Primer. 2014; http://www.healthcommcapacity.org/wpcontent/uploads/2014/09/Extended-Parallel-Processing-Model.pdf.

116. Wilson HD, Dansie EJ, Kim MS, Moskovitz BL, Chow W, Turk DC. Clinicians' attitudes and beliefs about opioids survey (CAOS): instrument development and results of a national physician survey. J Pain. 2013;14(6):613-627.

117. Martin PY, Turner BA. Grounded Theory and Organizational Research. The Journal of Applied Behavioral Science. 1986;22(2):141-157.

118. Holdsworth MT, Benson BE, Dole EJ. Risk-based strategy for outpatient pharmacy practice: Focus on opioids. J Am Pharm Assoc (2003). 2015;55(5):553-556.

119. Bachhuber MA, Southern WN, Cunningham CO. Profiting and providing less care: comprehensive services at for-profit, nonprofit, and public opioid treatment programs in the United States. Med Care. 2014;52(5):428-434.

120. American Society of Addiction Medicine. Treating Opioid Addiction as a Chronic Disease. 2014; http://www.asam.org/docs/default-source/advocacy/cmm-fact-sheet---1107-14.pdf?sfvrsn=0, 2017.

121. Kirkpatrick DL, Kirkpatrick JD. Evaluating training programs : the four levels. 3rd ed. San Francisco, CA: Berrett-Koehler; 2006. 


\section{Appendices}

\subsection{Supplemental Information- Chapter 2: Predictors of transitioning to incident chronic opioid therapy among working-}

aged adults

\begin{tabular}{|c|c|c|c|c|c|c|c|c|c|c|c|c|}
\hline \multirow{2}{*}{\multicolumn{7}{|c|}{$\begin{array}{c}\text { Supplemental Table 7.1.1. Logistic regression with adjusted oc } \\
\text { chronic opioid therapy after first opioid prescription, using Quin } \\
\text { Model } 1 \text { in } \\
\text { Training/Validation subsample }\end{array}$}} & \multirow{2}{*}{\multicolumn{3}{|c|}{$\begin{array}{l}\text { interval }(95 \% \mathrm{CI}) \text { for patients with } \\
\text { ted Claims - US, 2006-2015 } \\
\text { Fully-adjusted model in } \\
\text { Training/ Validation subsample }\end{array}$}} & \multirow{2}{*}{\multicolumn{3}{|c|}{$\begin{array}{c}\begin{array}{c}\text { Fully-adjusted model in Test } \\
\text { subsample }\end{array} \\
\end{array}$}} \\
\hline & & & & & & & & & & & & \\
\hline & & & Sig & AOR & $95 \% \mathrm{CI}$ & Sig & AOR & $95 \% \mathrm{CI}$ & Sig & AOR & $95 \% \mathrm{CI}$ & Sig \\
\hline Age (continuous) & 1.02 & {$[1.02,1.02]$} & $* * *$ & 1.02 & {$[1.02,1.03]$} & $* * *$ & 1.02 & {$[1.01,1.02]$} & $* * *$ & 1.02 & {$[1.01,1.03]$} & $* * *$ \\
\hline Male vs. Female & 1.45 & {$[1.37,1.53]$} & $* * *$ & 1.43 & {$[1.27,1.60]$} & $* * *$ & 1.50 & {$[1.41,1.59]$} & $* * *$ & 1.46 & {$[1.30,1.65]$} & $* * *$ \\
\hline $\begin{array}{l}\text { Highly likely chronic pain } \\
\text { vs. None }\end{array}$ & 5.98 & {$[5.01,7.11]$} & $* * *$ & 5.91 & {$[4.18,8.20]$} & $* * *$ & 5.59 & {$[4.68,6.66]$} & $* * *$ & 5.47 & {$[3.89,7.68]$} & $* * *$ \\
\hline $\begin{array}{l}\text { Likely chronic pain vs. } \\
\text { None }\end{array}$ & 2.15 & {$[2.02,2.27]$} & $* * *$ & 2.08 & {$[1.84,2.34]$} & $* * *$ & 2.08 & {$[1.96,2.21]$} & $* * *$ & 2.02 & {$[1.79,2.28]$} & $* * *$ \\
\hline Arthritis vs. None & 1.83 & {$[1.68,1.98]$} & $* * *$ & 1.92 & {$[1.63,2.25]$} & $* * *$ & 1.78 & {$[1.64,1.93]$} & $* * *$ & 1.86 & {$[1.58,2.20]$} & $* * *$ \\
\hline Hydrocodone vs. Codeine & 2.19 & {$[1.87,2.58]$} & $* * *$ & 2.04 & {$[1.49,2.87]$} & $* * *$ & 2.15 & {$[1.83,2.52]$} & $* * *$ & 1.97 & {$[1.42,2.73]$} & $* * *$ \\
\hline Oxycodone vs. Codeine & 2.52 & {$[2.13,3.01]$} & $* * *$ & 2.70 & {$[1.92,3.90]$} & $* * *$ & 2.53 & {$[2.13,3.02]$} & $* * *$ & 2.67 & {$[1.87,3.81]$} & $* * *$ \\
\hline Tramadol vs. Codeine & 7.03 & {$[5.99,8.31]$} & $* * *$ & 7.59 & {$[5.53,10.74]$} & $* * *$ & 6.79 & {$[5.77,8.01]$} & $* * *$ & 7.26 & {$[5.20,10.13]$} & $* * *$ \\
\hline $\begin{array}{l}\text { All other opioids vs. } \\
\text { Codeine }\end{array}$ & 6.03 & {$[4.68,7.75]$} & $* * *$ & 5.71 & {$[3.38,9.59]$} & $* * *$ & 5.89 & {$[4.57,7.60]$} & $* * *$ & 5.64 & {$[3.34,9.53]$} & $* * *$ \\
\hline $\begin{array}{l}\text { Long-acting vs. Immediate } \\
\text { release }\end{array}$ & 16.01 & {$[13.17,19.42]$} & $* * *$ & 12.43 & {$[8.13,18.83]$} & $* * *$ & 16.08 & {$[13.21,19.57]$} & $* * *$ & 12.28 & {$[8.06,18.72]$} & $* * *$ \\
\hline Moderate vs. Low dose $\dagger$ & 0.52 & {$[0.47,0.57]$} & $* * *$ & 0.45 & {$[0.37,0.55]$} & $* * *$ & 0.52 & {$[0.47,0.57]$} & $* * *$ & 0.45 & {$[0.37,0.54]$} & $* * *$ \\
\hline High vs. Low dose $†$ & 0.52 & {$[0.41,0.65]$} & $* * *$ & 0.71 & {$[0.47,1.05]$} & & 0.52 & {$[0.41,0.65]$} & $* * *$ & 0.68 & {$[0.45,1.02]$} & \\
\hline Very high vs. Low dose $\dagger$ & 1.77 & {$[1.40,2.22]$} & $* * *$ & 1.27 & {$[0.73,2.08]$} & & 1.72 & {$[1.36,2.17]$} & $* * *$ & 1.24 & {$[0.74,2.08]$} & \\
\hline $\begin{array}{l}\text { Benzodiazepine } \\
\text { prescription vs. None }\end{array}$ & 2.06 & {$[1.90,2.22]$} & $* * *$ & 1.99 & {$[1.69,2.33]$} & $* * *$ & 1.82 & {$[1.67,1.97]$} & $* * *$ & 1.82 & {$[1.54,2.16]$} & $* * *$ \\
\hline $\begin{array}{l}\text { Drug use disorder } \\
\text { diagnosis vs. None }\end{array}$ & 8.17 & {$[6.75,9.83]$} & $* * *$ & 4.96 & {$[3.13,7.58]$} & $* * *$ & 6.32 & {$[5.17,7.73]$} & $* * *$ & 4.02 & {$[2.53,6.40]$} & $* * *$ \\
\hline Self vs. Spouse & -- & & & -- & & & 0.96 & {$[0.88,1.05]$} & & 0.84 & {$[0.71,1.01]$} & \\
\hline Unknown vs. Spouse & -- & & & -- & & & 1.30 & {$[1.19,1.42]$} & $* * *$ & 1.19 & {$[1.00,1.43]$} & \\
\hline
\end{tabular}




\begin{tabular}{|c|c|c|c|c|c|c|c|c|}
\hline Other vs. Spouse & -- & -- & 0.82 & {$[0.70,0.97]$} & $*$ & 0.93 & {$[0.67,1.28]$} & \\
\hline PPO vs. HMO & -- & -- & 1.06 & {$[0.96,1.16]$} & & 1.20 & {$[0.99,1.46]$} & \\
\hline Othert vs. HMO & -- & -- & 0.86 & {$[0.77,0.96]$} & $* *$ & 1.06 & {$[0.84,1.34]$} & \\
\hline Midwest vs. East & -- & -- & 1.13 & {$[1.03,1.24]$} & $* *$ & 1.28 & {$[1.06,1.55]$} & $* *$ \\
\hline South vs. East & -- & -- & 1.21 & {$[1.11,1.32]$} & $* * *$ & 1.31 & {$[1.08,1.58]$} & $* *$ \\
\hline West vs. East & -- & -- & 1.02 & {$[0.90,1.15]$} & & 1.28 & {$[0.99,1.64]$} & \\
\hline $\begin{array}{l}\text { Cardio-metabolic condition } \\
\text { vs. None }\end{array}$ & -- & -- & 1.17 & {$[1.10,1.25]$} & $* * *$ & 0.90 & {$[0.79,1.03]$} & \\
\hline Mental illness vs. None & -- & -- & 1.34 & {$[1.25,1.45]$} & $* * *$ & 0.78 & {$[0.67,0.91]$} & $* *$ \\
\hline Asthma vs. None & -- & -- & 0.87 & {$[0.76,1.00]$} & $*$ & 0.85 & {$[0.64,1.13]$} & \\
\hline COPD vs. None & -- & -- & 1.24 & {$[0.92,1.67]$} & & 1.66 & {$[0.92,3.02]$} & \\
\hline Dementia vs. None & -- & -- & 1.33 & {$[0.84,2.11]$} & & 1.75 & {$[0.73,4.17]$} & \\
\hline Hepatitis vs. None & -- & -- & 1.55 & {$[1.18,2.04]$} & $* *$ & 1.94 & {$[1.19,3.15]$} & $* *$ \\
\hline Osteoporosis vs. None & -- & -- & 1.44 & {$[1.14,1.83]$} & $* *$ & 1.04 & {$[0.59,1.83]$} & \\
\hline Tobacco vs. None & -- & -- & 1.45 & {$[1.29,1.64]$} & $* * *$ & 1.34 & {$[1.04,1.73]$} & $*$ \\
\hline Any alcohol abuse vs. None & -- & -- & 0.93 & {$[0.73,1.18]$} & & 0.78 & {$[0.45,1.34]$} & \\
\hline $\begin{array}{l}\text { Acute pain condition vs. } \\
\text { None }\end{array}$ & -- & -- & 0.86 & {$[0.67,1.10]$} & & 0.95 & {$[0.59,1.53]$} & \\
\hline $\begin{array}{l}\text { Stimulant prescription vs. } \\
\text { None }\end{array}$ & -- & -- & 1.65 & {$[1.40,1.95]$} & $* * *$ & 1.33 & {$[0.93,1.91]$} & \\
\hline $\begin{array}{l}\text { Non-opioid analgesic vs. } \\
\text { None }\end{array}$ & -- & -- & 1.06 & {$[0.99,1.13]$} & & 1.14 & {$[1.00,1.29]$} & $*$ \\
\hline Polypharmacy vs. None & -- & -- & 1.09 & {$[1.02,1.17]$} & $*$ & 1.03 & {$[0.90,1.19]$} & \\
\hline
\end{tabular}

Note: This sample includes patients from QuintilesIMS RWD Adjudicated Claims - US, which were identified between 2007 and 2015 and had enrollment between

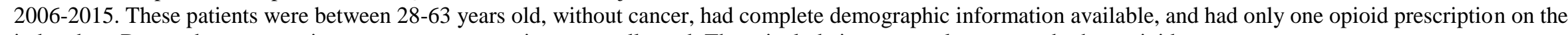
index date. Due to data use requirements, some categories were collapsed. These include insurance plan type and other opioids.

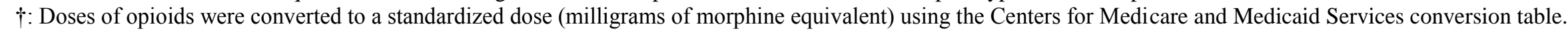

t: Other insurance types included fee-for-service, health savings account, and indemnity.

Significance: $0<\mathrm{p}<0.001=* * *, 0.001 \leq \mathrm{p} 0.01=* *, 0.01 \leq \mathrm{p}<0.05=*$ 
Supplemental Figure 7.1.1: Receiver operator characteristic (ROC) curves for Model 1 (orange, AUC $=0.767)$ and Fully Adjusted Model $2($ purple, AUC $=0.778)$ using the training/validation subsamples

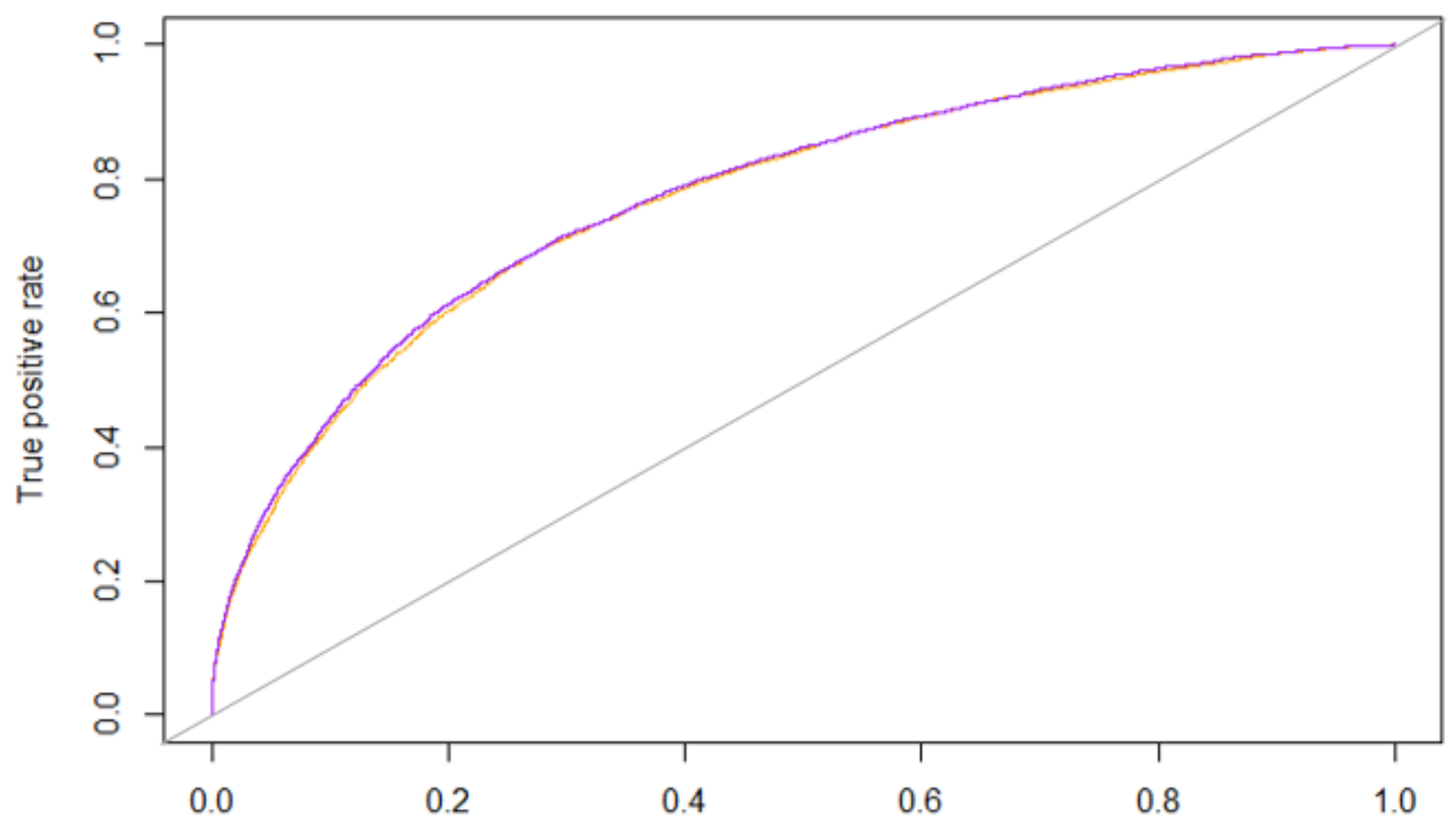

False positive rate 
Supplemental Figure 7.1.2. Receiver operator characteristic (ROC) curves for Model 1 using the training/validation subsample (black, AUC $=0.767$ ) and Model 1 using the test subsample (green, $\mathrm{AUC}=0.776$ ).

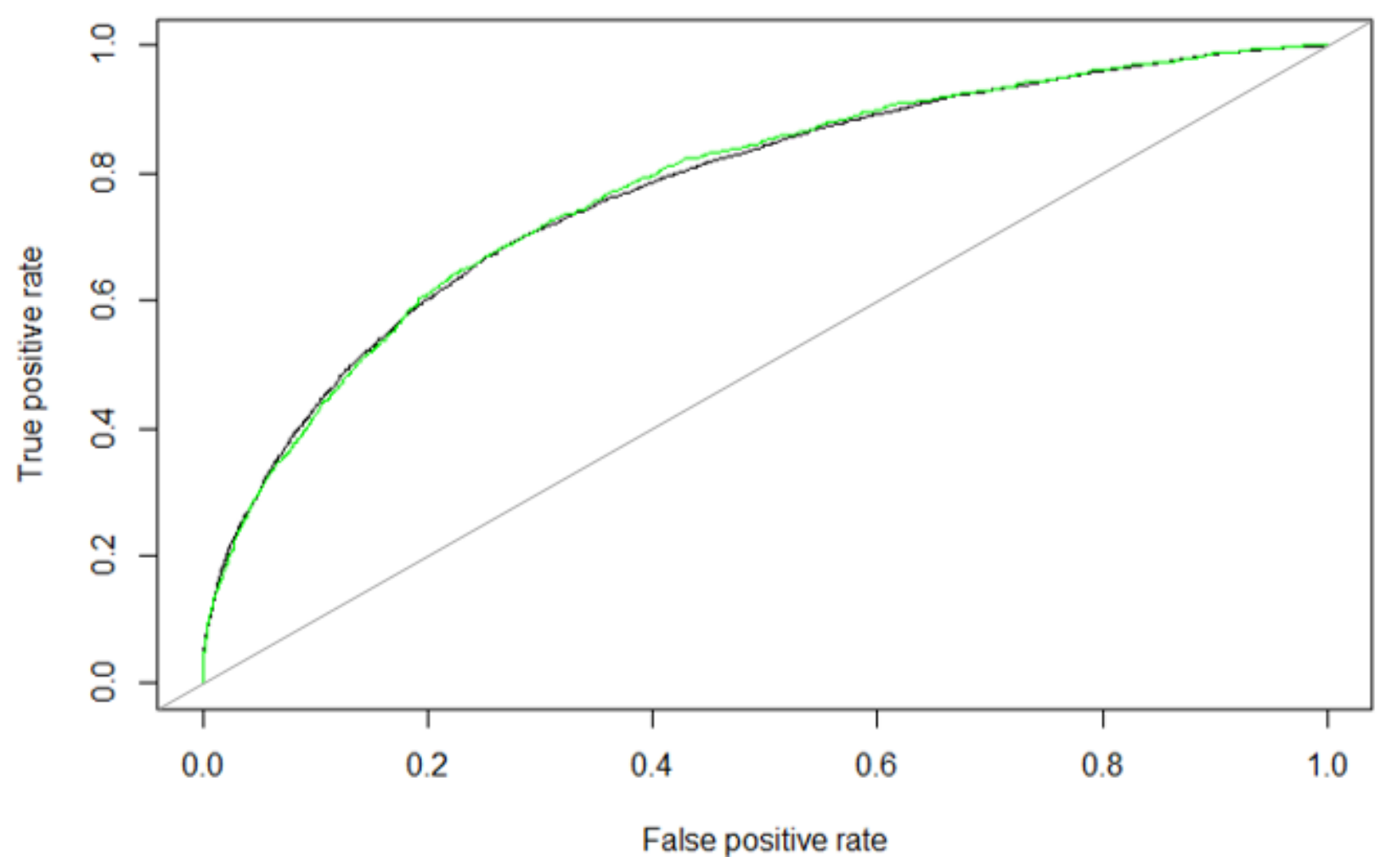




\subsection{Supplemental Information- Chapter 3: Increased healthcare utilization and expenditures associated with transition to chronic opioid therapy}

\begin{tabular}{|c|c|c|c|c|c|c|c|c|c|c|c|c|}
\hline \multicolumn{13}{|c|}{$\begin{array}{l}\text { Supplemental Table 7.2.1. } \\
\text { Patient characteristics before and after applying inverse probability of treatment weighting (IPTW) for patients with } \\
\text { incident opioid use by transition to chronic opioid therapy (COT) after first opioid prescription, } \\
\text { QuintilesIMS Real-World Data Adjudicated Claims Database - US, 2006-2015 }\end{array}$} \\
\hline \multirow{3}{*}{ All } & \multicolumn{7}{|c|}{ Before IPTW } & \multicolumn{4}{|c|}{ After IPTW } & \multirow[b]{3}{*}{ Sig. } \\
\hline & \multicolumn{2}{|c|}{ COT } & \multicolumn{2}{|c|}{ No COT } & \multirow[b]{2}{*}{$\begin{array}{c}\text { Chi- } \\
\text { square }\end{array}$} & \multirow[b]{2}{*}{ p-value } & \multirow[b]{2}{*}{ Sig. } & \multirow{2}{*}{$\begin{array}{c}\text { COT } \\
\text { Wt. \% }\end{array}$} & \multirow{2}{*}{$\begin{array}{c}\text { No COT } \\
\text { Wt. \% }\end{array}$} & \multirow[b]{2}{*}{$\begin{array}{c}\text { Chi- } \\
\text { square }\end{array}$} & \multirow[b]{2}{*}{ p-value } & \\
\hline & $\begin{array}{c}n= \\
3,776\end{array}$ & $\%$ & $\begin{array}{c}n= \\
16,425\end{array}$ & $\%$ & & & & & & & & \\
\hline Sex & & & & & 29.49 & $<0.001$ & **** & & & 1.18 & 0.277 & \\
\hline Male & 2,000 & 53.0 & 7,895 & 48.1 & & & & 49.8 & 49.0 & & & \\
\hline Female & 1,776 & 47.0 & 8,530 & 51.9 & & & & 50.2 & 51.0 & & & \\
\hline Age & & & & & 307.36 & $<0.001$ & $* * *$ & & & 7.61 & 0.055 & \\
\hline $\begin{array}{l}28-34 \\
\text { years } \\
35-44\end{array}$ & 305 & 8.1 & 2,522 & 15.4 & & & & 12.8 & 13.9 & & & \\
\hline $\begin{array}{l}\text { years } \\
45-54\end{array}$ & 757 & 20.0 & 4,402 & 26.8 & & & & 25.1 & 25.5 & & & \\
\hline $\begin{array}{l}\text { years } \\
55-63\end{array}$ & 1,377 & 36.5 & 5,402 & 32.9 & & & & 34.0 & 33.6 & & & \\
\hline years & 1,337 & 35.4 & 4,099 & 25.0 & & & & 28.2 & 27.0 & & & \\
\hline Region & & & & & 30.18 & $<0.001$ & $* * *$ & & & 1.80 & 0.614 & \\
\hline East & 580 & 15.4 & 2,991 & 18.2 & & & & 17.9 & 17.7 & & & \\
\hline Midwest & 1,290 & 34.2 & 5,478 & 33.4 & & & & 34.3 & 33.6 & & & \\
\hline South & 1,642 & 43.5 & 6,587 & 40.1 & & & & 40.0 & 40.7 & & & \\
\hline West & 264 & 7.0 & 1,369 & 8.3 & & & & 7.8 & 8.1 & & & \\
\hline \multicolumn{4}{|c|}{ Highly likely chronic pain condition } & & 301.41 & $<0.001$ & $* * *$ & & & 0.02 & 0.890 & \\
\hline Yes & 112 & 3.0 & 41 & 0.2 & & & & 0.8 & 0.8 & & & \\
\hline No & 3,664 & 97.0 & 16,384 & 99.8 & & & & 99.2 & 99.2 & & & \\
\hline \multicolumn{4}{|c|}{ Likely chronic pain condition } & & 938.71 & $<0.001$ & $* * *$ & & & 0.88 & 0.347 & \\
\hline Yes & 2,064 & 54.7 & 4,693 & 28.6 & & & & 34.1 & 33.5 & & & \\
\hline No & 1,712 & 45.3 & 11,732 & 71.4 & & & & 65.9 & 66.5 & & & \\
\hline \multicolumn{13}{|c|}{$\begin{array}{l}\text { Note: This sample includes patients from QuintilesIMS RWD Adjud } \\
2014 \text { and had enrollment between } 2006 \text { and } 2015 \text {. These patients we } \\
\text { demographic information available, and had only one opioid prescrip } \\
\text { been used for this analysis. } \\
\text { Abbreviations: COT- chronic opioid therapy; Wt- weighted } \\
\text { Sig: } 0<\mathrm{p}<0.001=* * *, 0.001 \leq \mathrm{p} 0.01=* *, 0.01 \leq \mathrm{p}<0.05=*\end{array}$} \\
\hline
\end{tabular}


Supplemental Figure 7.2.1. Difference in unweighted average expenditures between chronic opioid therapy (COT) and no COT transition for total (no prescription drug), emergency department (ED), inpatient (IP), and physician costs.

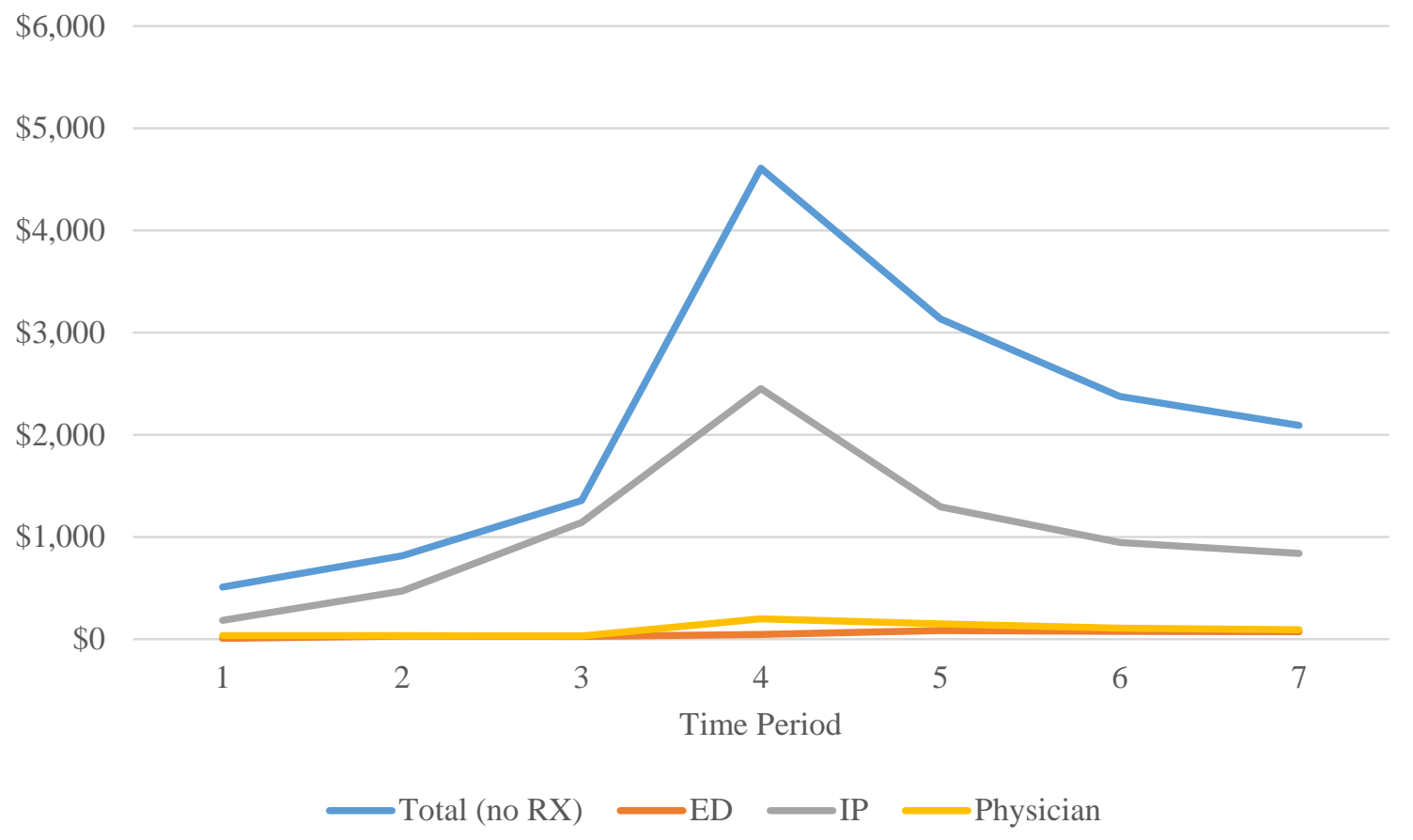

